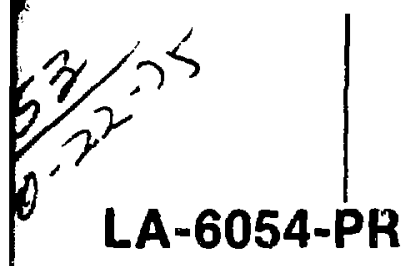

Progress Report

\section{HTGR Safety Research Program}

\section{April-June 1975}

Compiled by

William L. Kirk
UC.77

Issued: September 1975

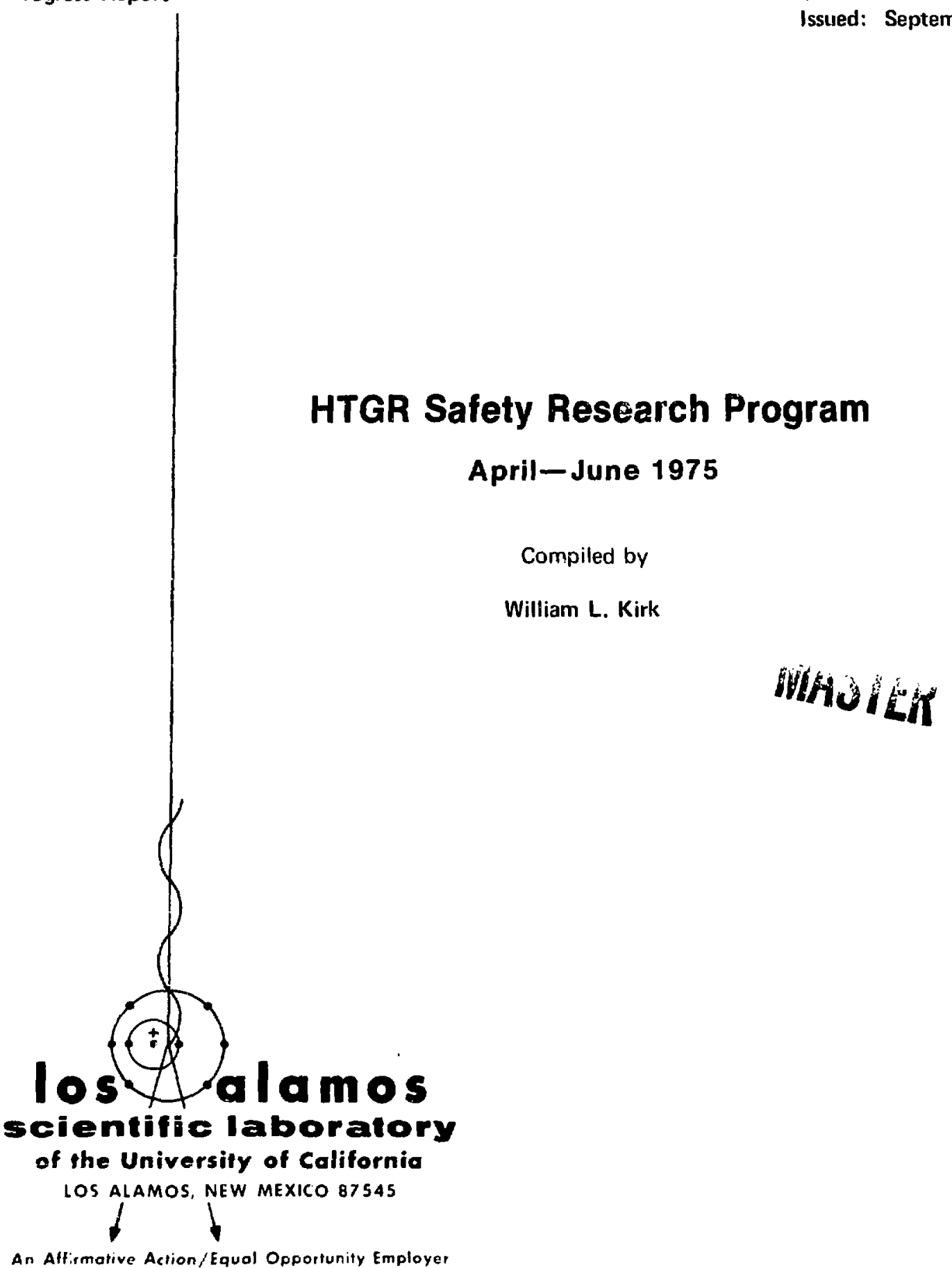

An Alfirmative Action/Equal Opportunity Employer 
Previous reports in this series, unclassified, are LA-5870-PR and LA-5975-PR.

In the interest of prompt distribution, this report was not edited by the Technical Information staff.

Work supported by the Reactor Safety Research Division of the Nuclear Regulatory Commission. 


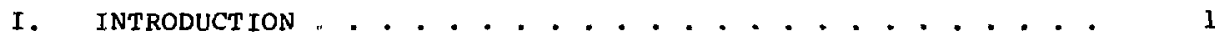

II. SUMMARY ...................... I

III. FISSION PRODUCT TECHNOLOGY ....................... 3

A. Parameter Study on Temperatures and Iodine Release . . . 3

B. Fission Product Transport from the PCR! . . . . . . . . 7

C. The Interaction Between Cesium and Graphite for Use in the Study of Surface Phenomena . . . . . . . . . . . . . 11

IV. PRIMARY COOLANT IMPURITIES . . . . . . . . . . . . . 17

A. Code Development . . . . . . . . . . . . . 17

B. Corrosion and Mass Transport Phenomena.......... 18

C. Reactions of Impurities with Graphite and Metallic Components.................. 22

v. STRUCTURAL INVESTIGATION ............... 25

A. Constitutive Relations of Plain and Reinforced Concrete 25

B. Code Development for the Analysis of PCRV's . . . . . 25

C. Analytical Model Development for Core Seismic Response . 26

D. Physical Model Test Program for Core Seismic Response . 32

VI. SAFETY INSTRUMENTATION AND CONTROL SYSTEMS . . . . . . . . 37

A. Impurities Monitoring . . . . . . . . . . . . . 37

B. Temperature Sensors . . . . . . . . . . . . . 39

ViI. ACCIDENT DELINEATION ................... 41

VIII. PHENOMENA MODELING AND SYSTEMS ANALYSIS . . . . . . . 41

A. HTGR Neutronic Analysis . . . . . . . . . . . . . 41

B. Nuclear Data Processing for HTGR Safety Research. . . . 45

C. Chap code status ................... 50

D. Status of HTGR Systems Analysis and Neutronics Codes.. 51

REFERENCES .................... . . . 54

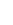

(1)


HTGR SAFETY RESEARCH PROGRAM

QUARTERLY PROGRESS REPORT

for

APRIL - JUNE 1975

\section{INTRODUCTION}

The Los Alamos Scientific Laboratory (LASL) is carrying out a broad program of research in High-Temperature Gas-Cooled Reactor (HTGR) safety technology under the direction of the Reactor Safety Research Division of the United States Nuclear Regulatory commission. The present LASL program includes the following task areas:

- Fission Product Technology

- Primary Coolant Impurities

- Structural Evaluation

- Saf̈ry Instrumentation and control Systems

- Accident Delineation

- Phenomena Modeling and Systems Analysis

This program was started in March 1974 and is a continuing effort. Previously, progress has been reported in a series of informal monthly progress reports. This present report is the third in a series of formal quarterly progress reports.

\section{I. SUMMARY}

Calculatiors of core temperatures and consequent frac“ional ${ }^{13 . l}$ I releases during the loss of for zed cooling (LOFC) accident have been examined for sensitivity to the size of element used in the AYER heat conduction code. Three cases were compared: 1) the basic element size used in earlier calculations, 2) an element size a factor of four smaller, 3) an element size a factor of four larger. The results of the comparison show that the sensitivity to element size is not great and that the basic element size provides a good balance between computing accuracy and time.

A simple gas transport model has been developed to partially account for the hold up of fission products within the PCRV during the Maximum Hypothetical Fission Product Release (MHFPR) accident. Using this model to replace the usual assumption that fission products released from the core are completely and instantly transported into the containment building results in a significant decrease in the rate at which an isotope is released from the containment building irto the atmosphere and a significant decrease in the total release of short-li, 1 fission products.

The complex transport behavior of cesium in graphite is being studied. One portion of the problem, fast surface diffusion, can be examined by means of computer dynamic simulation of the transport of one cesium atom across a graphite surface. The derivation of a potential energy function for this motion is described in subsequent sections, together with calculational results which show possibly fortuitous agreement with experiment.

The OXIDE- 3 code has been rewritten in a different style which reduces code length and running time. The new version,tentatively labeled OXIDE-3A is now operational, 
but requires some further work. LASL review of OXIDE- 3 has been aissussed with General Atomic Company (GAC) personnel. We believe that the conversion effort has shown that there are no signifigant programming errors in OXIDE- 3 .

Work has continued on conplex equilibrium calculations including development of the computer code QUIL. Calculations of the equilibria to be expected in the presence of cesium have just begun. A number of calculational results are reported and inalyzed. These efforts indicate that, as a first approximation, equilibria of the carbon-steam system can be treated by consideration of the major species $\left(\mathrm{H}_{2}, \mathrm{H}_{2} \mathrm{O}, \mathrm{CO}, \mathrm{CO}_{2}, \mathrm{CH}_{4}\right)$ only. The experimental set up for using electrical resistance measurements to follow the kinetics of gas-metal reactions has been improved to increase the sensitivity of the measurements. An experiment to determine the oxidation of pure $\mathrm{Ni}$ in air was repeated with excellent results; however, two subsequent experiments involving more complex reactions met with limited success. It appears that the use of electrical resistance measurements withcut supplementary data to determine the kinetics of gas-metal reactions is limited to cases where only surface oxidation occurs or to cases where surface oxidation plus internal changes occur simultaneously.

A computer code which computes constitutive relationships for plain and reinforced concrete from basic materials data has been obtained, made operational on LASL computers, and incorporated into NONSAP. This code appears to be the most advanced one available for representing the complex behavior of reinforced concrete.

Application of NONSAP is currently restricted by the lack of several features in the code. Work is underway to provide a number of needed features and others will soon be attacked.
Dowel pirss and slots have been added to the two-dimensjonal core seismic analytical model. A movie illustrating the affects of the pins under single-frequency horizontal excitation has been prepared.

Studies have been undertaken to estimate stiffness of the core block, locating pin, and locating pin slot. Results are reported for the first two in subsequent sections.

The use of the computer program SIMEAR for providing earthquake excitation to the core block model has been attempted during this quarter. It was found that acceleration, velocity, and displacement time histories furnished by SIMEAR were independent and consequently produced incredible results. Current application of SIMEAR input uses only the acceleration time history.

scaling law studies for physical models of core seismic response have been extended. The results of studies of four systems are reported.

The improved version of the LASL Afterglow Impurities Monitor was completed and operated at Fort St. Vrain on May 28

and 29, 1975. On May 28th, the monitor indicated 504 ppmv water in the primary coolant. A level of 25 ppmv was measured on May 29 th.

The reactivity worths of several IITGR control rod configurations were calculated with a two-dimensional model cross section provided by GAC. Where comparison data are available, there j.s good agreement between these calculations ar.s previous GAC and onedimensional LASL calculations.

The reactivity change resulting from the failure of the three graphite posts supporting the central refueling region and a consequent $2-m$ drop of the refueling region has been calculated to be small and negative regardless of the position of the central control-rod pair. 
Neutronic kinetics parameters calculated for the Fulton Generating station are in good agreement $w_{1}$ th those reported in the PSAR.

Independent LASL cross-section prepuration for homogeneous HTGR media has progressed to the point that neutronic calculations using these cross sections are in reasonable agreement with calculations based on GAC cross sections, taking into account the expected effect of core heterogeneity. The source of error for earlier at tempts to generate HTGR cross sectons at LASL has been identified and eliminated. CHAP code development is continuing.

II I. TASK 1, FISSION PRODUCT TECHNOLOGY

A. Parameter study on Temperatures and Iodine Release (J.H. Fu and G. E. Cort)

1. Objectives of the study One problem of concern in the HTGR safety study is the time-dependent temuerature of the reactor core, resulting in release of fission products from fuel particles, during the loss of forced circulation (LOFC) accident. Previously, the lodine release problem was analyzed using a simplified uniform core temperature model. 1 This simplified model revealed the essential concepts about the fission product release calculation techniques. In addition, the problem was analyzed in detail using an AYER heat conduction model. 2 The AYER heat condustion model is a modified version of the LASL AYER leat conduction computer iode ${ }^{3}$ which uses the finite element method ${ }^{4}$ (FEM) as the computation scheme. The prasent calculations are based on this heat conduction model.

The purposes of this study are to examine the variations in computed results, such as the temperature of the reactor core and fractional isi I release, as a function of the variation of the size of the element used in the finite element method, and to search for a set of optimal size parameters which will furnish both computational efficiency and relatively accurate results.

\section{Size Parameter Ranges}

In previous AYER heat conduction model studies, the selected input size parameter led to the use of 361 annulusring elements in total, of which 112 elements were in the reactor zore. In the present study, three different size parameters have been investigated:

- Case A - The size of an element in the active core is four times larger than that used in the previous study. The total number of elements in the reactor core is 28, and "he total number of eler.ents usrd in the finite element method calculation is 180 .

- Case B - The size parameter of the previous study is used.

- Case c - The size of an element in the active core is equal to one-fourth that of pre$v$ ious study. There are 446 elements in the reactor cule, and a total of 918 annulus-ring elements are used in the finite element method calculation.

The size parameters used in the finite element method calculations for these three cases are summarized in Table I.

\section{Calculations}

The time-dependent core temperatures and the fractional 131 I releases were calculated fior the three cases described. In each case, the calculations covered a period of $12 \mathrm{~h}$ after the onset of the LOFC accident. The time increments used in the calculations were: 1) every $300 \mathrm{~s}$ up to $900 \mathrm{~s}, 2$ ) every $900 \mathrm{~s}$ up to $2 \mathrm{~h}$, and 3) every hour up to $12 \mathrm{~h}$. Assumptions, physical parameters, and initial 
TABLE I

\author{
SIZE PARAMETERS USED \\ IN THE FINITE ELEMENT METHOD CALCULATIONS
}

\begin{tabular}{ll} 
Case & $\begin{array}{l}\text { Number of Elements } \\
\text { in the Active Core }\end{array}$ \\
\hline
\end{tabular}

$\begin{array}{rrrr}\text { A } & 28 & 180 & 208 \\ \text { B } & 112 & 361 & 400 \\ \text { C } & 448 & 918 & 980\end{array}$

Total Number of Nodes Used in the FEM and boundary conditions used in the present study are similar to those used in previous studies. Some of the important ones are:

- The HTGR has been operating at a constant power of $3000 \mathrm{MW}_{\mathrm{t}}$ prior to the LofC accident.

- The irradiation history of fuel particles in the reactor core is four years.

- The temperature range for fuel particles to fail is from 1303 to $1673 \mathrm{~K}$, and the fraction of fuel particles is a linear function of the local temperature of the reactor core within tilis range. 5

- It is assumed that 108 of the fuel particles have failed prior to the LOFC accident.

- The fission product iodine is released only from failed fuel particles with the release rate given by the usual Arrhenius relation(Ref. 5, Fig. 5-3) i.e. Rate of Rejease for $131_{1}=$ $6796.7 \exp (-22075.5 / \mathrm{T})$.

- The initial temperature of the reactor core is $1100 \mathrm{~K}$.

The afterheat generation rate in each finite element in the reactor core is proportional to the decay power. For convenience of comparison the proportionality constant has been assigned a value of unity in the present study.

The calculated temperatures for the three cases are given in Table 11 , and the average temperatures are plotted versus time in Fig. 1. Only a single curve has been plotted for the maximum temperature of the reactor core because the differences in the maximum temperatures for these cases are too small to be separated on the plot. A comparison of the extremes (Case $\Lambda$ and case $c$ ) snows that the masimum difference in the average temperature is only $2 \%$. This difference occurs at: the end of the time period of the calculations; i.e., at $12 \mathrm{~h}$.

Table III is a comparison of the fractional 131 I releage for the three cases during the first $12 \mathrm{~h}$ after the onset of the accident. In Fig. 2 , the 131 I release data are plotted against time after the onset of the LOFC accident. The results of the earlier simplified uniform core temperature modol ${ }^{l}$ are plotted as Case D for: comparison.

pinally. a comparison of computation times on the CDC 7600 required in these three cases is given in Table IV; the computation time for Case $C$ is longer than that for case $A$ by more than sixfold. 
MAXIMUM AND AVERAGE TEMPERATURES OF THE PEAC'TOR CORE FOR THE THREE CASES LISTED IN TABLE I VERSUS TIME AFTER ONSET OF THE LOFC ACCIDENT

\begin{tabular}{|c|c|c|c|}
\hline Time & Average & Temperat & te (K) \\
\hline (hour) & Case A & Case B & Case C \\
\hline 0.083 & i1 137.1 & 1139.8 & 1141.6 \\
\hline 0.167 & 1164.2 & 1168.0 & 1170.4 \\
\hline 0.250 & 1188.0 & 1192.7 & 1195.7 \\
\hline 0.500 & 1245.4 & 1252.0 & 1256.0 \\
\hline 0.750 & 1295.6 & 1303.6 & 1308.3 \\
\hline 1.000 & 1341.1 & 1350.4 & 1355.8 \\
\hline i. 250 & 1383.4 & 1393.9 & 1399.9 \\
\hline 1.500 & 1423.3 & 1434.8 & 1441.4 \\
\hline 1.750 & 1461.0 & 1473.6 & 1480.7 \\
\hline 2.000 & 1497.0 & 1510.6 & 1518.2 \\
\hline 3.000 & 1620.6 & 1637.6 & 1646.4 \\
\hline 4.000 & 1730.2 & 1750.4 & 1760.1 \\
\hline 5.000 & 1829.7 & 1852.8 & $\$ 863.0$ \\
\hline 6.000 & 1921.2 & 1946.7 & 1957.4 \\
\hline 7.000 & 2006.0 & 2033.8 & 2044.8 \\
\hline 8.000 & 2085.3 & 2115.0 & 2126.2 \\
\hline 9.000 & 2159.8 & 2191.2 & 2202.7 \\
\hline 0.000 & 2230.3 & 2263.3 & 2274.9 \\
\hline 1.000 & 2297.2 & 2331.7 & 2343.5 \\
\hline 2.000 & 2361.0 & 2396.8 & 2408.7 \\
\hline
\end{tabular}

\begin{tabular}{|c|c|c|}
\hline Maximum & Temperat & re \\
\hline Case $A$ & Case $\mathrm{B}$ & Case C \\
\hline 1146.1 & 1146.0 & 1146.0 \\
\hline 1178.7 & 1178.6 & 1178.6 \\
\hline 1207.8 & 1207.6 & 1207.5 \\
\hline 1279.0 & 1278.4 & 1278.4 \\
\hline 1342.0 & 1340.9 & 1340.9 \\
\hline 1399.5 & 1398.4 & 1398.4 \\
\hline 1453.4 & 1452.6 & 1452.6 \\
\hline 1504.5 & 1504.1 & 1504.1 \\
\hline 1553.5 & 1553.5 & 1553.5 \\
\hline 1601.1 & 1601.1 & 1601.1 \\
\hline 1770.5 & 1770.6 & 1770.6 \\
\hline 1926.0 & 1926.3 & 1926.3 \\
\hline 2072.1 & 2072.6 & 2072.7 \\
\hline 2210.5 & 2211.4 & 2211.6 \\
\hline 2342.6 & 2344.0 & 2344.3 \\
\hline 2469.3 & 2471.2 & 2471.7 \\
\hline 2591.4 & 2594.2 & 2594.9 \\
\hline 2709.5 & 2713.3 & 2714.2 \\
\hline 2824.1 & 2828.8 & 2830.0 \\
\hline 2935.3 & 2941.1 & 2942.6 \\
\hline
\end{tabular}


FRACTIONAL IODINE RELEASED FROH THE FAILED FUEL PARTICLES

IN THE REACTOR CORE DURING THE LOFC ACCIDENT

FOR THOSE THREE CASES LISTED IN TABLE I

Time After Onset of the Accident (hour)

\begin{tabular}{|c|}
\hline 0.083 \\
\hline 0.167 \\
\hline 0.250 \\
\hline 0.500 \\
\hline 0.750 \\
\hline 1.000 \\
\hline 1.250 \\
\hline 1.500 \\
\hline 1.750 \\
\hline 2.000 \\
\hline 3.000 \\
\hline 4.000 \\
\hline 5.000 \\
\hline 6.000 \\
\hline 7.000 \\
\hline 8.000 \\
\hline 9.000 \\
\hline 10.000 \\
\hline 11.000 \\
\hline 12.000 \\
\hline
\end{tabular}

\begin{tabular}{|c|c|c|c|c|c|c|c|}
\hline \multicolumn{3}{|c|}{ Case A } & \multicolumn{3}{|c|}{ Case B } & \multicolumn{2}{|c|}{ Case C } \\
\hline 2.124 & $x$ & $10^{-7}$ & 2.227 & $x$ & $10^{-7}$ & $2.290 \mathrm{x}$ & $10^{-7}$ \\
\hline 5.519 & $x$ & $10^{-7}$ & 5.844 & $x$ & $10^{-7}$ & $6.047 \times$ & $10^{-7}$ \\
\hline 1.059 & $x$ & $10^{-6}$ & 1.131 & $x$ & $10^{-6}$ & $1.177 \times$ & $10^{-6}$ \\
\hline 4.860 & $x$ & $10^{-6}$ & 5.319 & $\mathbf{x}$ & $10^{-6}$ & $5.599 \times$ & $10^{-6}$ \\
\hline 1.705 & $x$ & $10^{-5}$ & 2.062 & $x$ & $10^{-5}$ & $2.233 x$ & $10^{-5}$ \\
\hline 5.744 & $\mathbf{x}$ & $10^{-5}$ & 6.998 & $x$ & $10^{-5}$ & $7.682 \mathrm{x}$ & $10^{-5}$ \\
\hline 1.575 & $x$ & $10^{-4}$ & 1.915 & $\mathrm{x}$ & $10^{-4}$ & $2.098 x$ & $10^{-4}$ \\
\hline 3.660 & $x$ & $10^{-4}$ & 4.449 & $\mathbf{x}$ & $10^{-4}$ & $4.861 \times$ & $10^{-4}$ \\
\hline 7.553 & $x$ & $10^{-4}$ & 9.189 & $\mathbf{x}$ & $10^{-4}$ & $1.001 x$ & $10^{-3}$ \\
\hline 1.427 & $x$ & $10^{-3}$ & 1.738 & $\mathbf{x}$ & $10^{-3}$ & $1.890 \times$ & $10^{-3}$ \\
\hline 1.311 & $x$ & $10^{-2}$ & 1.566 & $x$ & $10^{-2}$ & $1.686 \times$ & $10^{-2}$ \\
\hline 4.235 & $x$ & $10^{-2}$ & 4.995 & $\mathrm{x}$ & $10^{-2}$ & $5.329 x$ & $10^{-2}$ \\
\hline 9.844 & $x$ & $10^{-2}$ & 1.154 & $\mathbf{x}$ & $10^{-1}$ & $1.224 x$ & $10^{-1}$ \\
\hline 1.859 & $x$ & $10^{-1}$ & 2.157 & $x 1$ & $10^{-1}$ & $2.276 \times$ & $10^{-1}$ \\
\hline 2.973 & $x$ & $10^{-1}$ & 3.388 & $\times 1$ & $10^{-1}$ & $3.554 \times$ & $10^{-1}$ \\
\hline $4.136=$ & $x$ & $10^{-1}$ & 4.594 & $\times 1$ & $10^{-1}$ & $4.786 x$ & $1 v^{-1}$ \\
\hline 5.167 , & $x$ & $10^{-1}$ & 5.562 & $\times 1$ & $10^{-1}$ & $5.749 \times$ & $10^{-1}$ \\
\hline 5.999 & $x$ & $10^{-1}$ & 6.236 & $\times 1$ & $10^{-1}$ & $6.421 x$ & $10^{-1}$ \\
\hline 6.651 & $x$ & $10^{-1}$ & 0.785 & $x 1$ & $10^{-1}$ & $6.898 \times$ & $10^{-1}$ \\
\hline 7.154 & $x$ & $10^{-1}$ & 7.205 & $\times 1$ & $10^{-1}$ & $7.269 x$ & $10^{-1}$ \\
\hline
\end{tabular}




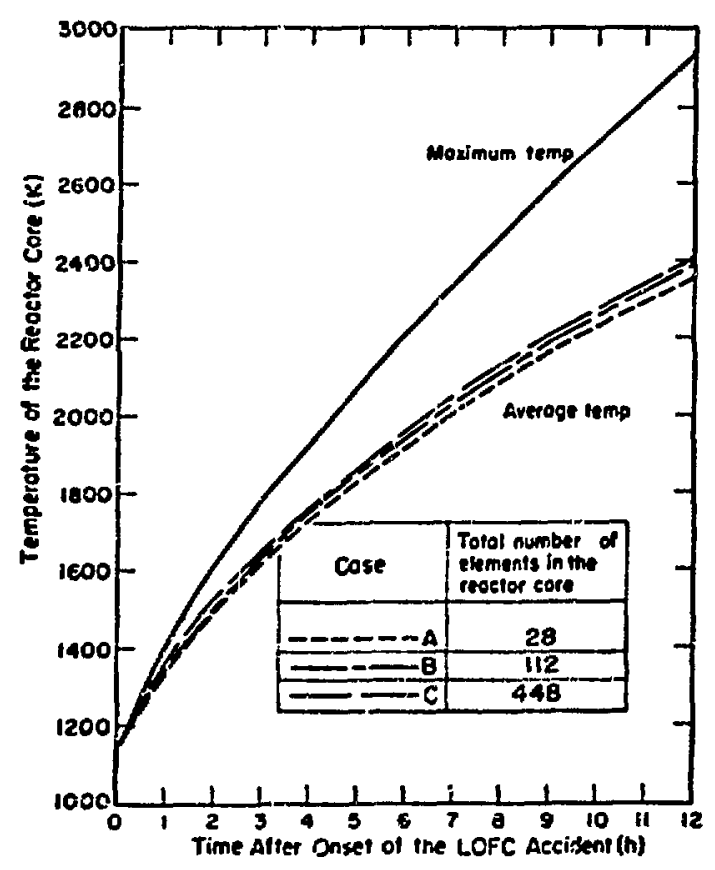

$\bar{F}$ ig. 1. The maximum and average temperatures of the reactor core versus time after onset of the LOFC accident.

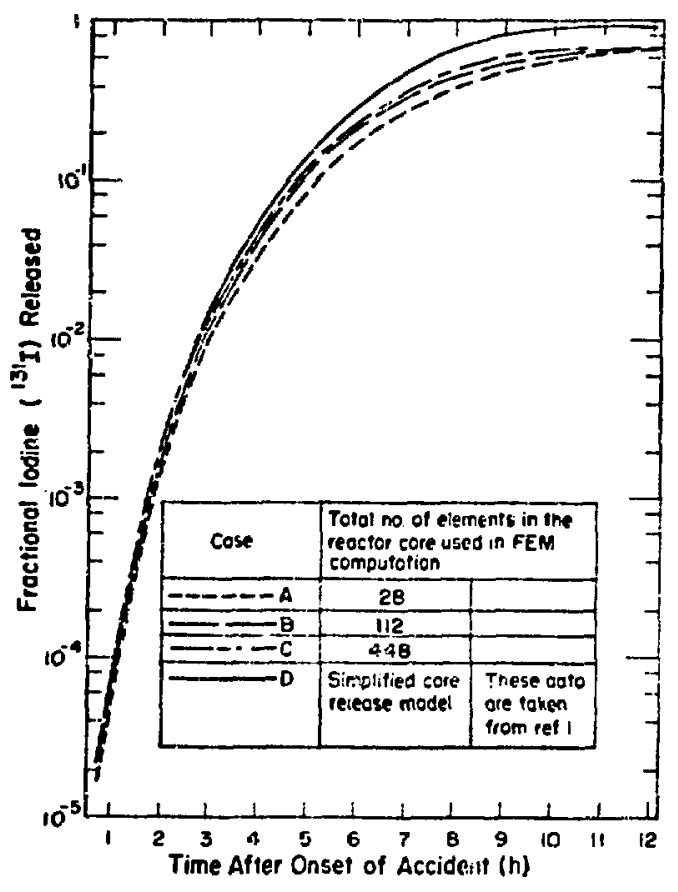

Fig. 2. Fractional ${ }^{131}$ I release versus time after onset of the LOFC accident

\section{TABLE IV}

COMPUTATION TIME FOR THE THREE CASES LISTED IN TABLE I

$\begin{array}{cr}\text { Size Parameter } & \text { Computation Time (s) } \\ \text { Case A } & 19.31 \\ \text { Case B } & 36.07 \\ \text { Case C } & 130.58\end{array}$

4. Summary

The purpose of this study was to examine the variations in calculated reactor core temperature and fractional iodine release caused by varying the size of parameters used in the AYER heat conduction model calculations. During the time period covered by the present calculations, the maximum variation in the tempexature of the reactor core (between the extreme cases $A$ and $C$ ) is only 28 ; howev' $:$, the computation times for the extremes differ by more than sixfold. Based on these comparisons, the element size used in the previous studies ${ }^{2}$ (Case B) appears to be an adequate compromise between competing goals of computational accuracy and efficient computer usage.

\section{B. Fission Product Transport frem the PCRV (J. E. Foley) 1. Introduction \\ A simple gas transport model was} developed $\mathbf{s} r$ that the time-dependent release of fission products from the PCRV during the MHFPR accident could be calculated. In the fission product release computer programs currently being used for 
release calculation (e.g. $\mathrm{AYER}^{2}$ and SORS ${ }^{5}$ ), it is assumed that fission products which are volatilized from the core are transported instartaneously into the containment building through the penetration failure which caused the accident. The gas transport model was developed so that the time-dependent transport of fission products from the PCRV could be included in the release calculations. The model is applicable only to single PCRV penetration failures; it does not apply to failures that establish a natural circulation flow between the PCRV and the containment building.

The gas inside the PCRV depressurizes at the onset of the MHFPR accident and an equilibrium pressure is established between the residual gas inside the PCRV and the gas inside the containment buildirg. In the gas transport model described here, it is assumed that the subsequent flow of gas into the containment building is produced by an expansion of the residual gas inside the PCRV as the gas temperature (T) rises due to core decay heat.

2. Identification of PCRV Leak Rate It will be assumed that the gas inside the PCRV obeys the ideal gas law. It will be assumed further that, after the initial depressurization of the PCRV, the pressures inside and outside the PCRV are the same and that they remain constant during the time period of interest. This assumption is justified because the pressure inside the containment building for the Summit Plant, for example, is calculated to decrease only $\sim 1$ psi from $\sim 25$ psia at $2 \mathrm{~h}$ to $\sim 24$ psia at $18 \mathrm{~h}$ following the onset of the MHFPR accident: 6 i.e., the containment building pressure remains nearly constant with time. This assumption allows us to decouple the PCRV from the containment building and to analyze the PCRV flow independently.

The time-dependent change in the amount of gas inside the PCRV is given by

$$
\begin{aligned}
\frac{d N}{d t} & =\left(\frac{\partial N}{\partial T}\right)\left(\frac{d T}{d t}\right) . \\
& =-\left(\frac{P V}{R T^{2}}\right)\left(\frac{d T}{d t}\right) .
\end{aligned}
$$

This equation can be rewritten in a more convenient form:

$$
\frac{d N}{d t}=-\left(\begin{array}{ll}
\frac{1}{T} & \frac{d T}{d t}
\end{array}\right) N .
$$

The leak rate (fractional release rate) of the PCRV is thus identified in Eq. (3) as

$$
L(t)=\frac{1}{T} \frac{d T}{d t}
$$

\section{Fission Product Leakage from} the PCRV

The fission products which are volatilized from the core and become gasborne are assumed to be well mixed with the coolant gas inside the PCRV. The rate of change in the amount (n) of the gasborne isotope is given by

$$
\frac{d n(t)}{d t}=s(t)-[\lambda+L(t)] n(t)
$$

where

$S$ is the source term of the isotope in the coolant gas lequal to the rate at which the isotope is volatilized from the core),

$\lambda$ is the radioactive decay constant of the isotope,

$L$ is the leak rate of the PCRV defined by Eq. (4).

Plateout of the isotope on surfaces interior to the PCRV has been ignored, but it could be included by setting $\lambda=\lambda+P$ where $P$ is a fractional rate for plateout. Equation 5 is of the same form as that used in Ref. 1, Eq. (13) to describe fission product release from a containment builaing. Thus, the same formulation that is used to calculate the time-dependent leakage from the containment building can be used for this problem. 
If the source term $S(t)$ and the leak rate $L(T)$ are considered to be constants during short time intervals of length $\Delta t$, then the amount of the gasborne isotope released $\left(R_{i}\right)$ into the containment building from the PCRV during the $i^{\text {th }}$ time interval is given by Eq. (16) of Ref. 1 , i.e.

$$
\begin{aligned}
R_{i}= & \frac{L_{i}}{\lambda_{i}^{*}}\left(n_{i-1}-\frac{S_{i}}{\lambda_{i}^{*}}\right)\left(1-e^{-\lambda_{i}^{*} \Delta t}\right) \\
& +L_{i} \frac{S_{i}}{\lambda_{i}^{k}} \Delta t
\end{aligned}
$$

where

$$
\begin{aligned}
& \mathrm{n}_{i-1} \text { is the amount ( } \mathrm{C} \text {, moles, atoms, } \\
& \text { etc) of the isotope gasborne in- } \\
& \text { side the PCRV at the end of the } \\
& (i-1) \text { st time interval (at time } \\
& \left.t_{i-1}\right), \\
& L_{i} \text { ds the leak rate of the PCRV } \\
& \lambda_{i}^{*} \text { equaling the time interval, }
\end{aligned}
$$

The source term $S_{i}$ is the average rate of release of the isotope from the core during the time interval; it can be identified as the release rate from the core obtained using either the LASL AYER or the GAC SORS computer prograns.

$$
\text { 4. Calculations }
$$

these calculations, but the analysis could be applied equally well to any other isotope. The assumptions used for the AYER calculations are similar to, but not exactly the same as, those used for the parametric study discussed earlier. Because of slight differences in the assumptions, the temperatures and release rates presented in this section are slightly different from those presented earlier. These slight differences are not important for this discussion.

It will be assumed that the coolant gas temperature is equal to the average core temperature; this assumption results in gas temperatures that are too high, but these temperatures are sufficiently accurate for this analysis. The time-deperdent leak rate, defined by Eq. (4), is calculated using the temperature data from the AYER calculations. It is assumed that the average core temperature increases linearly over 1-h time intervals. During the 4- to 5-h time interval $(i=5)$, for example, the average gas temperature is $1804.8 \mathrm{~K}$ and the temperature rise is $106.7 \mathrm{~K}$ (From $1751.5 \mathrm{~K}$ to $1858.2 \mathrm{~K}$ ); therefore, the leak rate of the HCRV during the time interval is

$$
L_{5}=\frac{106.7 \mathrm{~K} / \mathrm{h}}{1804.8 \mathrm{~K}}=0.0591 \mathrm{~h}^{-1}
$$

Thus, 5.918 of the gasborne fission products inside the PCRV leak into the containment bujlding during the time j.nterval 4- to 5-h after the onset of the MHFPR accident. The PCRV leak rates for the other time intervals are calculated in the sume way: they are given in Table $V$.

The source terms $S_{i}$ for ${ }^{131} I$ for each time interval are given in Table VI; these values are based on a total core inventory of ${ }^{131} \mathrm{I}$ of $7.78 \times 10^{7}$ $\mathrm{Ci}$ for a $3000 \mathrm{MW}_{t}$ reactor (Ref. 1, Appen$\operatorname{dix}$ A).

\section{Results of the Calculations} The calculated time-dependent release curves of ${ }^{131}$ I from the PCRV are shown in Fig. 3 for: 1) the release of the fission products directly from the core to the containment building, and 2 ) the release using the PCRV leak rate of $\frac{l}{T} \frac{d T}{d t}$ given in Table $v$. It is seen that the rate of release of the isotope from the PCRV is significantly slower using the $\frac{1}{\mathrm{~T}} \frac{\mathrm{dT}}{\mathrm{dt}}$ leak rate than it is using the direct release model.

The analysis was extended to include calculations of the time-dependent release of the isotope into the environment from the containment building. The timedependent release rates into the containment building from the PCRV were used for 
TABLE $V$

LEAK RATE OF PCRV

\begin{tabular}{|c|c|c|c|}
\hline $\begin{array}{l}\text { Time Interval } \\
(\mathrm{h})\end{array}$ & $\begin{array}{c}\text { Avg. Temp. } \\
(\mathrm{K})\end{array}$ & $\begin{array}{r}\mathrm{dT} \\
(\mathrm{K}) \\
\end{array}$ & $\begin{array}{c}\text { Leak Rate } \\
\left(\mathrm{h}^{-1}\right)\end{array}$ \\
\hline $0-1$ & 1220.3 & 240.6 & 0.197 \\
\hline $1-2$ & 1419.8 & 158.5 & 0.112 \\
\hline $2-3$ & 1566.2 & 134.2 & 0.0857 \\
\hline $3-4$ & 1692.4 & 118.2 & 0.0698 \\
\hline $4-5$ & 1804.8 & 106.7 & 0.0591 \\
\hline $5-6$ & 1907.0 & 97.6 & 0.0512 \\
\hline $6-7$ & 2000.8 & 90.1 & 0.0450 \\
\hline $7-8$ & 2087.2 & 82.6 & 0.0396 \\
\hline $8-9$ & 2167.3 & 77.6 & 0.0358 \\
\hline $9-10$ & 2242.8 & 73.4 & 0.0327 \\
\hline $10-11$ & 2314.3 & 09.6 & 0.0301 \\
\hline $11-12$ & 2382.3 & 66.4 & 0.0279 \\
\hline $12-13$ & 2447.2 & 63.4 & 0.0259 \\
\hline $13-14$ & 2509.2 & 60.7 & 0.0242 \\
\hline $14-15$ & 2558.8 & 58.4 & 0.0227 \\
\hline $15-16$ & 2026.2 & 56.3 & 0.0214 \\
\hline $16-17$ & 2681.4 & 54.3 & 0.0203 \\
\hline $17-18$ & 2733.1 & 49.0 & 0.0179 \\
\hline
\end{tabular}

TABLE VI

131 I RELEASE FROM CORL

\begin{tabular}{|c|c|c|}
\hline $\begin{array}{c}\text { Time Interval } \\
\text { (h) }\end{array}$ & $\begin{array}{l}\text { Fractional } \\
\text { Release Rate } \\
\left(\mathrm{h}^{-1}\right)\end{array}$ & $\begin{array}{c}\text { Release Rate } \\
(\mathrm{Ci} / \mathrm{h})\end{array}$ \\
\hline $0-1$ & $2.570 \times 10^{-5}$ & $1.999 \times 10^{3}$ \\
\hline $1-2$ & $2.034 \times 10^{-3}$ & $1.582 \times 10^{5}$ \\
\hline $2-3$ & $1.344 \times 10^{-2}$ & $1.046 \times 10^{6}$ \\
\hline $3-4$ & $3.720 \times 10^{-2}$ & $2.894 \times 10^{6}$ \\
\hline $4-5$ & $7.330 \times 10^{-2}$ & $5.703 \times 10^{6}$ \\
\hline $5-6$ & $1.110 \times 10^{-1}$ & $8.636 \times 10^{6}$ \\
\hline $6-7$ & $1.270 \times 10^{-1}$ & $9.881 \times 10^{6}$ \\
\hline $7-8$ & $1.230 \times 10^{-1}$ & $9.569 \times 10^{6}$ \\
\hline $8-9$ & $8.900 \times 1 \mathrm{i}^{-2}$ & $0.924 \times 10^{6}$ \\
\hline $9-10$ & $6.400 \times 10^{-2}$ & $4.979 \times 10^{6}$ \\
\hline $10-11$ & $4.900 \times 10^{-2}$ & $3.812 \times 10^{6}$ \\
\hline $11-12$ & $4.000 \times 10^{-2}$ & $3.112 \times 10^{6}$ \\
\hline $12-13$ & $3.300 \times 10^{-2}$ & $2.567 \times 10^{6}$ \\
\hline $13-14$ & $2.700 \times 10^{-2}$ & $2.101 \times 10^{C}$ \\
\hline $14-15$ & $2.400 \times 10^{-2}$ & $1.867 \times 10^{6}$ \\
\hline $15-16$ & $1.900 \times 10^{-2}$ & $1.478 \times 10^{6}$ \\
\hline $10-17$ & $1.700 \times 10^{-2}$ & $1.323 \times 10^{6}$ \\
\hline $17-18$ & $1.500 \times 10^{-2}$ & $1.107 \times 10^{6}$ \\
\hline
\end{tabular}

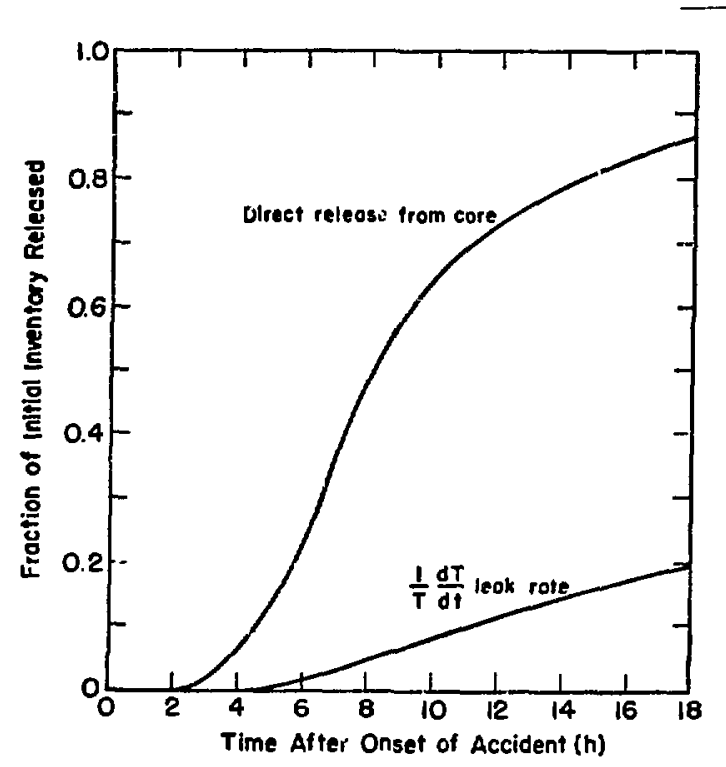

Fig. 3. Time-dependent release of ${ }^{131_{I}}$ from the PCRV during the MHFPR accident. the source terms of the isotope inside the containment building. The leakage from the containment building was then determined using Eq. (6), ${ }^{\star}$ as described in $R \in f .1$, p. 6-8. It was assumed that all of the iodine released from the core lexcept for that which undergoes radioactive decay) is available for release from the containment building, i.e., the arbitrary 258 factor for availability (Ref. 1, p. 6) was not used (this factor can be included by multiplying the release values by 0.25 ). The time-dependent release curves for ${ }^{131_{I}}$ from the containment building were calculated for the two cases given in Fig. 3; they are shown in Fig. 4. It is seen that the use of the $\frac{1}{1} \frac{d T}{d t}$ PCRV leak rate results

\footnotetext{
"The leak rate of the containment building was assumed to be $0.18 /$ day and the cleanup rate for the containment cleanup system was assumed to be $0.9 h^{-1}$.
} 


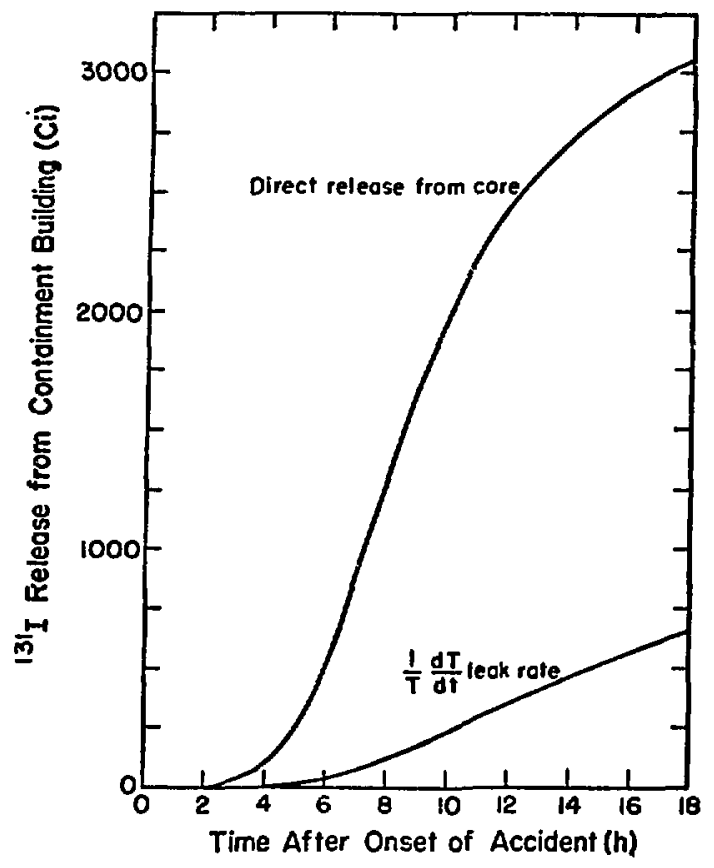

Fig. 4. Time-dependent release of ${ }^{131_{I}}$ from the containment building during the MHFPR accident.

in a significant decrease in the rate at which ${ }^{131} \mathrm{I}$ is released to the atmosphere. The total amount of ${ }^{131}$ I released to the atmosphere decreases if the $\frac{1}{\mathrm{~T}} \frac{\mathrm{dT}}{\mathrm{d}} \mathrm{t}$ PCRV leak rate is used because of the additional time for radioactive decay resulting from the holdup time of the isotope inside the PCRV. For short-lived isotopes the additional holdup results in a significant decrease in the amount of the isotope released; for long-lived isotopes, the additional holdup results in little decrease in the total amount released to the atmosphere, although the time required for the release is spread out over a longer period of $t i m e$.

\section{Summary \\ Including the gas transport}

model for the PCRV in the fission product release calculations results in a significant decrease in the rate at which an isotope is released from the PCRV during the MHFPR accident. The additional hold up time of the isotope inside the PCRV results in a significant decrease in the total amount of the short-lived isotopes released to the atmosphere. The total amount of the long-lived isotopes released does not decrease significantly.

The slower release rate offers some advantage in satisfying the CFR Title 10, Part $100 \mathrm{criteria}^{7}$ for both the $2-\mathrm{h}$ Exclusion Area Boundary (EAB) dose and the Low Population zone (IPZ) dose. If the gas transport model is ignored (direct release from the core to the containment), then most of the ${ }^{131}$ I release occurs during the time period $4 \mathrm{~h}-12 \mathrm{~h}$ following the onset of the MHFPR accident (see Fig. 4) and, because this is the time period for the worst atmospheric transport conditions 8,9 [the time period for largest atmospheric diffusion factors $\left.\left(\frac{x}{Q}\right)\right]$, the calculated thyroid dose will be its maximum value. On the other hand, if the gas transport model is used, most of tha release of the long-lived isotopes occurs at times $>12 \mathrm{~h}$ when better atmospheric conditions prevail, and thus the calculated population dose is lower. A long, slow release of an isotope results in a lower overall calculated dose than does a short, fast release of the same total amount.

\section{c. The Interaction Between Cesium and Graphite for Use in the Study of Surface Phenomena (B. L. Holian) 1. Introduction \\ There is stowing interest in} the complex transport behavior of cesium in graphite. 10,11 at least two transport modes are indicated by recent experiments: 1) slow bulk diffusion and 2) fast surface diffusion. In order to study the mechanisms involved in the latter phenomenon, molecular dynamics computer simulations of the transport of a cesium atom across a graphite surface have been undertaken. The classical equations of motion need be 
solved for one atom only, since the behavior at low surface coverage, where the interaction between adsorbed cesium atoms can be neglected, is of particular theoretical and practical interest. Even with this simplification of the dynamics to the motion of one particle, the force acting on the cesium atom is quite complicated. In this section structural considerations and theoretical estimates of atomic properties will be combined to give a reasosable potential energy function for use in subsequent molecular dynamics calculations. The following six subsections describe individual terms in the potential, with the results presented in the last subsect $:$

\section{Zero of Energy}

The zero of energy for a cesium atom interacting with the graphite surface will be taken to be that of the atom separated infinitely far from the graphite crystal. As the atom approaches the surface, the electronic configuration of the atom becomes more and more distorted. The outer $6 \mathrm{~s}$ electron, being loosely bound to the core, is easily snatched from the cesium by the metal-like graphite surface plane. When an electron is donated to the conduction band of the graphite plane (chemical symbol of graphite, Gr) energy is released - the electron work function, $E_{w}(\mathrm{Gr})$ :

$$
G r+e^{-}=G r^{-}+E_{w}(G r)
$$

The first ionization of cesium requires eneray - the ionization potential, $F_{I}(1)$ (Cs) :

$$
\mathrm{Cs}+\mathrm{E}_{\mathrm{I}}(1)(\mathrm{Cs})=\mathrm{Cs}^{+}+\mathrm{e}^{-}
$$

The overall reaction (the sum of Eqs. (7) and (8) ] requires energy $w$ :

$$
\mathrm{Cs}+\mathrm{Gr}+\mathrm{W}=\mathrm{Cs}^{+}+\mathrm{Gr}^{-},
$$

where $W=E_{I}^{(1)}$ (Cs) $-E_{W}(G r)$ is negative, i.e., heat is given off by the reaction. In units of $\mathrm{kK}=1000 \mathrm{~K}, \mathrm{E}_{\mathrm{I}}^{(1)}(\mathrm{Cs})=45.18$, $E_{w}(G r)=53.62$, and $w=-8.44$.

3. Bulk Electrostatic Interaction The ionized cesium atom inter-

acts with its donated electron in the graphite conduction band much like a point charge over an infinite perfectly conducting plane; i.e., the classical electrostatic problem of the image charge. The principal uncertainty in this model is the location of the conducting plane. If we assume that the cesium atom is centered over a hexagon of carbon atoms at a height of $z_{m}=2.97 \mathrm{~A}$ above the graphite plane (as in the case of interlamellar cesium-graphite compounds), 12,13 then the height of the conducting plane above the plane of the carbon nuclei $z_{0}$ is simply $z_{m}-r\left(\mathrm{Cs}^{+}\right)$, where $r\left(\mathrm{Cs}^{+}\right)=1.69 \AA$ is the ionic radius of cesium. 14 This is consistent with a Van der Waals' radius for a graphite carbon a tom of $r(\mathrm{C})=1.602 \AA$ ine $\mathrm{C}-\mathrm{C}$ bond length in graphite is $r_{0}=1.421 \AA$ and the spacing between layers is $c_{0}=3.354 \AA$ ) ; $r$ (c) is therefore very close to $1 / 2 \mathrm{c}_{0}=$ $1.677 \AA$, the Van der Waals' radius in graphite. (See Figs. 5 and 6.) The values of $r(c)$ for rubidium and potassium interlamellar compounds ${ }^{12}$ are $1.682 \stackrel{\circ}{\AA}$ and $1.721 \stackrel{\circ}{A}$, giving a small but systematic deviation for the series $K, \mathrm{Rb}$, and $C s$ of +2.68 , +0.38 , and -4.58 .

The image-charge potential energy is given by

$$
v_{\text {image }}(z)=-\frac{e^{2}}{4\left(z-z_{0}\right)} .
$$

At the equilibrium position, $v_{\text {image }}=$ $-24.72 \mathrm{kK}$. The image-charge force is given by

$$
\begin{aligned}
F_{z}^{(\text {image })}(z) & =-\frac{d V_{\text {image }}(z)}{d z} \\
& =-\frac{e^{2}}{4\left(z-z_{0} j^{2}\right.} .
\end{aligned}
$$




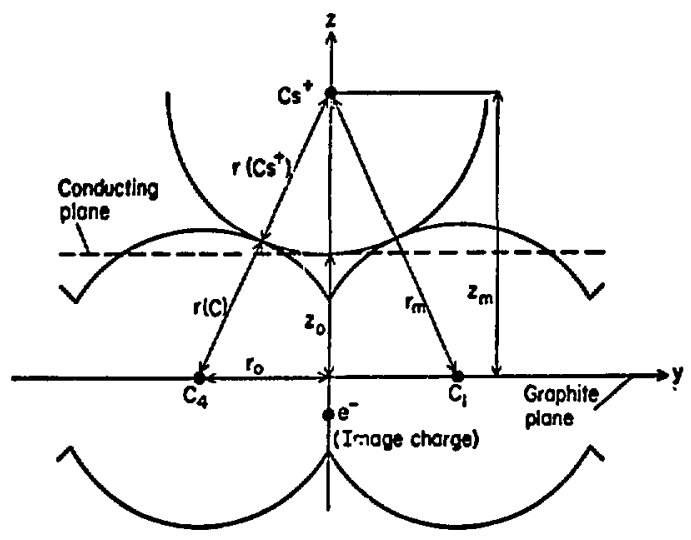

Fig. 5. Side view of bonding geometry of adsorbed cesium atom on graphite; $\mathrm{c}_{1}$ and $\bar{c}_{4}$ are carbon atoms as shown in $\mathrm{Fig.6}$; $\mathrm{e}^{-}$is position of image charge (other symbols defined in text).

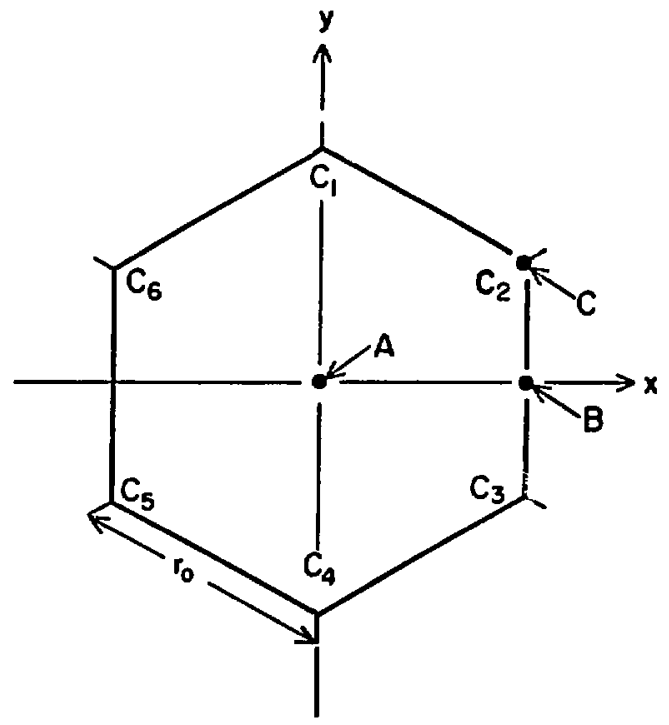

Fig. 6. Top view of bonding geometry of adsorbed cesium atom on graphite; site $A$ is adsorption site (minimum of potential energy), site $B$ is above $C-C$ bond (saddle point in potential energy surface), and site $C$ is above carbon atom (maximum of potential energy). which is just the coulomb force between two charges te and -e separated by $2\left(z-z_{0}\right)$. If the surface has defects, i.e., missing carbon atoms, the above approach must be modified. 15 Let us suppose that there are $M$ defects (circular holes in the conduction plane) located at $\left(x_{m}, y_{m}\right)$ with radii $a_{m}(m=1,2, \ldots . M)$; then given the following functions,

$$
\begin{aligned}
A(x, y) & =\sum_{m=1}^{M} a_{m}^{2} \exp \mid-\left[\left(x-x_{m}\right)^{2}\right. \\
& \left.+\left(y-y_{m}\right)^{2}\right] / a_{m}{ }^{2} \mid,
\end{aligned}
$$

and

$$
\begin{aligned}
A_{\alpha}(x, y)= & \sum_{m=1}^{M}\left(x_{\alpha}-x_{\alpha m}\right) \exp \mid-\left(\left\langle x-x_{m}\right)^{2}\right. \\
& \left.\left.+\left(y-y_{m}\right)^{2}\right\} / a_{m}^{2}\right\}
\end{aligned}
$$

where $\alpha=x$ or $y$, the potential energy of a charge te located at $(x, y, z)$ in the presence of $M$ defects in the conducting plane at $\mathbf{z}=z_{0}$ can be approximated by:

$$
v(x, y, z)=-\frac{e^{2}}{4\left[A(x, y)+\left(z-z_{0}\right)^{2}\right]^{1 / 2}}
$$

and the forces are

$$
F_{\alpha}(x, y, z)=\frac{e^{2} A_{\alpha}(x, y)}{4\left[A(x, y)+\left(z-z_{0}\right)^{2}\right]^{3 / 2}}
$$

for $\alpha=x$ or $y$ and

$$
F_{z}(x, y, z)=-\frac{e^{2} z}{4\left[A(x, y)+\left(z-z_{0}\right)^{2}\right]^{3 / 2}} .
$$

These expressions reduce to the imagecharge expressions (Egs. 7 and 8) far from defects, including the condition thet $F_{X}$ and $F_{y}$ vanish. Further, from Eq. (15) it is clear that a defect is a scatering center from considerations of the bulk electrostatic interaction. 


\section{Induction Interaction}

The charge on the cesium ion can induce an instantaneous dipole moment in the carbon atoms of the graphite crystal (and vice-versa), which leads to a potential energy contribution of the following form $^{16}$

$$
\phi^{(\text {ind })}(R)=-\frac{C_{4}}{R^{4}}
$$

where $\phi^{\text {(ind) }}$ is in units of $e^{2 / 2 a_{0}}$ (e is the electronic charge and $a_{0}=0.5292 \mathrm{~A}$ is the first Bohr radius), $R$ is in units of $a_{0}$, and $c_{4}$ is given by

$$
c_{4}=q_{1}^{2} \alpha_{2}+q_{2}^{2} a_{1} \text {. }
$$

where $q_{i}$ is the charge (in units of e) on atom $i$ and $\alpha_{i}$ is its polarizability (in units of $\left.\mathrm{a}_{0}{ }^{3}\right)$. The polarizability of $\mathrm{Cs}^{+}$ can be estimated using slater's screening constants (Ref. 16, p. 951-ff). A better estimate is obtained by multiplying the observed value for iso-electronic xenon, 17 $\alpha_{X e}=27.1 a_{0}^{3}$, by the ratio of $\alpha_{c s^{+}}{ }^{+}$to $\alpha_{x e}$ as calculated via the slater method. The result is $\alpha_{\mathrm{Cs}^{+}}=17.4 \mathrm{a}_{0}{ }^{3}$. Since the polarizability of a molecule is the sum of its bond polarizabilities, the polarizability of graphite per carbon atom can be obtained from the linear interpolation of the aliphatic (singie bond, bond order $n=1$ ) and aromatic (benzene, $n=1-1 / 2$ ) bond polarizabilities (carbon bond polarizability versus bond order is fairly linear). The polarizability of a graphite carbon atom is then $\frac{3}{2}{ }^{\alpha} c-c(n=1-1 / 3)$, since the graphite bond order (Ref. 14, p. 235) is $1-1 / 3$ and there are $1-1 / 2$ such bonds per atom. The result is $\alpha_{c}=10.8 \mathrm{a}_{0}{ }^{3}$. The electron donated by the cesium atom is shared by at least six nearest carbon atoms, so that the charge on any carbon atom is no more than $-\mathrm{e} / 6$. Therefore, taking $q_{C}=-1 / 6$ as being correct for the most important nearby carbon atoms, $c_{4}=11.26 \frac{\mathrm{e}^{2}}{2 \mathrm{a}_{0}} \cdot \mathrm{a}_{0}{ }^{4}$.
Define

$$
A=\frac{C_{4}}{r_{m}^{4}} \text {, }
$$

the induction contribution per nearest carbon atom at the equilibrium position (position $A$ in Fig. 6); then $A=1.188 \mathrm{kK}$.

\section{Dispersion Interaction}

Although the charge distribution

in a free atom or ion is spherical, there are fluctuations due to the rapidly moving electrons that result in a net instantaneous dipole moment. This dipole can then induce an instantaneous dipole in another atom, leading to a potential energy contribution of the following form (Ref. 16, p. 963),

$$
\phi^{(\mathrm{dis})}(\mathrm{R})=-\frac{\mathrm{C}_{6}}{\mathrm{R}^{6}}
$$

where $\phi^{\text {(dis) }}$ is in units of $e^{2 / 2 a_{0}}, R$ in units of $a_{0}$, and $C_{6}$ is given by the LondonPitzer formula 17

$$
c_{6}=\frac{3}{2} \frac{{ }^{\alpha_{1} \alpha_{2}}}{E_{1}^{-1}+E_{2}^{-1}},
$$

where $\alpha_{i}$ is in units of $a_{0}{ }^{3}$ and $E_{i}$, the characteristic energy of atom $i$, is in units of $e^{2 / 2 a} a_{0}$. Pitzer has shown empirically that $E_{i}$ is roughly twice the ionization potential. Since $\mathrm{E} / \mathrm{E}_{\mathrm{T}}=2.27$ for neon and 2.39 for xenon, 17 let us take $E_{C}=2.77 \mathrm{E}_{I}^{(1)}(\mathrm{C})=1.878 \mathrm{e}^{2} / 2 \mathrm{a}$ and $E_{C s^{+}}=2.39 \mathrm{E}_{I}^{(2)}(\mathrm{Cs})=4.409 \mathrm{e}^{2} / 2 \mathrm{a}_{0}$. Therefore, $C_{6}=370.8 \frac{e^{2}}{2 a_{0}} \cdot a_{0}{ }^{6}$.
Define

$$
B=\frac{c_{6}}{r_{m}^{6}}
$$

the dispersion contribution per nearest carbon atom at the equilibrium position; then $B=1.010 \mathrm{kK}$.

\section{Valence Interaction} At short range, the overlap of electron charge clouds of two atoms gives rise to a repulsive potential energy 
contribution of the form (Ref. 16, P. 26)

$$
\phi^{(v a l)}(R)=b \exp \left(-a R / a_{0}\right)
$$

where $R$ is in units of $a_{0}$ and $a$ is given by

$$
a\left(\frac{e^{2}}{2 a_{0}}\right) 1 / 2=E_{I}^{1 / 2}(1)+E_{I}^{1 / 2}(2),
$$

with $E_{I}(i)$ in units of $e^{2 / 2 a} \cdot E_{I}^{(1)}(C)=$ $0.8273 \mathrm{e}^{2} / 2 \mathrm{a}_{0}$ and $E_{I}^{(2)}(\mathrm{Cs})=E_{I}^{(1)}\left(\mathrm{Cs}^{+}\right)=$ $1.845 \mathrm{e}^{2} / 2 \mathrm{a}_{\mathrm{o}}$ i hence $\mathrm{a}=2.268$. Define

$$
a=a \frac{r_{m}}{a_{0}} ;
$$

then $a=14.11$ and

$$
\phi^{(\operatorname{val})}(R)=0 \exp \left[\alpha\left(1-\frac{R}{r_{m}}\right)\right] .
$$

where $Q$ is the valence contribution per nearest carbon atom at the equilibrium position. Q can be determined by requiring that the force on the cesium ion at position $A$, the adsorption site on a perfect graphite surface, be zero.

\section{Integral corrections}

Because the potential energy of interaction of the cesium ion with the free-surface graphite crystal converges slowly with distance into the crystal, an integral correction must be added to the discrete sum over graphite carbon atoms. In Fig. 7, the problem is indicated schematically as a spherical sector containing discrete atoms and a continuous distribution over the remainder of the crystal (free-surface bulk minis a crater). The distance $R_{\max }$ is sufficiently large that only the induction and dispersion terms are appreciable. The integral correction for the potential term $\phi$ is

$$
\delta \phi\left(R_{\max }\right)=2 \pi \rho f_{R_{\max }}^{\infty} \mathrm{dR} R(R-z) \phi(R),
$$

where $\rho$ is the number density of graphite and $z$ is the height of the cesium ion over

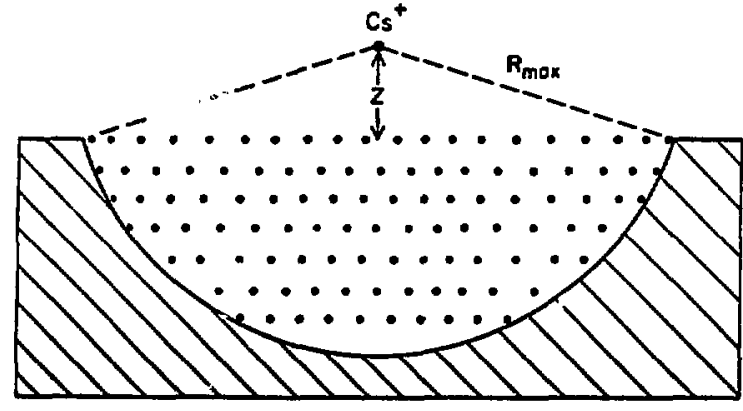

Fig. 7. Schematic representation of 1attice summation and integral correction (continuous distribution) to potential energy of cesium ion over graphite surface.

the graphite plane. Likewise, it can be showr $t$ at the $z$-gradient correction is

$$
\begin{aligned}
\delta \nabla_{z} \phi\left(R_{\max }\right)= & -2 \pi n\left[\frac{1}{2}\left(R_{\max }{ }^{2}-z^{2}\right) \phi\left(R_{\max }\right)\right. \\
& \left.+\delta_{R_{\max }}^{\infty} \mathrm{dR} R \phi(R)\right] .
\end{aligned}
$$

\section{Results}

As outlined above, $Q$ was calcu-

lated by summing over 8050 graphite carbon atoms within a radius of $R_{\max }=10.29 r_{m}$ $\left(r_{m}=3.292 \AA\right)$ and applying the integral corrections for the remainder of the graphite crystal. The resulting value of $Q$ is $1.792 \mathrm{kK}$, which exceeds by about 0.28 the value obtained for an $R_{\max }$ half as big (approximately one-ninth the number of carbon atoms). Q was also calculated, as a check, by sumning over the six nearest carbons, integrating over a uniform surface distribution for the top graphite plane minus a disk of six times the atomic surface area), and integrating over the bulk (minus the first graphite plane). The result was remarkably close to the "exact" lattice sum plus correction and was about 38 too small (likewise for the magnitude of the adsorption energy). Table VII shows results for the barriers to translational motion of a cesium ion on a perfect graphite surface. (The positions 


\begin{tabular}{|c|c|c|c|c|}
\hline Position, i & $z_{i}(\stackrel{0}{A})$ & $\Phi_{i}(k K)$ & $\phi_{i}(\operatorname{expt.})(k K)$ & ${ }_{i}{ }_{(k K)}{ }^{\Phi} A$ \\
\hline A & 2.970 & -61.562 & -60.5 & 0 \\
\hline B & 3.046 & -59.875 & & 1.687 \\
\hline$c$ & 3.055 & -59.679 & & 1.883 \\
\hline
\end{tabular}

A, B, and $C$ are shown in Fig. 6 and are defined such that the total force on the cesium atom is zero.) The kinetic energy at a temperature of about $1000 \mathrm{~K}$ or more is enough for a cesium ion to surmount the barriers on a perfect graphite surface, i.e., the ion behaves essentially like a free particle. The experimental value for the adsorption energy ${ }^{18}$ was obtained from two adsorption isotherms of cesium on TS-688 graphite in the Henry's Law regime, i.e.. where the cs partial pressure is proportional to concentration. In view of the serious nature of the approximations herein employed, the close agreement with experiment should be viewed with some caution. Ho:cover, zumwalt has pointed out that the true adsorption site is probably over a defact. 19 The effect on the calculated adsorption energy due to a defect will be examined in future work.

Wteh rogard to adsorption behaviol itgelf, it should bo noted that the na ure of the interaction changes dramatically as the cosium atom loaves the sut face and the fonization reaction of Eq. (9) is reversed to qive a desorbad neutral cesium atom. This casentially quantum mechanical effect can be accounted for in a seml-ompirical way by multiplying tho appropriate ionic quantities (polarizability, charge, cte.) by an ionic charactor function $x(z)$ shown in Fig. 8 .

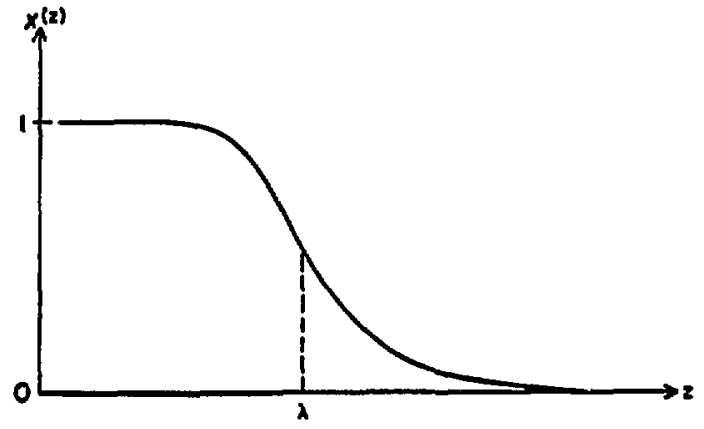

Fig. 8. Ionic character function $x(z)$ as a function of the distance $z$ of the ion above the free surface of a crystal; $\lambda$ is the characteristic length of $x$.

and the corresponding atomic (neutral) quantities by $1-x(z)$. Thus, a completely classical calculation, such as a molecular dynamics simulation, would include implicitly this electronjs rearrangement in the potential energy terms. The characteristic length $A$ of the ionic character function as well as its shape could, in principle, be inferred from quantum mechanical electronic calculations. 20

Future work will include the molecular dynamic calculation of various 
correlation functions * of a cesium ion wandering over both perfect and defective graphite surfaces. If the defect holes are either attractive or repulsive (adsorbers or scatterers), the surface transport at high temperatures should be like a random walk, or classical diffusion in two timensions. If the surface is very smooth, however, the transport will be much like that of a free particle in a two-dimensional box. Also, a more precise calculation of the electrostatic froblem of a charge over a conducting plane with a circular hole is being undertaken. 22

IV. TASK 2, PRIMARY COOLANT IMPURITIES Efforts within this task area are directed to the analytical and experimental study of the interactions between impurities in the helium primary coolant gas and the various materials in the primary coolant circuit. The most likely impurities are steam and the products of the steamgraphite reaction: hydrogen, carbon monoxide, or carbon dioxide. Materials of interest are the core and related graphite structures, and metallic components such as steam generators, helium circulators, orifice valves, and control rod systems. Interactions between gaseous impurities and fission products, with possible formation of volatile species, are also of interest.

A. Code Development (A. Bowman)

The OXIDE- 3 code received from GAC has been rewritten in a different stylo. The modified version, tentatively designaced OXIDE-3A, is analytically equivalent to OXIDE-3, but the Fortran source code has been reduced in length by 403 and the running time has been reduced by approximately 158. The modification consists

The diffusion coefficient can be shown to be the time integral of the velocity autocorrelation function; see for example Ref. 21. primarily of the elimination of unused statements, arrays, and single variables, and the combination of related groups of variables into arrays. Some of the flow paths have also been changed to eliminate unnecessary subroutines, loops, and transfers. The rounded-off atomic weights used in OXIDE-3 have been replaced by 1966 values without round-off.

The conversion to OXIDE-3A has yielded three principal benefits:

1. A cleaner, more efficient code which is easier to read;

2. a thorough understanding of the OXIDE- 3 model and its computational pr "esses; and

3. the elim!stion of several programming errors. Only two of the errors had any significant effect on the results. These involved the release of metallic fission products (an error already discovered and corrected by GAC) and the initialization of coolant temperatures in the core.

A meeting was held on June 16, 1975 with A. Barsell and M. Peroomian of GAC to discuss the OXIDE-3A modification and possible programming errors. This meeting increasew our understanding of OXIDE-3, cleared up several points of uncertainty, and defined a few areas for further study.

The OXIDE-3A code is now operational, but some debugging is required and there are still a few sections to be modified. The results of this conversion effort suggest that there are no significant programming errors in OXIDE-3. The future work with OXIDE-3 will include a study of the validity of the model and of the simplifying assumptions used to facilitate computation. Now primary effort will be directed toward the further development of the CIMPRE code. 
B. Corrosion and Mass Transport Phenomena

(R. Feber, J. Lunsford, and W. A. Stark)

In the past quarter continued effort has been expended in the area of complex equilibria calculations. part of this effort has been devoted to the continued development of an interactive computer code, QUIL. This code features a preprocessor which accepts a chemical statement of the problem as input. The preprocessor then generates the set of nonlinear equations required by the problem at execution time.

The first system solver used by eUIL. relied on a combination of techniques; the Newton-Raphson, a weighted NewtonRaphson, and the method of steepest ascent. Increased use of the code in a variety of applications indicated instances for which solutions could not be obtained and consequently a more powerful technique has substituted for the method used earlier. This new method is a modification of the Levenberg-Marquardt 23,24 algorithn. After an initial search is performed for an optimum factor by which to scale the solution vector ( $E$ search), a two-dimensional search is performed which employs both the $E$ method and the Levenberg-Marquardt method (P search). A method of smallest least squares solutions as proposed by osborne 25 which can operate with singular systems is used to extract the solution vector. This allows the system solver to operate with ill-conditioned as well as singular systems and to increase the likelihood of convergence in the wide variety of problems which occur.

various features have been incorporated into guIL to increase its convenience and utility. The code has been modified so as to be able to calculate equilibria in the presence of surface phases. In particular, onother code, ISOT, was written which will decompose experimental sorption isotherms into a parametric model and will load these parameters into the library in a manner identical to that in which conventional reactions have been treated. The code has been modified so that it will calculate the potential to occur for reactions which are assumed to be out of equilibrium. These "reaction potentials" are then plotted over the range of the calculation. Instances of mixed equilibria are also of interest wherein certain reactions in a system are assumed to be in equilibrium while others are not. For example, one might wish to partition equilibrium in a given system by assuming gasgas equilibrium in the absence of gassolid equilibrium. The code has been modified to allow for such conditions of partitioned equilibria to be imposed. QUIL has also been modified so as to allow the reactions in the library to be loaded as sums and differences.

Calculations on equilibria to be expected in the presence of cesium isotherms have only just begun. The first data so treated are those for cesium sorption on TS-688 graphite taken at GAC. 26 Although it is still too early to make extensive equilibrium predictions on the behavior of cesium in the reactor environment, some trends are beginning to appear of the sort indicated in Fig. 9. The ordinate of this plot is the negative log of the activity of species assumed to be present over a cesium isotherm. Here the activity is computed as the product of (concentration)(total pressure) for gas phases, the concentration for condensed phases, and as the fractional cuverage relative to one mono-layer coverage for surface phases. The environment chnsen for the calculation is the Peach Bottom steady state stoichiometry. 27 The cesium introduced corresponds to an initial coverage of 0.01 of monolayer covirage, or about 0.01 micromoles of cesiuin per mole of graphite. The temperature range indicated is from 300 to $1500 \mathrm{~K}$, which is the limit to which the data in question may be extrapolated, As a matter of fact, the results should be taken 


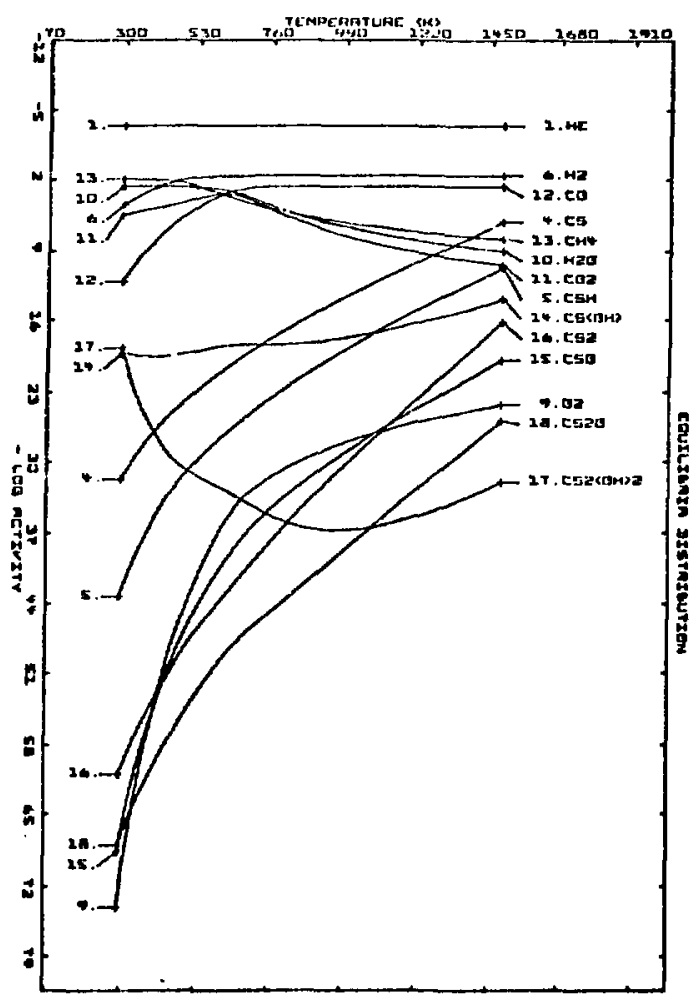

Fig. 9. Peach Bottom steady state stoichiometry in the presence of a 0.018 cesium isotherm. Gas phase assumed to be in equilibrium with solid carbon. operating pressure of $2296 \mathrm{kPa}(20 \mathrm{~atm})$.

judiciously outside of the range of the original data, which is from 800 to $1100 \mathrm{C}$. Above $1200 \mathrm{~K}$, elemental cesium vapor is seen to exist in abundance relative to several of the species due to gaseous impurities in the helium. Also, below about $725 \mathrm{~K}, \mathrm{Cs}(\mathrm{OHI})$ begins to increase in abundance relative to the $\mathrm{Cs}_{\mathrm{v}}$ apor. The remaining species of cesium are seen to be unimportant in the environment in question over the range 300 to $1500 \mathrm{~K}$.

Figure 10 shows the activity of the isotherm for the calculation, where the activity is taken as proportional to coverage and equal to one at a one mono-layer coverage. It can be weon that, except for temperatures above $1450 \mathrm{~K}$.

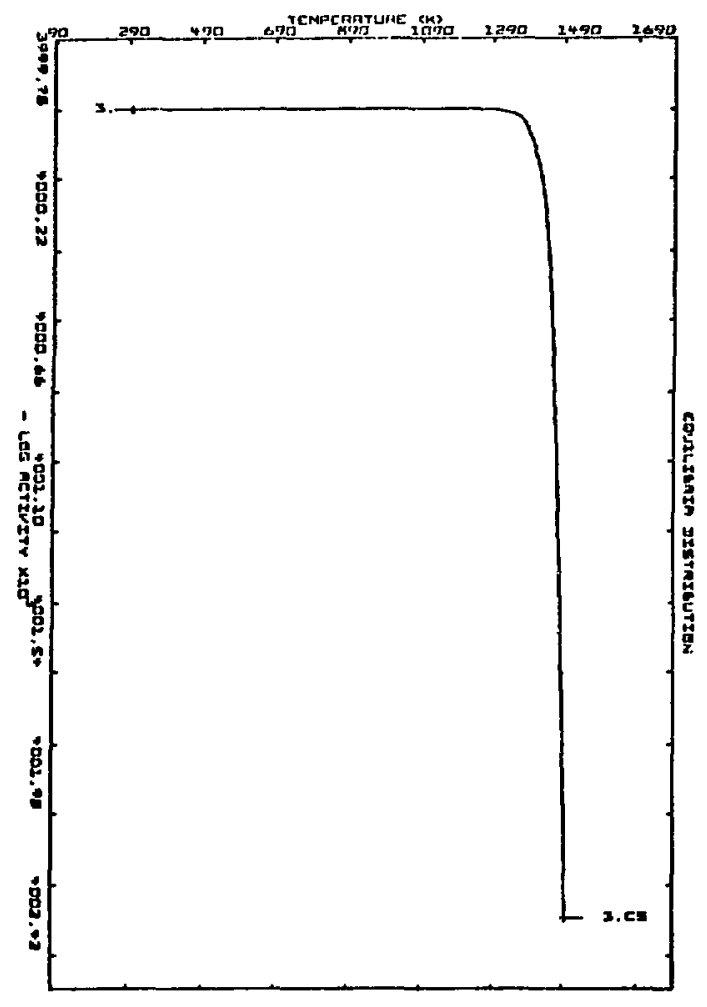

Fig. 10. Activity of a 0.018 cesium isotherm in the Peach Bottom steady state stoichiometry in equilibrium with solid carbon. Operating pressure of $2296 \mathrm{kPa}$ (20 atm).

little if any effect of the environment upon the isotherm is evident. To date, this has been borne out in calculations as high as 18 cesium coverage to $1000 \mathrm{ppm}$ water. At water levels approaching $10000 \mathrm{ppm}$ water, cesium is oxidized from che isotherm in anounts of the order of 108. For almost all reasonable changes in environment comporition, the net effect of the environment on the isotherm is practically nil as indicated by equilibrium calculations. Tentative results from a few calculations on the effect of pressure suggest that the isotherm is also insenBitive to depressurization. However, a rise in temperature will effectively clear the cesium from the graphite ourface. 
These two graphs suggest a tentative conclusion: although the cesium isotherm is insensitive to the gaseous environment. over the isotherm, the distribution of cesium species that occur in the gas phase is very sensitive to the composition of that gas phase.

Reaction potentials are also computed for precipitation reactions in the system. For deposition reactions involving condensed phases at unit activity, the equilibrium constant can be somputed with the condensed phases assumed to be present or absent. As an example, consider the two reactions

$$
\mathrm{Co}_{2}(g)=\mathrm{c}(\mathrm{s})+\mathrm{O}_{2}(\mathrm{~g})
$$

and

$$
C O(g)=C(s)+1 / 2 O_{2}(g),
$$

which could be solved under equilibrium assumptions to give the equilibrium distribution of species present. In this case there would be $\mathrm{CO}_{2}(g), \mathrm{O}_{2}(g), \mathrm{CO}(\mathrm{g})$, and $c(s)$. The presence of solid carbon affects the resultant distribution significantly, and is equivalent to the assumption of gassolid equilibrium. In the event that this assumption seems unwarranted, it is possible to solve for the following distribution instead. Taking the sum and difference of the two reactions presented above, one obtains

$$
\mathrm{CO}_{2}(g)=0.50_{2}(g)+\mathrm{CO}(g)
$$

as a single reaction. The resultant distribution of species, is exactly that which wolild prevail if the system as assembled had no carbon in it. In effect, the system has been solved under the assumption that gas-gas equilibrium prevails while gassolids does not. Having excluded $c(s)$ from the calculation, it is now of interest to know if the environment as calculated is predisposed to precipitate carbon or to react with it. Consider the definition of the equilibrium constant for the first reaction written above:

$$
\mathrm{K}=\mathrm{P}_{2} / \mathrm{P}_{\mathrm{CO}_{2}}
$$

Since the reaction was not included in the system as solved in the second iustance, the equality as written above is not satisfied. If instead one substitutes the identity

$$
k^{\prime}=\mathrm{P}_{2}^{\prime} / \mathrm{P}^{\prime} \mathrm{CO}_{2}
$$

where $K^{\prime}$ is computed from the composition distribution solved in the absence of $C(s)$, then the ratio

$$
R=K / K^{\prime}
$$

is a measure of the extent to which the $\mathrm{CO}_{2}$ reaction is out of balince and is thus a measure of the "potential" of the reaction to occur in the system as written. In this case, it is the :endency of the system to precipitate carbon from the gaseous environment assumed to be in equilibrium. The log of the ratio of these two equilibrium constants is then treated as a reaction potential. A positive reaction potential indicates a tendency for the reaction in question to-run to the right as written.

Figure 11 indicates the reaction potential for the deposition of $\mathrm{Cs}(\mathrm{OH})$ in the liquid state in the Peach Bottom equilibrium environment in the presence of carbon. Indications are that no such precipitation would occur, since the plot is positive over the range of the calculation. Figure 12 shows the reaction potential for the deposition of cesium liquid. Again, no tendency to precipitation is indicated in the Peach Bottom environment in the presence of carbon. Calculations are yet to be made on the effect of 


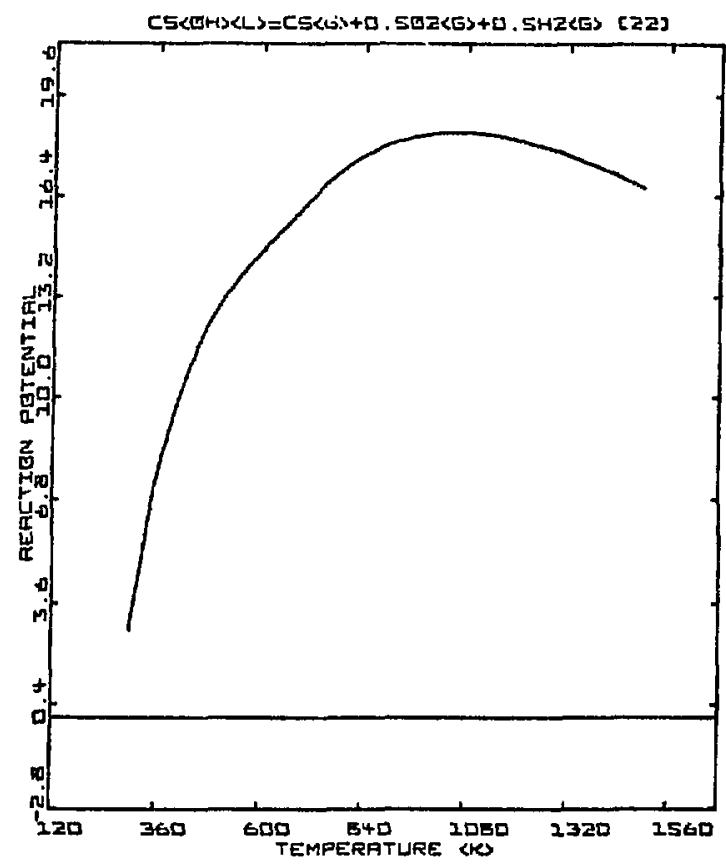

Fig. 11. Reaction potential for Cs(OH) (L) in the Peach Bottom steady state stoichiometry with a 0.018 cesium isothorm present. Gas phase assumed to be in equilibrium with solid carbon. Operating pressure of $2296 \mathrm{kPa}(20 \mathrm{~atm})$.

precipitation isotherms on heat exchanger materials in the reactor coolant loop circuit.

Actually, the trend that may be observed in the absence of carbon with increasing water is quite interesting. Since the isotherm is virtually unaffected by the gaseous environment, it effectively maintains the Cs partial pressure above the isotherm constant. In the reaction

$$
\mathrm{Cs}(\mathrm{OH})=\mathrm{Cs}+0.5 \mathrm{O}_{2}+0.5 \mathrm{H}_{2}
$$

as the (hydrogen) (oxygen) product increases, the partial pressure of the $\mathrm{Cs}(\mathrm{OH})$ goes up correspondingly. What happens in the absence of carbon at high water pressures is that the activity of the cesium hydroxide may reach the ppm level. Since

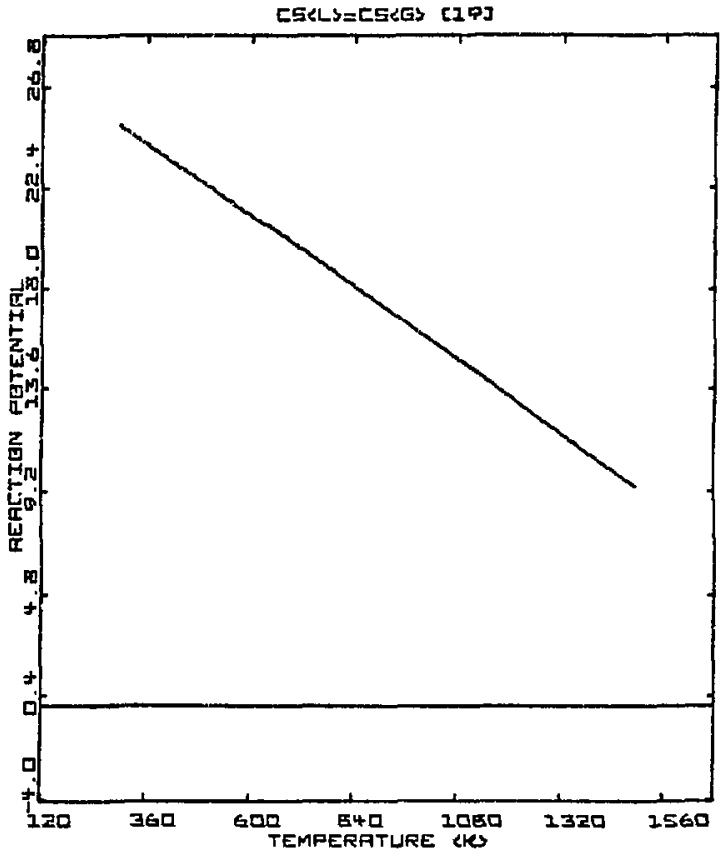

Fig. 12. Reaction potential for $C s(L)$ in the Peach Bottom steady state stoichiometry with a 0.018 cesium isotherm present. Gas phase assumed to be in equilibrium with solid carbon. Operating pressure of $2296 \mathrm{kPa}$ $(20$ atm).

the carbon will eventually oxidize the water, it is instructive to carry out the calculation with carbon present. When one does, it is found that the reaction products of the water reduction have no such effect on the Cs(OH) activity. Thus one would expect that the $\mathrm{Cs}(\mathrm{OH})$ activity would first rise and then fall after a water ingress depending upon the rate of reduction of the water by the carbon.

Estimates of thermodynamic equilibrium compositions in the carbon-steam system have been obtained by an analytical approach which begins with material balances on hyarogen and oxygen, respectively:

$$
\begin{aligned}
& \mathrm{P}_{\mathrm{H}_{2}}^{\mathrm{O}}+\mathrm{P}_{\mathrm{H}_{2} \mathrm{O}}^{\mathrm{O}}=\mathrm{P}_{\mathrm{H}_{2} \mathrm{O}}+\mathrm{P}_{\mathrm{H}_{2}}+{ }^{2} \mathrm{P}_{\mathrm{CH}_{4}} \\
& \mathrm{P}_{\mathrm{CO}}^{\circ}+\mathrm{P}_{\mathrm{H}_{2} \mathrm{O}}^{\circ}=\mathrm{P}_{\mathrm{H}_{2}} \mathrm{O}+\mathrm{P}_{\mathrm{CO}}+2 \mathrm{P}_{\mathrm{CO}_{2}},
\end{aligned}
$$


where

$$
\begin{aligned}
P_{i}= & \text { partial pressure of component } i \\
& \text { at equilibrium } \\
P_{i}^{0}= & \text { initial partial pressure of } \\
& \text { component } i .
\end{aligned}
$$

On substitution of $K_{1}, K_{3}$, and $K_{4}$, which are, respectively, the equilibrium constants for the reactions

$$
\begin{aligned}
& \mathrm{H}_{2} \mathrm{O}(\mathrm{g})+\mathrm{C}(\mathrm{s}) \rightleftharpoons \mathrm{CO}(\mathrm{g})+\mathrm{H}_{2}(\mathrm{~g}) \\
& \mathrm{CO}(\mathrm{g})+\mathrm{H}_{2} \mathrm{O}(\mathrm{g}) \rightleftharpoons \mathrm{CO}_{2}(\mathrm{~g})+\mathrm{H}_{2}(\mathrm{G}) \\
& 2 \mathrm{H}_{2}(\mathrm{~g})+\mathrm{C}(\mathrm{s}) \rightleftharpoons \mathrm{CH}_{4}(\mathrm{~g})
\end{aligned}
$$

the material balance for hydrogen yields

$$
\begin{aligned}
\mathrm{P}_{\mathrm{H}_{2} \mathrm{O}} & =\frac{1+\mathrm{R}_{\mathrm{H}}}{4 \mathrm{~K}_{4} \mathrm{R}_{\mathrm{H}}^{2}}\left[\sqrt{1+8 \mathrm{~K}_{4} \mathrm{R}_{\mathrm{H}}^{2}\left(\mathrm{P}_{\mathrm{H}_{2} \mathrm{O}}^{\mathrm{O}}+\mathrm{P}_{\mathrm{H}_{2}}^{\circ}\right)}-1\right] \\
& \sim \frac{\mathrm{P}_{\mathrm{H}_{2} \mathrm{O}}^{\circ}+\mathrm{P}_{\mathrm{H}_{2}}^{\circ}}{1+\mathrm{R}_{\mathrm{H}}}
\end{aligned}
$$

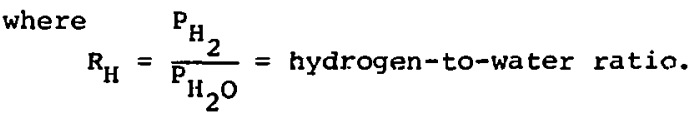

This approximation inserted into the oxygen material balance yields a cubic equation in $\mathrm{R}_{\mathrm{H}}$ :

$R_{H}^{3}-R_{H}^{2}(K+D)-R_{H} K\left(1+2 K_{3}\right)-2 K K_{3}=0$

where now $K=\left(\frac{K_{1}}{\mathrm{P}_{\mathrm{H}_{2} \mathrm{O}}^{\mathrm{O}}+\mathrm{P}_{\mathrm{CO}}^{\circ}}\right)$ and $\mathrm{D}=\left[\frac{\mathrm{P}_{\mathrm{H}_{2}}^{\mathrm{O}}-\mathrm{P}_{\mathrm{CO}}^{\circ}}{\mathrm{P}_{\mathrm{CO}}^{\mathrm{O}}+\mathrm{P}_{\mathrm{H}_{2} \mathrm{O}}^{\circ}}\right]^{\mathrm{H}_{2}}{ }^{\mathrm{O}}$ Equation (42) may

be solved for $R_{\boldsymbol{H}}$ using an iteration technique; at high temperatures results are in quite good agreement with those calculated using the more sophisticated free energy minimization routines such as QUIL, as shown in Table VIII and Table IX. The discrepancies at the lower temperature are due primarily to the approximations used in the derivation of $\mathrm{Eg}$. (41).
These efforts indicate that, as a

first approximation, equilihria of the carbon-steam system can be treated by consideration of the major species $\left(\mathrm{H}_{2}, \mathrm{H}_{2} \mathrm{O}\right.$. $\mathrm{Co}, \mathrm{CO}_{2}, \mathrm{CH}_{4}$ ) only. Concentrations of minor species can then be determined from suitable equilibrium constants. In principle also, the effect of additional co or $\mathrm{H}_{2}$ upon equilibrium compositions can be determined analytically from Eq. (42).

c. Reactions of Impurities with Graphite and Metallic Components (L. C. Michels and W. A. Stark)

A technique employing electrical resistance measurements is being evaluated for possible use in determining the kinetics of gas-metal reactions. Experimental details and the results of initial experiments were reported in the previous HTGR Safety Research Program Quarterly Progress Report, Section IV-B. 28 The experimental setup has since been refined to provide electrical resistance measurements with a sensitivity of \pm 0.18 (formerly \pm 18 ). This was accomplished through the use of a high precision digital voltmeter to measure the voltage drops across the specimens and calibrated standard resistor.

The initial experiment involving a determination of the surface oxidation kinetics of pure $\mathrm{Ni}$ in flowing air at $900^{\circ} \mathrm{C}$ was repeated with excellent results. The specimen was again $998 \mathrm{Ni}$ wire of nominal $0.051 \mathrm{~mm}(0.020-i n.) \mathrm{diam}$. As was reported previously an equation was derived relating the measured change in electrical resistance $(R)$ to the thickness $(T)$ of the metal. layer lost due to surface oxidation:

$$
\begin{aligned}
& T=k t^{1 / 2} \\
& R=\frac{A}{\left(r_{0}-k t^{1 / 2}\right)^{2}}
\end{aligned}
$$

in which $k$ is the parabolic rate constant, $A=\frac{\rho l}{\pi}$, assumed constant, and $r_{0}$ is the initial specimen radius. Following the procedure previously described, values for 
COMPARISON OF ANALYTICAL AND NUMERICAL COMPUTATIONS

OF EQUILIBRIUM $\mathrm{R}=\mathrm{P}_{\mathrm{H}_{2}} / \mathrm{P}_{\mathrm{H}_{2}} \mathrm{O}$ Ratios

Helium Pressure $=50$ atm. $\quad P_{C O}^{\circ}=P_{H_{2}}^{\circ}=0$

$\mathrm{T}=1100 \mathrm{~K}$

$\underline{T}=600 \mathrm{~K}$

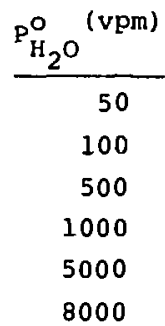

$\frac{\mathrm{P}_{\mathrm{H}_{2} \mathrm{O}}^{\mathrm{O}}}{\left.2.5 \times 10^{-3}\right)}$
$5.0 \times 10^{-3}$
$2.5 \times 10^{-2}$
$5.0 \times 10^{-2}$
.25
40

$\frac{R_{\text {AN }}}{4419}$

$\frac{R_{\text {NUM }}}{4420}$

$\frac{\mathrm{R}_{\mathrm{AN}}}{1.392}$

RUM

2211

2211

1.047

1. 342

$444.6 \quad 444.9$

0.557

0.982

223.8

224.0

0.430

0.470

47.00

47.22

0.239

0.339

30.37

30.58

0.202

0.157

0.125

TABLE IX

COMPARISON OF ANALYTICAL AND NUMERICAL COMPUTATIONS, HELIUM PRESSURE $=50$ atm

\begin{tabular}{|c|c|c|c|c|c|c|}
\hline \multirow[b]{2}{*}{$\mathrm{P}_{\mathrm{H}_{2} \mathrm{O}}^{\mathrm{O}}(\mathrm{atm})$} & \multirow[b]{2}{*}{$\mathrm{P}_{\mathrm{CO}}^{\mathrm{O}}(\mathrm{atm})$} & \multirow[b]{2}{*}{$\mathrm{P}_{\mathrm{H}_{2}}^{\mathrm{O}}(\mathrm{atm})$} & \multicolumn{2}{|c|}{$\underline{T}=1100 \mathrm{~K}$} & \multicolumn{2}{|c|}{$\underline{T}=600 \mathrm{k}$} \\
\hline & & & $\mathrm{R}_{\mathrm{AN}}$ & $\mathrm{R}_{\mathrm{NUM}}$ & $\mathrm{R}_{\mathrm{AN}}$ & $\mathrm{R}_{\mathrm{NUM}}$ \\
\hline$-0-$ & $5.0 \times 10^{-2}$ & $5.0 \times 10^{-2}$ & 223.8 & 224.2 & 0.430 & 0.339 \\
\hline $5.0 \times 10^{-3}$ & $7.5 \times 10^{-3}$ & $7.5 \times 10^{-3}$ & 886.2 & 886.2 & 0.728 & 0.647 \\
\hline $5.0 \times 10^{-3}$ & $2.5 \times 10^{-2}$ & $2.5 \times 10^{-2}$ & 371.0 & 371.5 & 0.520 & 0.431 \\
\hline $5.0 \times 10^{-2}$ & $2.5 \times 10^{-3}$ & $2.4 \times 10^{-3}$ & 213.2 & 213.5 & 0.422 & 0.331 \\
\hline $5.0 \times 10^{-2}$ & .25 & .25 & 39.62 & 40.02 & 0.224 & 0.144 \\
\hline $5.0 \times 10^{-2}$ & $5.0 \times 10^{-3}$ & 0.0 & 203.6 & 203.9 & 0.383 & - \\
\hline $5.0 \times 10^{-2}$ & 0.0 & $5.0 \times 10^{-3}$ & 223.9 & 224.2 & 0.470 & 0.350 \\
\hline
\end{tabular}


$A$ and $k$ were found to be:

$$
\begin{aligned}
& A=7.60 \times 10^{-3}\left(\Omega \cdot \mathrm{mm}^{2}\right), \\
& k=4.21 \times 10^{-5} \mathrm{~mm} / \mathrm{s}^{1 / 2} .
\end{aligned}
$$

Using these values of $A$ and $k$ in Eq. (44), the measured values of $R$ were reproduced to within $\pm 0.25 \%$; the thickness of the lost metal layer was calculated from Eq. (43) to be $7.43 \times 10^{-3} \mathrm{~mm}$. A metallographic determination of the thickness $y$ ielded a value of $7.62 \times 10^{-3} \mathrm{~mm}$ showing excellent agreement between the two different techniques.

For a comparison of the parabolic rate constant to literature values, $k$ converts to a value of $9.74 \times 10^{-6} \mathrm{~g} / \mathrm{cm}^{2}$ $x s^{-1 / 2}$. The value of $k$ calculated using the equation given in Ref. 29 for nickel of comparable purity $(99.78 \mathrm{Ni})$ is $11.07 \times 10^{-6} \mathrm{~g} / \mathrm{cm}^{2} \times \mathrm{s}^{-1 / 2}$, about 128 higher than the measured value.

In a similar experiment $998 \mathrm{Ni}$ wire was exposed to a flowing mixture of carbon monoxide and helium at atmospheric pressure in an attempt to follow the progress of carburization. The gas mixture was one to one by volume; the flow rate was $6 \times 10^{-6} \mathrm{~m}^{3} / \mathrm{s}\left(0.76 \mathrm{ft}^{3} / \mathrm{h}\right)$; and the experiment was carried out at a temperature of $1173 \mathrm{~K}$. The electrical resistance of the specimen increased rapidly for the first $3.6 \mathrm{ks}(1 \mathrm{~h})$ of the run, then approached a constant value. The measured resistance became essentially constant by $\sim 7.2 \mathrm{ks}(2 \mathrm{~h})$.

Metallographic examination of the specimen revealed extensive precipitation in the grain boundaries near the surface of the specimen (within about $0.02 \mathrm{~mm}$ of the surface). This precipitate is most. likely graphite, since $\mathrm{Ni}_{3} \mathrm{C}$ is believed to be unstable under the prevailing conditions. Attempts to correlate the resistance time data with a logarithmic function derived from a simplified diffusion analysis or several power functions were unsuccessful.
It appears that the technique is not useful in a situation of this complexity without considerable additional data. A quantitative analysis of the results of this experiment would require a detailed diffusion analysis, data on the electrical resistivity of nickel as a function of carbon content, and a knowledge of the kinetics of precipitation and solution of graphite in nickel.

In a third experiment a specimen of c1095 steel was exposed to a flowing mixture of air and helium at atmospheric pressure in an attempt to follow the progress of surface oxidation plus any internal changes that might occur. The gas mixture was one to one by volume and the experiment was carried out at a temperature of $983 \mathrm{~K}$.

The electrical resistance was observed to increase slowly throughout the experiment. The increase was approximately linear with time. The total observed resistance increase was $1.02 \%$. The resistivity of the specimen decreased 2.018. These observations indicate that in addition to an increase in resistance of the specimen due to surface oxidation and consequent geometrical changes there was a decrease in resistivity due to some other process or processes occurring simultaneously. The electrical resistance of the specimen exposed to pure helium was observed to remain constant to within the sensitivity of the measurements.

Metallographic examination of the specimens revealed no differences in microstructure to which the decrease in resistivity could be attributed. However, very accurate diameter measurements on specimens oxidized for increasing periods of time could be used for an independent determination of the kinetics of surface oxidation. This information would then allow the kinetics of the resistivity decrease to be determined from the original resistance versus time data. 
It appears that the use of electrical resistance measurements to determine the kinetics of gas-metal reactions without considerable supplementary data is limited to cases in which only surface oxidation occurs (producing excellent results), and to cases in which surface oxidation plus internal changes throughout the base material occur simultaneously.

\section{TASK 4, STRUCTURAL INVESTIGATION}

A. Constitutive Relations of Plain and Reinforced Concrete (E. G. Endebrock and J.B. Paynel

A computer code for the plain and reinforced concrete constitutive relations of Ref. 30 has been cbtained and made operational on LASL computers. This code incorporates a number of the most recent advances in the theoretical and experimental behavior of plain and reinforced concrete. Featured in the code are:

1. Plain or reinforced concrete behavior.

2. All multiaxial stress combinations in compression and tension.

3. Effects of differing amounts and directions of the reinforcing steel.

4. Orthotropic behavior after cracking in tension.

5. crack initiation and propagation.

6. Bond-slip action between concrete and reinforcing steel under tensile stresses.

7. Rebonding effect whenever unloading and reloading occur

8. Dowel action effects.

9. Unloading and reloading capability.

This code was developed for use in general purpose finite elcment stress analysis programs. since nonlinearities are inherent in plain and reinforced concrete behavior, an important feature of the code is the incremental solution of nonlinear equations. The code is limited to small deformations, stable inelastic material behavior (i.e. the stress-strain curve must have a positive tangent modulus), and it does not include creep and temperature effects. Even so, this code appears to be the most advanced one available for representing the complex behavior of reinforced concrete.

\section{B. Code Development for the Analysis of} PCRV's

As has been reported previously the general purpose finite element code NONSAP ${ }^{31}$ has been selected as a basis for the development of a LASL computer code for use in the analysis of PCRV's. Important features of NONSAP are:

1. Static and dynamic analysis capability.

2. Three-dimensional isoparametric finite elements.

3. Incremental solution with time as the dependent variable.

4. Nonlinear elastic and plastic material behavior.

5. Load input as a function of time. These features permit modification to include creep effects, tendon relaxation, and a load-history analysis.

Our present version of NONSAP is restricted by the lengthy input information required for execution of realistic problems, by limitation of output information (e.g. stresses) to the global rectangular coordinate system, by lack of a pressure loading input capability, and by lack of a thermal capability. Addition of a mesh generator and suitable transformation matrices will eliminate the first three restrictions, and these modifications to NONSAP are now underway. Addition of some sort of thermal analysis capability and programing to maximize the number of nodes and elements available for solving threedimensional problems on LASL's computers are two efforts which we will soon undertake.

The code for the plain and reinforced concrete constitutive relations discussed in Sec. A has been incorporated into NONSAP. 
C. Analytical Mocel Development for Core Seismic Response (J.G. Bennet, R. C. Dove, K. H. Duerre, and J. L. Merson)

1. Two-dimensional Core Seismic Analytical Model

The two-dimensional core seismic analytical model shown in Fig. 13, has been extended to include the effects of a dowel pin on the upper face of cach block and a matching lower slot on the bottom of each block. The bottom row is also pinned to the lower boundary by an Identical pin-slot arrangement. A free body diagram representaticn of the basic elen ment that is currently in the two-dimensiunal model is shown in Fig. 14. The model has the capability of allnwing for a difierent vertical contact stiffness, horizontal contact stiffness, pin ztiffness, and slot stiffness.

Future applications of this model $w i l l$ be to study the influence of the pins in terms of the pin clearance to contact gap clearance razios, pin stiffness and the other parameters in the light of studies conducted on the one-dimensional model that have been completed to date.

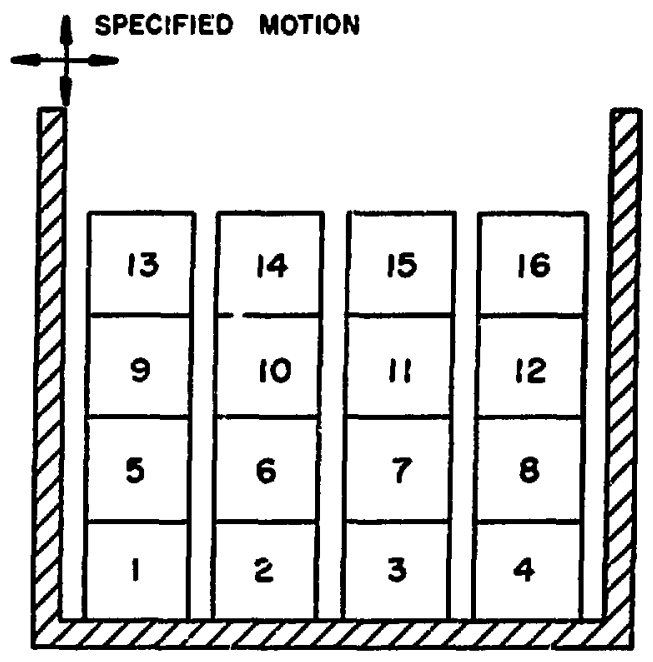

Fig. 13. Two-dimensional model.

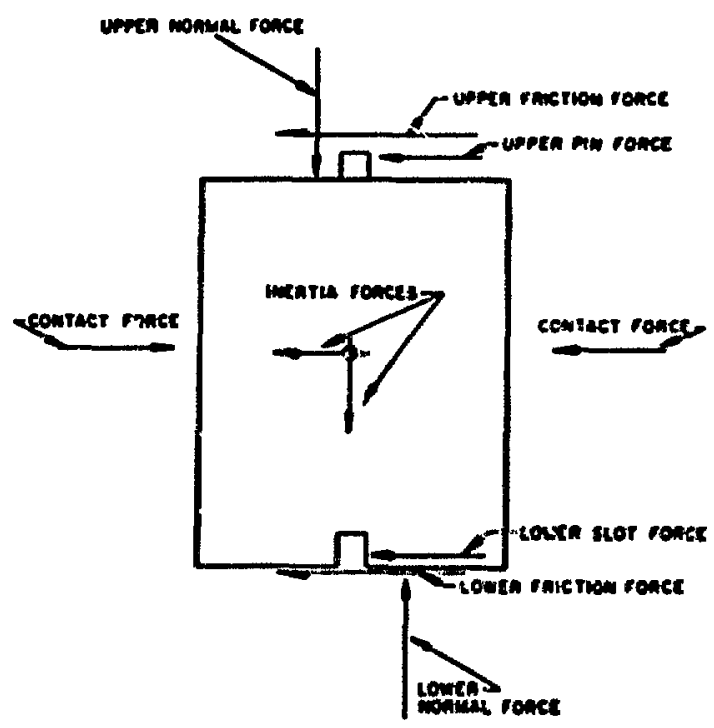

Fig. 14. Frce body digaran 111ustrating all effects currently in the twi-dimensional model.

Preliminary indlcations are that tho pins will serve to limit the motion of the biocks considarably, but this will probably produce rather large pin shear forces.

A computer praducse movic that illustrates the pin connacted model under horizontal siagle froquency excitation has been completed and was shown at tho first annual HTGR structural Review held at Germantown, Maryland, on Junr: 12, 1975.

2. Core Component Stiffnesg Studies

As has been previously reported. studies have been undertaken to provide estimates of the stiffness for various core components. This input is needed for the core analytical model (Fig. 13).

The HTGR fuel block, locating pin. and locating pin slot are shown in Fig. 15. Two different finite element models (Figs. 16 and 17$)$ were made of those components. The material (nuclear graphite) in all cases was assumed to be linear elastic and isotropic with values of Young's Modulus and Poisson's ratio of $13.8 \times 10^{9}$ $\mathrm{N} / \mathrm{m}^{2}\left(2 \times 10^{6} \mathrm{psi}\right)$ and 0.1 respectively. 


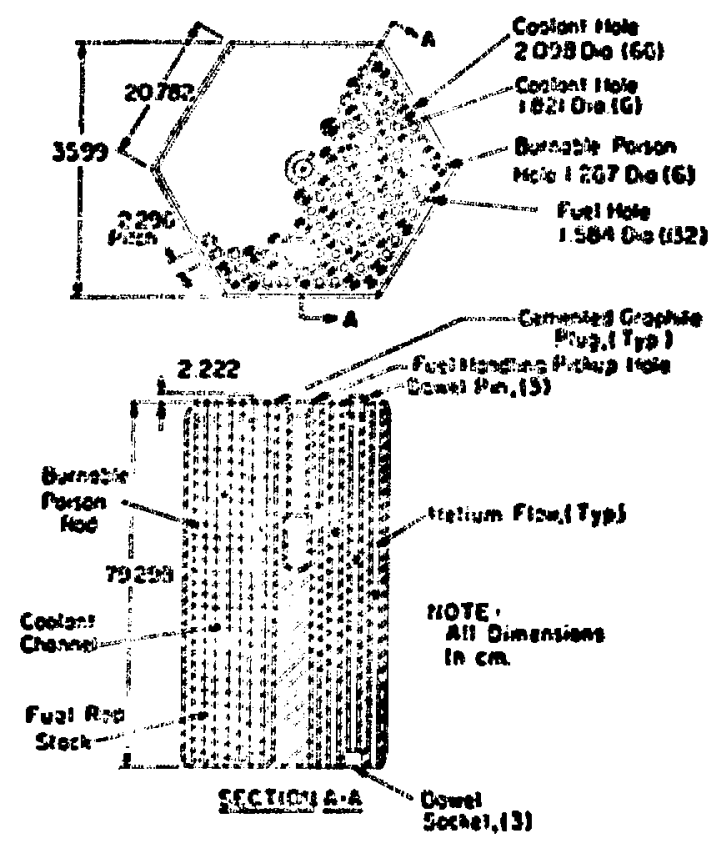

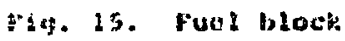

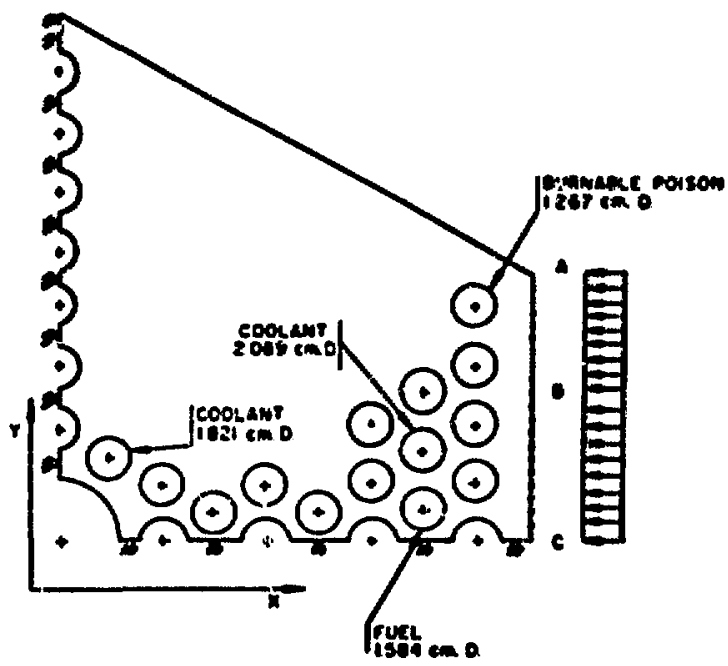

Fig. 16. One model for fuel block stiffness calculation.

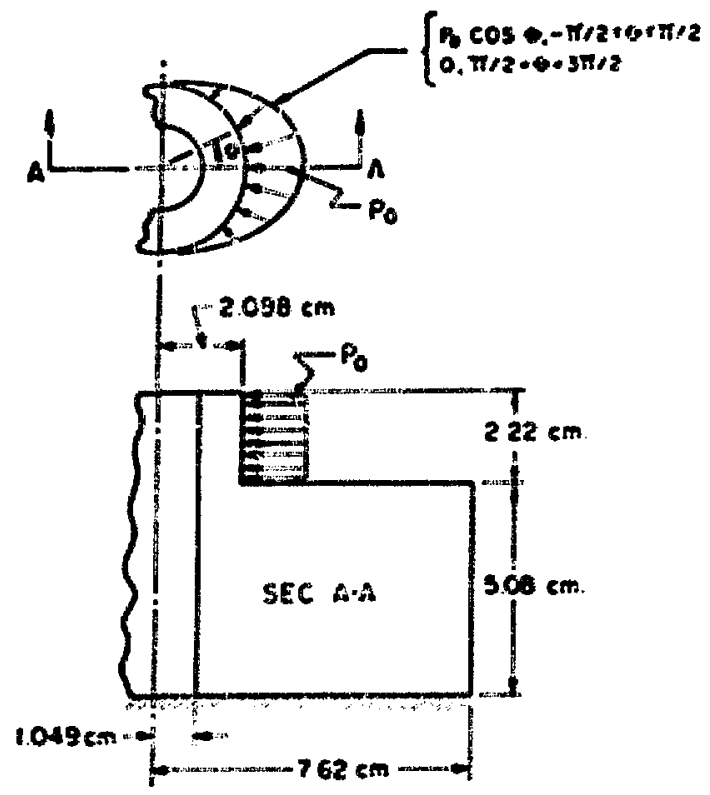

Pig. 17. Anistmeric motod tor dowel pin ceifrness caldutacion.

tressurot were spiljed to a race of the componont and tho reoulting nodal disphacementes wero aseumed to behave similarly to an array of parallol epringu. Tho total seiffnes of the component is chen juat the sum of nodal seiffnesans i.e..:

$$
k_{T}=\ddot{n}_{1}^{n} H_{i}
$$

whore:

$$
\begin{aligned}
& n \text { - the number of nodes along the } \\
& \text { prossure tace. } \\
& n_{i}=\text { cqutvalent epring stiffness for } \\
& \text { the ith node. }
\end{aligned}
$$

The cquivalent spring stiffness is defined as the slope of the force-disjacement curve. $k-F / d$, for a given node. Values wero determined for each $k_{i}$ at several lcadings in the linear clastic range for the finite elenent models of the components in Figs. 16 and 17. 
3. Fucl Block llorizontal and Verticle stiffness

A special program was written to excate a mosh for the plane quarter seczion represented in Fig. 16 for the hexafonal fuel block. Five-hundred eightytwo cioments were constructed from 679 nodiss. The computer program SAP-IV ${ }^{32}$ was isted with the plane strain uption to obAin the node detlections of the fucl ilock rodel for given applied pressures. Wigure is shows typical force-deflection curtes from which nodal stiffnesses are directy obtained. The total stiffness for the plane model was determined to be $72.9 \times 10^{6} \mathrm{X} / \mathrm{t}$ : from Eq. (45). Taking account of the length of the block then gave a cotal block horizontal stiffness of $\mathrm{y}_{\mathrm{H}}=22.8 \times 10^{8} \mathrm{x} / \mathrm{m}$.

The vertical stiffness for the graphite block was determined from $k_{y}=$ EN/t whero $E$ is Young's Modulus. A is the cross sectional area lexcluding the voidsl, and: is the block length. This is the axial stiffness of a finite length bar under uniform axial loading. For the given block parameters, $k_{V}=10.5 \times 10^{8}$ $x / m$.

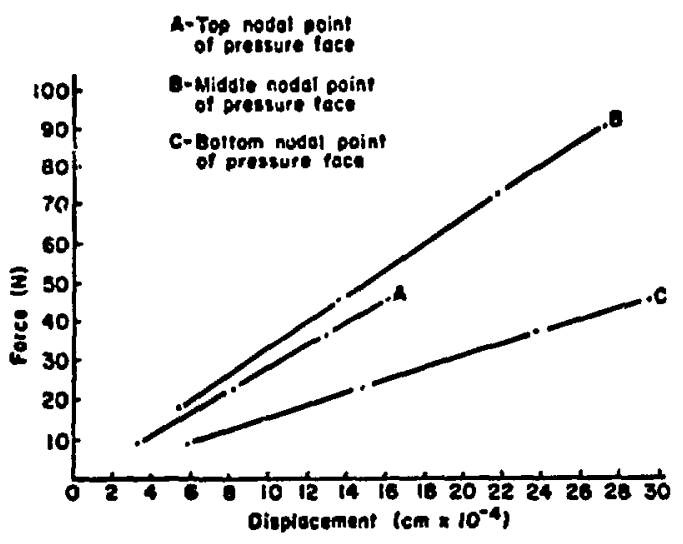

Fig. 18. Typical nodal force-displacement curve from fuel block stiffness močlel.
4. Fuel Block Locating Pin Stiffness

DRusTIC ${ }^{33}$ computer code was used to analyze the locating pin under static loadings.

This version of SABOR is designed to handle axisymmetric geometries under non-axisymmetric loads based on Fourier representations of the load and has been modified at LASL to handle a continuum element. A short preprocessor was written to prepare the input to SABOR based on an axisymmetric model of the hollow pin shown in Fig. 17. The half-cosine static load in Fig. 19 was built up from the five Fourier components illustrated in Fig. 20 . since the pressure distribution is an even function, only the cosine terms and constant of the Fourier series representation are non-zero. The Fourier coefficients for the first five non-zero harmonics are given in Table $x$. Results of these calculations are given in Fig. 21 . The element stiffness based on axial height of the pin is seen to be a smoothly decreasing function.

The total effective lateral stiffness is taken to be $3 \times L K_{i}$ for one pin:

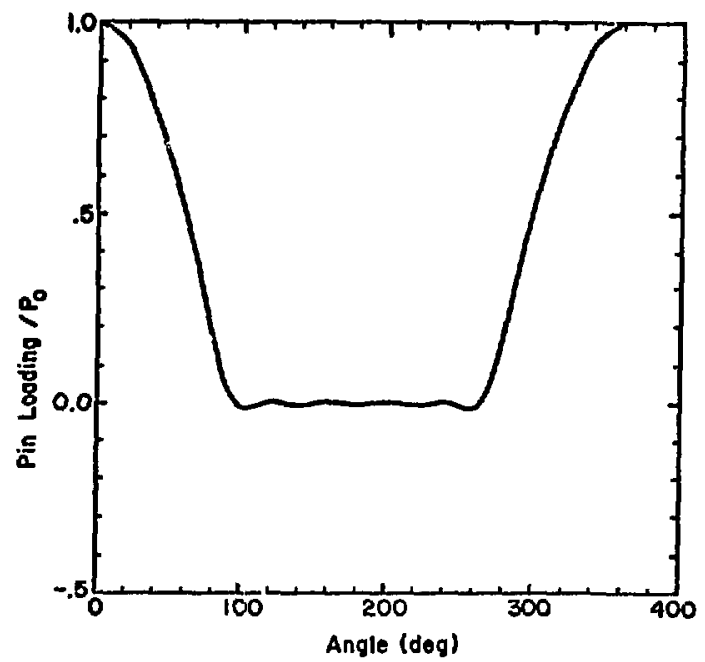

Fig. 19. Sum of Fourier components for pin loading. 


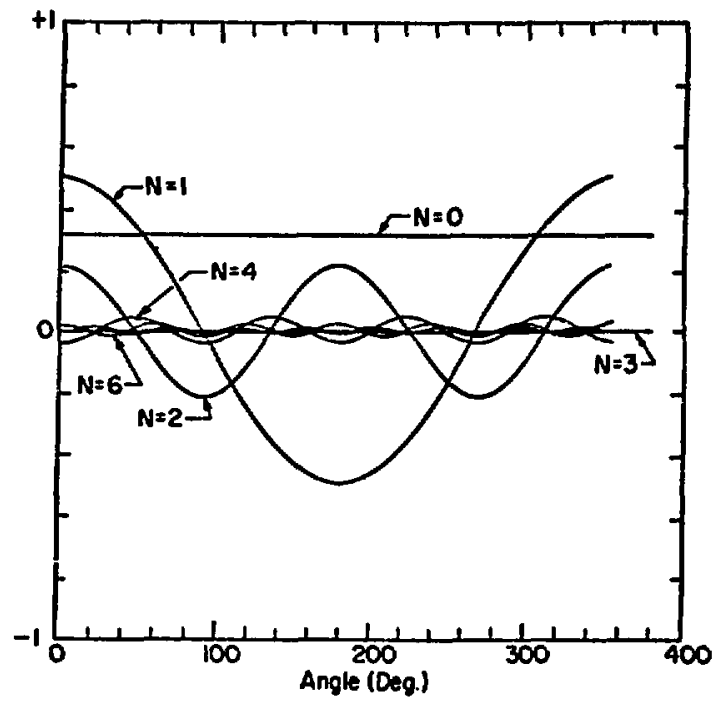

Fig. 20. Fourier components used to simulate pin loading.

TABLE $\mathbf{X}$

NON 2ERO FOURIER COEFFICIENTS FOR LOADING OF LOCATING PIN AND SLOT

$\begin{array}{cc}\text { Harmonic } & \text { Fourier coefficient } \\ 0 & +0.3183 \\ 1 & +0.5 \\ 2 & +0.2122 \\ 4 & -0.04244 \\ 6 & +0.01818\end{array}$

$$
K_{p}=10.84 \times 10^{8} \mathrm{~N} / \mathrm{m} \text {. }
$$

Based only on shear deformation of the circular pin, a lower bound estimate of $4.7 \times 10^{8} \mathrm{~N} / \mathrm{m}$ was obtained for this value.

5. Fuel Block Locating Pin slot Stiffness

A similar type of finite element model is being prepaxed for estimating the matching lower slct stiffress for the fuel block, but results are not yet available.

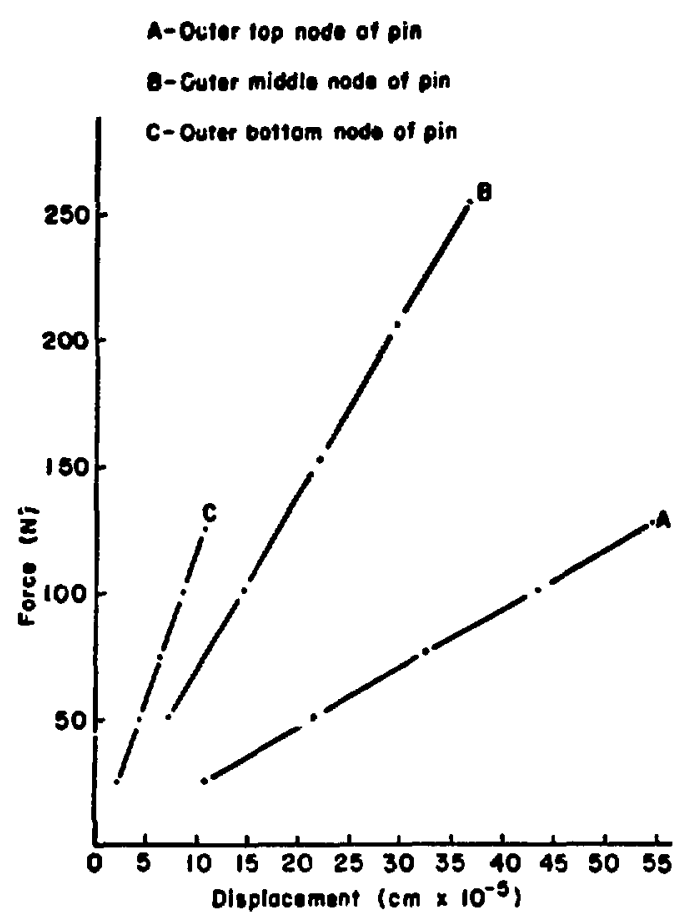

Fig. 21. Typical noda! force-displacement curves from pin stiffness model.

6. Summary of Core Component Stiffness Estimates to Date Estimates of $64 \times 10^{8} \mathrm{~N} / \mathrm{m}$ and $19.5 \times 10^{8} \mathrm{~N} / \mathrm{m}$ for solid fuel block lateral and vertical stiffness are reduced, due to fuel and coolant holes to the values $22.8 \times 10^{8} \mathrm{~N} / \mathrm{m}$ and $10.5 \times 10^{8} \mathrm{~N} / \mathrm{m}$ respectively, as obtained from finite element calculations. The lateral stiffness of the locating pin was found to be $10.8 \times 10^{8} \mathrm{~N} / \mathrm{m}$. These are the values that are currently being used as input to the core seismic analytical models.

7. Earthquake Excitation of the Onedimensional Core Seismic Analytical Model

During the present quarter significant modifications have been made in the data output from the core block model programs. The purposes of these modifications have been to display block accelerations and contact forces versus time. 
These new output forms have been used to reprcaent the syeten responst to carthquake oxcitation and in the extension of the seaiing law studias which are dincussud in tho following section.

A program (SIMEAR) for gancrat-

ing sinulated acceloration, velocity, and displacement versua time earthquake historice was deacribed in the previous quarterly report. During the present quarter, motion versus time histories produced by stakar have beon used to drive the one-dimensional, analytical, fourblock model (see fig. 22). Bccause of previous teating of this model cver a wide frequency range the responso expected to be produced by carthruake input was anticipated. However, when the model was driven by the simulated earthquake, the response was considered incredible. As a result, the model program was rechecked by driving it with a mixed frequency consisting of five sinusoidal components $(0.5,1,5,10$, and $25 \mathrm{hz}$ ) and the simuiated earthquake motionhistories were investigated for consistency. The model was found to respond as expected to the analytically defined mixed frequency driving function and so attention was focused on the simulated earthquake signal. It was found that the three time histories (acceleration, velocity and displacement) furnished from the SIMEAR program are independent (i.e.,

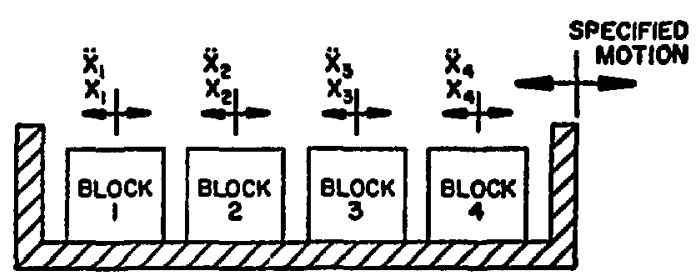

Fig. 22. One-dimensional core seismic model. velocities and displacemonts are not tirst and second integrals of the acceleration-timo history). This is important whon using the simuloted carthquake to drive tho model becsuse all throe motioncime signula lacceleration. velocity and disflucemont are used simultancously in model conputations. As a result of this finding. Simbar is being used to produco only the sppropriske acecderation-tink hiatory. which is thon corrected as necoseary to produce a velociey time history that begins and ends at zero velocity; the velocity time and the displacement-iime histories are then produced by integration of the accoleration-time history. Fiqures 23, 24, and 25 show a SIMEAR generated and corrected acceleration-time history and the assoriated velocity-time and displacement-time histories. Figure 26 compares the response spectra for the acceleration-time history shown in Fig. 23 to the NRC response spectra. Motion-time histories generated in this manner are now being used successfully to drive the core block models. Figure 27 shows the

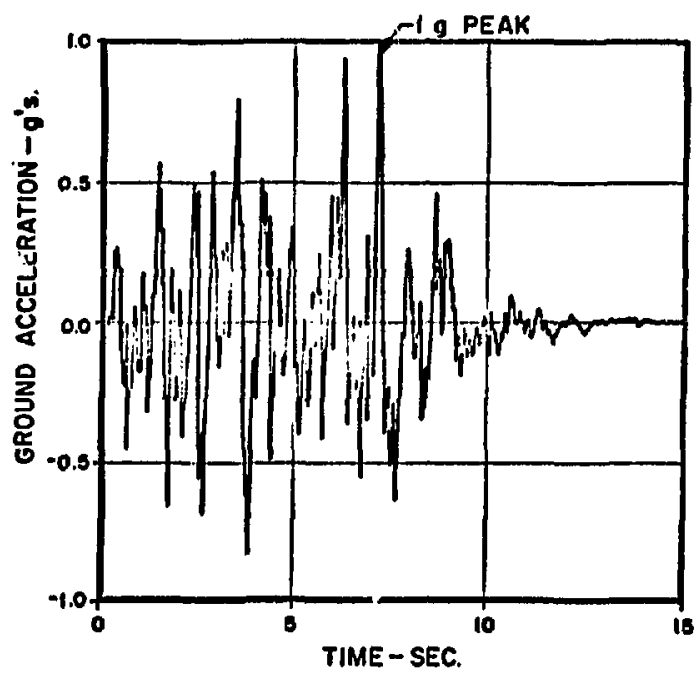

Fig. 23. Simulated earthquake-acceleration. 


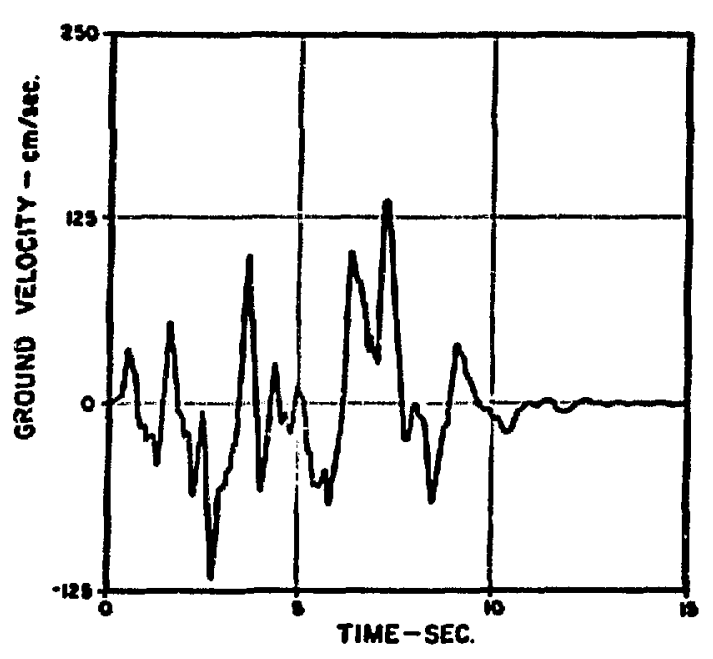

Fig. 24. Velocity-time history from integration of Fig. 23 .

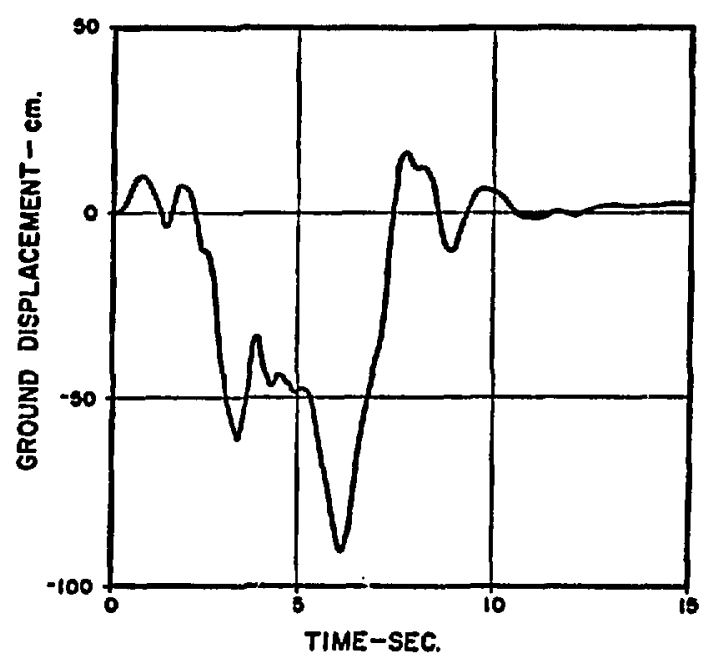

Fig. 25. Displacement-time history from integration of Fig. 24.

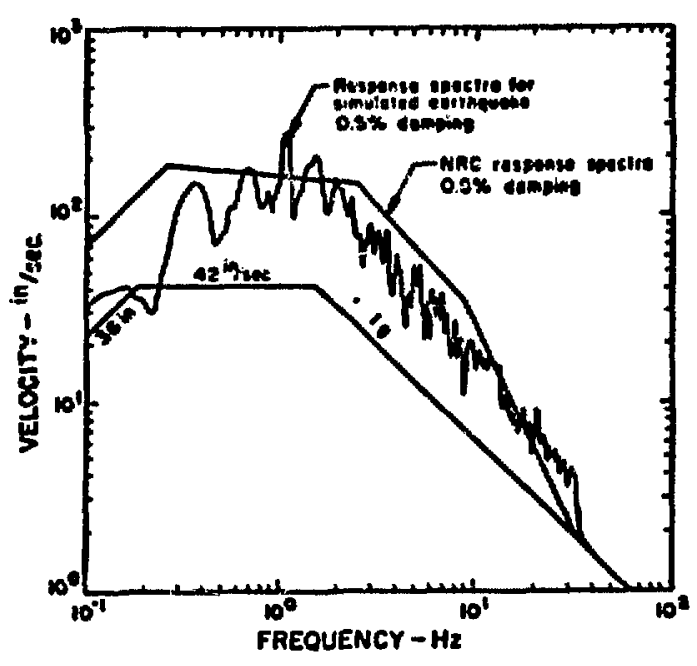

Fig. 26. Response spectra for the acceleration-time signal shown in Fig. 23.

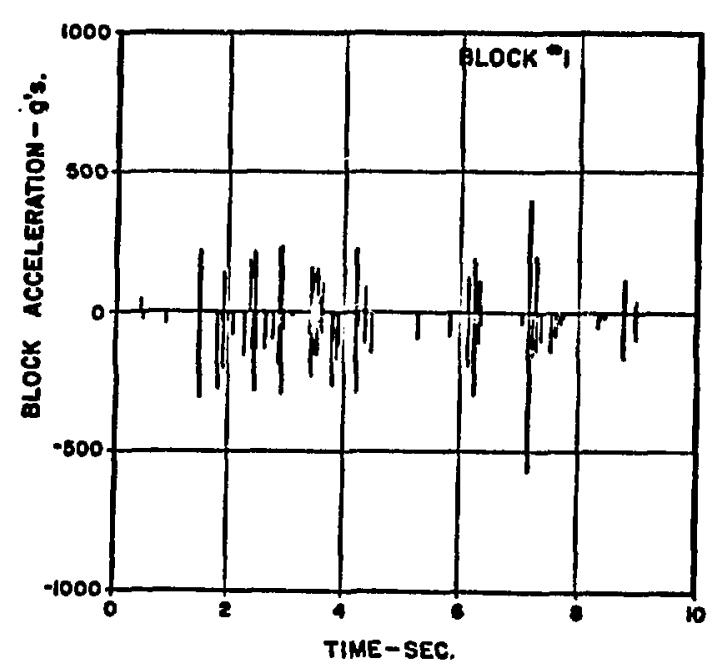

Fig. 27. Acceleration response of four block model to the earthquake shown in Fig. 23. 
acceleration response of block 11 (see Fig. 22J, during the first $10 \mathrm{~s}$, to the simulated earthquake shown in Fig. 23. Eigure 28 shows the contact forces imposed by the boundary on the left side of black 1. as a result of this earthguake excitation. This information is, of course, available for all blocks in the syatem.

D. Physical Model Test Program for Core Seismic Response (R. C. Dove.J.G. Bennett. J. L. Merson) In the previous quarterly progreas report ${ }^{28}$ and in Ref. 35 we discussed the scaling laws used to guide the devolopment of scale models of the IITGR core and the use of the simple four-klock analytical model to check these scaling laws. During the present quarter these sculing law studies have been extended. As before. the four-block analytical model lsee Fig. 22) was used in making the computations: however, comparisons between the several prototype and model syatems are made on the basis of accelerations and forces rather than displacements.

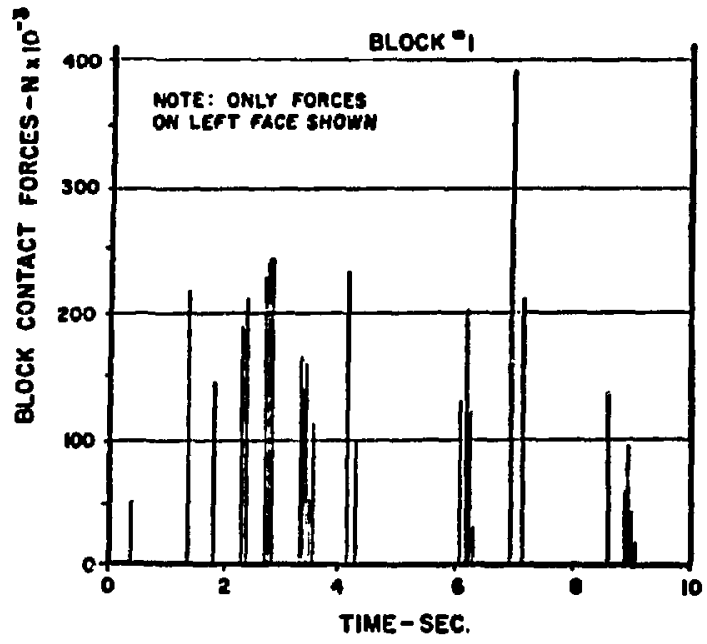

Fig. 28. Contact forces on four-block model.
Four different systems, having the parameter values shown in Table $k I$ were run. All three of the "models" ate designed with a length scale $\left(N_{d}\right)$ of four, bur. differ greatly in other ways. The "true model" is designed so as to satiafy all of the scale relationships dictated by the laws of similitude. These are:

$$
\begin{aligned}
& \text { Time scale: } \quad N_{t}=\sqrt{H_{d}} \\
& \text { Acceleration scale: } N_{\dot{X}}=1
\end{aligned}
$$

since the gravitational constant is assumed to be the same in each system test environment.

$$
\text { Force scale: } N_{Q}=\frac{E_{D}}{E_{m}} \cdot N_{d}^{2}
$$

that is, the force scale is the ratio of prototype modulus $\left(E_{p}\right)$ to model modulus $\left(E_{m}\right.$ i times the length scale squared $\left(N_{d}\right)^{2}$.

The above three imply that the ratio of model modulus $\left(E_{m}\right)$ to model weight $\left(w_{\text {in }}\right)$ is equal to the ratio of prototype modulus $\left(E_{p}\right)$ to prototype weight $\left(w_{p}\right)$ times tho length scale squared $\left(N_{d}\right)^{2}$.

Figure 29 shows the acceleration response of block 1 in the prototype system to a $1 \mathrm{~g}, 5 \mathrm{H}_{2}$ excitation. Figure 30 shows the acceleration response of block 1 in the true model system to a $=1 \mathrm{~g}, 10 \mathrm{H}_{2}$ excitation (since model times are scaled by dividing by $2, i . e ., \sqrt{N_{d}}$, frequencies are doubled). Close inspection of these two acceleration time histories shows that when properly scaled $\left(N_{\ddot{x}}=1\right.$, $\mathrm{N}_{t}=2$ ) the true model is indeed predicting the prototype acceleration-time history. The prediction is most accurate during early times and as time progresses accumulating computational errors produce some divergence of results.

The next system considered is referred to in Table XI as a "distorted model". This particular model is distorted in the following way: having picked a length scale $\left(N_{d}\right)$ arbitrarily, we will then use 
TABLE XI

"PROTOTYPE" AND "MODEL" STUDY PARAMETERS

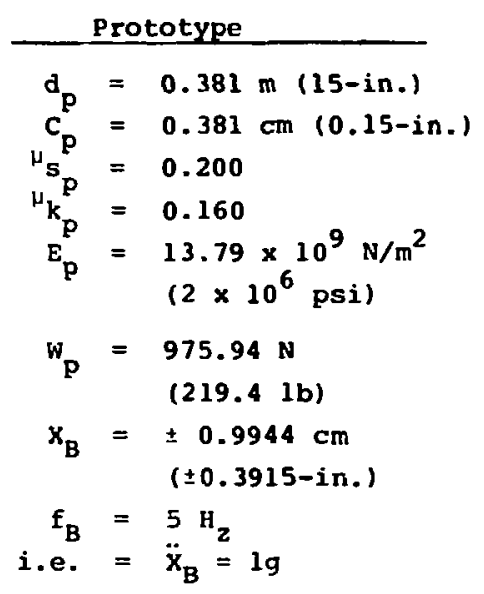

\section{True Model}

$0.381 / 4 \mathrm{~m}$

0.200

0.160

$\left(\frac{E_{m}}{W_{m}}=\frac{E_{p}}{W_{p}} \times 4^{2}\right)$

\section{Scales}

Length - $\mathbf{N}_{\mathrm{d}}$

Time - $\mathbf{N}_{\mathbf{T}}$

Acceleration - $\mathrm{N}_{\mathbf{x}}$

Force - $\mathrm{N}_{\mathrm{Q}}$

Stress - $\mathbf{N}_{\sigma}$
$0.381 / 4 \mathrm{~cm}$

$\pm 0.9944 / 4 \mathrm{~cm}$

$5 \times \sqrt{4}=10 \mathrm{H}_{2}$

$1 g$

\section{Distorted Model}

\section{$0.381 / 4 \mathrm{~m}$}

$0.381 / 4 \mathrm{~cm}$

0.200

0.160

$13.97 \times 10^{9} \mathrm{~N} / \mathrm{m}^{2}$

$975.94 / 4^{3} \mathrm{~N}$

$\pm 0.9944 / 4 \mathrm{~cm}$

$5 \times 4=20 \mathrm{H}$

$4 \mathrm{~g}$

4
$1 / 4$
$4^{2}$

$E_{p} / E_{m} \times 4^{2}$
$N_{Q} \doteqdot 4^{2}$
Friction Corrected Distorted Model

$0.381 / 4 \mathrm{~m}$

$0.381 / 4 \mathrm{~m}$

$0.2 \times 4$

$0.16 \times 4$

$13.97 \times 10^{9} \mathrm{~N} / \mathrm{m}^{2}$

$975.94 / 4^{3} \mathrm{~N}$

$.0 .9944 / 4 \mathrm{cn}$

$5 \times 4=20 \mathrm{H}_{2}$

49

4
4
$1 / 4$
$4^{2}$
1




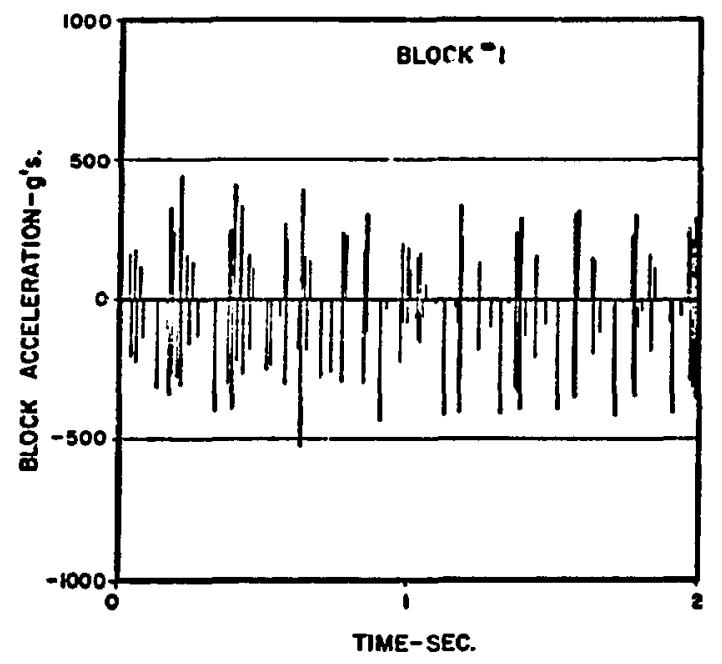

Fig. 29. Acceleration response of prototype system to $1 \mathrm{~g}, 5 \mathrm{H}_{\mathrm{z}}$, excitation

the same material for the model as was used for the prototype. As a result, the material modulus of the model equals the material modulus of the prototype $\left(E_{m}=E_{p}\right.$ ) and since, for equal material density. weight varies as the cube of the dimension, $W_{m}=W_{p} / N_{d}{ }^{3}$. Hence, $E_{m} / W_{m}=E_{p} / W_{p}$ $x \mathrm{~N}_{\mathrm{d}}{ }^{3}$, instead of the required $\mathrm{E}_{\mathrm{m}} / \mathrm{w}_{\mathrm{m}}=$ $E_{p} / W_{p} \times N_{d}^{2}$. The result is a model that is too light for its stiffness if it is tested in the same gravitational field as the prototype. These choices also result in a time scale equal to the length scale $\left(N_{t}=N_{d}\right)$ and an acceleration scale equal to the reciprocal of the length scale $\left(\mathrm{N}_{\ddot{\mathrm{x}}}=1 / \mathrm{N}_{\mathrm{d}}\right)$. Figure 31 shows the acceleration response of block $\# 1$ in this distorted model system to $a \pm 4 \mathrm{~g}, 20 \mathrm{~Hz}$ (since model times are scaled by dividing by 4 , frequencies are multiplied by 4 ). Comparison of this record to the prototype system acceleration response (Fig. 29) indicates how this system response differs from that of the prototype. In general we note that in the distorted model the impacts are more uniformly spaced in time; however, the similarities between the two systems are more

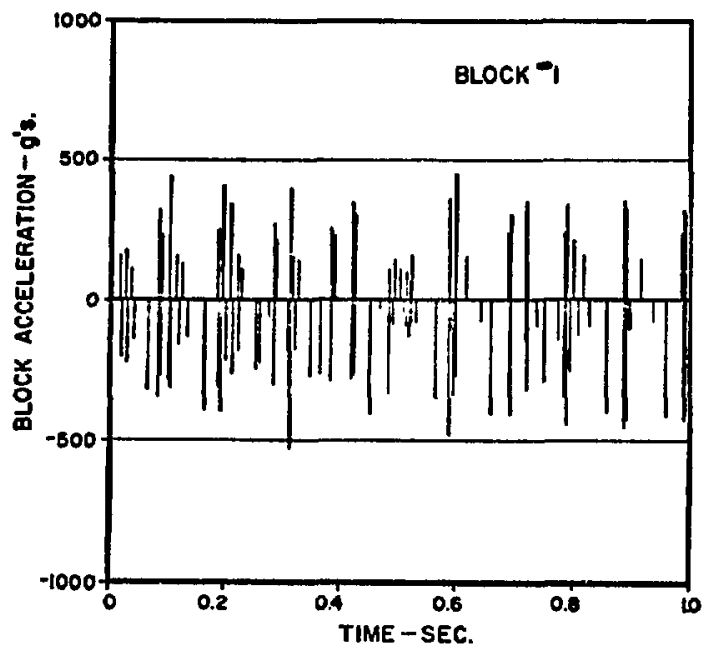

Fig. 30. Acceleration response of true model to $\mathrm{lg}, 10 \mathrm{H}_{z}$, excitation.

surprising than the differences. In comparing Figs. 29 and 3.2 we note that although the peak accelerations occur at different times the distorted model predicts (when properly scaled) the peak values with reasonable success. For the

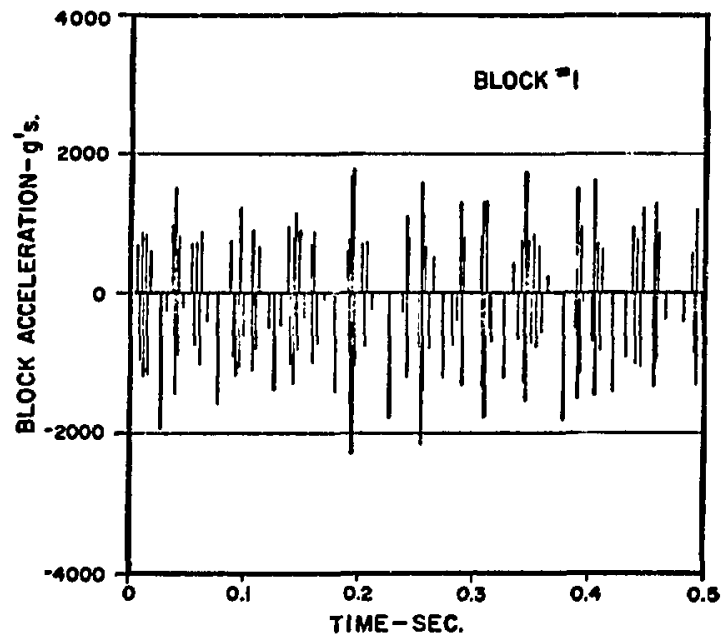

Fig. 31. Acceleration response of distorted model to $4 \mathrm{~g}, 20 \mathrm{H}_{\mathrm{z}}$ excitation. 
prototype system:

Positive peak acc. $=437.5 \mathrm{~g}$ at $0.204 \mathrm{~s}$ Negative peak acc. $=-534.8 \mathrm{~g}$ at $0.623 \mathrm{~s}$. For the distorted model system:

positive peak acc. $=1751 \mathrm{~g}$ at $0.196 \mathrm{~s}$ which scales to $437.8 \mathrm{~g}$ at $0.782 \mathrm{~s}$.

Negaitve peak acc. $=-2310 \mathrm{~g}$ at $0.195 \mathrm{~s}$ which scales to $-577.5 \mathrm{~g}$ at $0.779 \mathrm{~s}$.

Furthermore the distorted model predicts that block \#l will receive 149 impacts in a scaled time of $2 \mathrm{~s}$. The prototype test shows block \#1 actually received $147 \mathrm{im}-$ pacts. However, in Ref. 34 it was shown that this distorted model responds with a completely different displacement time history than does the prototype system.

The fourth system considered is referred to as a "friction correction distorted model" in Table XI. This system is the result of the observation that since the distorted model is too light, and hence frictional forces are too small when tested in a $1 \mathrm{~g}$ field, a correction should be possible and, hence, coefficients of friction ( $\mu_{s}$ and $\mu_{k}$ ) have been increased by a factor of four. Figure 32 shows the acceleration response of block \#1 in this "corrected" system to $a \pm 4 \mathrm{~g}$, $20 \mathrm{H}_{2}$ excitation. Comparison of Fig. 32 to Fig. 29 shows that this corrected model predicts the prototype acceleration response exactly (model results must, of course, be scaled i.e.. $\ddot{x}_{p}=\ddot{x}_{m} / 4$, $\left.t_{p}=4 \times t_{m}\right)$. This type of correction also allows this model to accurately predict prototype Aisplacement-time histories. Whether this simple type of correction would be physically possible or whether it would be completely effective in a threedimensional model subjected to three orthogonal motion inputs is still unknown.

Alternately, the model might be tested in an artificial, higher "g" field.

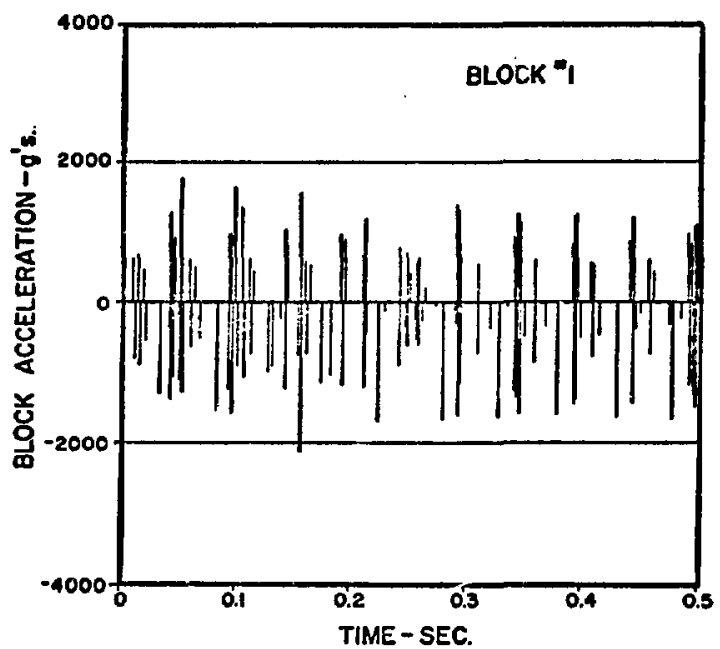

Fig. 32. Acceleration response of friction corrected model to $4 \mathrm{c}$, $20 \mathrm{~Hz}$, excication.

The results of a parameter study, which was made using the simple four-block system (see Fig. 22), were discussed in the previous quarterly report. 28 During the present quarter an attempt has been made to relate parameter studies of this type to the interpretation of physical model study results. The procedure for establishing a "prediction factor" which may be used with a distorted model is described in Part II of Ref. 36.

We assume that the functional equation which was developed in the previous quarterly report $^{28}$ can be rewritten as follows:

Equation (25) from Ref. 28 is:

$\frac{\ddot{x}}{\sigma}=\psi\left(\frac{x_{B}}{d}, \frac{c}{d}, \frac{E d^{2}}{w}, \mu_{k}, \frac{\mu_{s}}{\mu_{k}}, \frac{E}{D}, \frac{x_{B}}{g t^{2}}\right)$.

By assuiting the function is a product form we will rewrite $\mathrm{Eq}$. (46) as

$$
\begin{aligned}
\frac{\ddot{x}}{g}= & \psi^{\cdot}\left(\frac{E d^{2}}{w}\right) \\
& x \psi^{\prime \prime}\left(\frac{x_{B}}{d}, \frac{c}{d}, \mu_{k}, \frac{\mu_{s}}{\mu_{k}}, \frac{E}{D^{\prime}}, \frac{x_{B}}{g t^{2}}\right) .
\end{aligned}
$$


With a model distorted by using the same material for model and prototype only the term $\mathrm{Ed}^{2} / \mathrm{W}$ need be distorted, so we write:

$$
\frac{\left(\frac{\ddot{z}}{g}\right)_{p}}{\left(\frac{\ddot{x}}{g}\right)_{m}}=\frac{\psi \cdot\left(\frac{E d^{2}}{w}\right)_{p}}{\psi \cdot\left(\frac{E d^{2}}{w}\right)_{m}}
$$

since the function $\psi "$ is identical for both model and prototype. The "prediction factor" "is defined as

$$
i=\frac{\nu^{\cdot}\left(\frac{E d^{2}}{W}\right) p}{v^{\prime}\left(\frac{E d^{2}}{w}\right) m} .
$$

Hence

$$
\left(\frac{\ddot{x}}{\mathrm{~g}}\right)_{\mathrm{p}}=9(\ddot{x})_{\mathrm{m}}
$$

In the previous quarterly report it was shown that the effect of the term $E d^{2} / W$ on block acceleration $\ddot{x}$ could be expressed as

$$
\ddot{x}=425\left(\frac{E d^{2}}{W} \times 10^{-6,}\right)^{0.5}
$$

(See Eq. 30 in Ref. 28). Thus $\psi^{\prime}$ is a square roit function and hence

$$
s=\sqrt{\left(\frac{E d^{2}}{N}\right)_{p}:\left(\frac{E d^{2}}{W}\right)} \mathrm{m} \text {. }
$$

To test this method of approach, $\theta$ was computed from the values of $E, d$, and $w$ assigned to the "prototype" and "distorted" models shown in Table XI. It can be easily shown that $\theta$ is equal to $\gamma^{-} N_{d}$ and hence equal to 2 . The "distorted model" was then tested just as if it had been a true model (i.e., $X_{B}=+0.9944 / 4 \mathrm{~cm}$, $f_{B}=10 H_{z}$ and the results are multiplied by the prediction factor, $\theta$, to predict prototype response. Figure 33 shows the acceleration response of block 1 in the distorted model system when driven just as

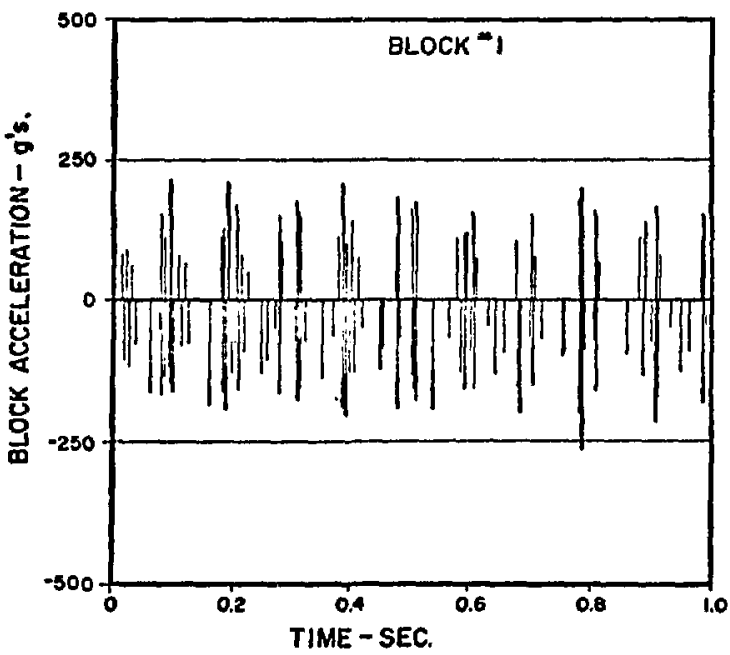

Fig. 33. Acceleration response of distorted model tested for prediction factor correction.

if it were a true model. Comparison of Fig. 33 with Fig. 29 indicated that when model accelerations are multiplied by a prediction factor of 2 the prototype acceleration is predicted for homologous times $\left(t_{p}=2 t_{m}\right)$.

During this quarter we have also investigated the possiblity of using "compensated distortion" as discussed in Ref. 36. That is, two or more $\pi$ terms may ke distorted (one or more deliberately in a controlled manner) so as to produce a total, or net, prediction factor, $\theta$, of unity. The "coefficient of friction correction of the distorted model" discussed previously is an example of this approach. Another possibility which suggests itself is to test the distorted model at an inpat level that will provide a prediction factor which is the reciprocal of the prediction factor associated with the distortion in term $\left(\mathrm{Ed}^{2} / \mathrm{W}\right)$. This is possible using the relationship between block acceleration response $(\ddot{x})$ and input acceleration $\left(\ddot{x}_{B}\right)$ determined in the parameter study of Ref. 27 [i.e., $\ddot{x}=670\left(\ddot{x}_{B}-\right.$ $\left.\mu_{s}\right)^{0.451} l$. This was done by exciting the 
"distorted model" system at $\ddot{\mathrm{x}}_{\mathrm{B}}=0.372 \mathrm{~g}$ and the resultant acceleration response of block \#1 is shown in Fig. 34. Comparison of Figs. 29 and 34 indicates that although there has been some success in predicting "peak" acceleration (in Fig. 34, $\ddot{x}_{\text {peak }}=-494 \mathrm{~g} ;$ in Fig. $\left.29, \ddot{x}_{\text {peak }}=-535 \mathrm{~g}\right)$, the time history and number of impacts are grossly distorted. clearly, this is not a suitable method.
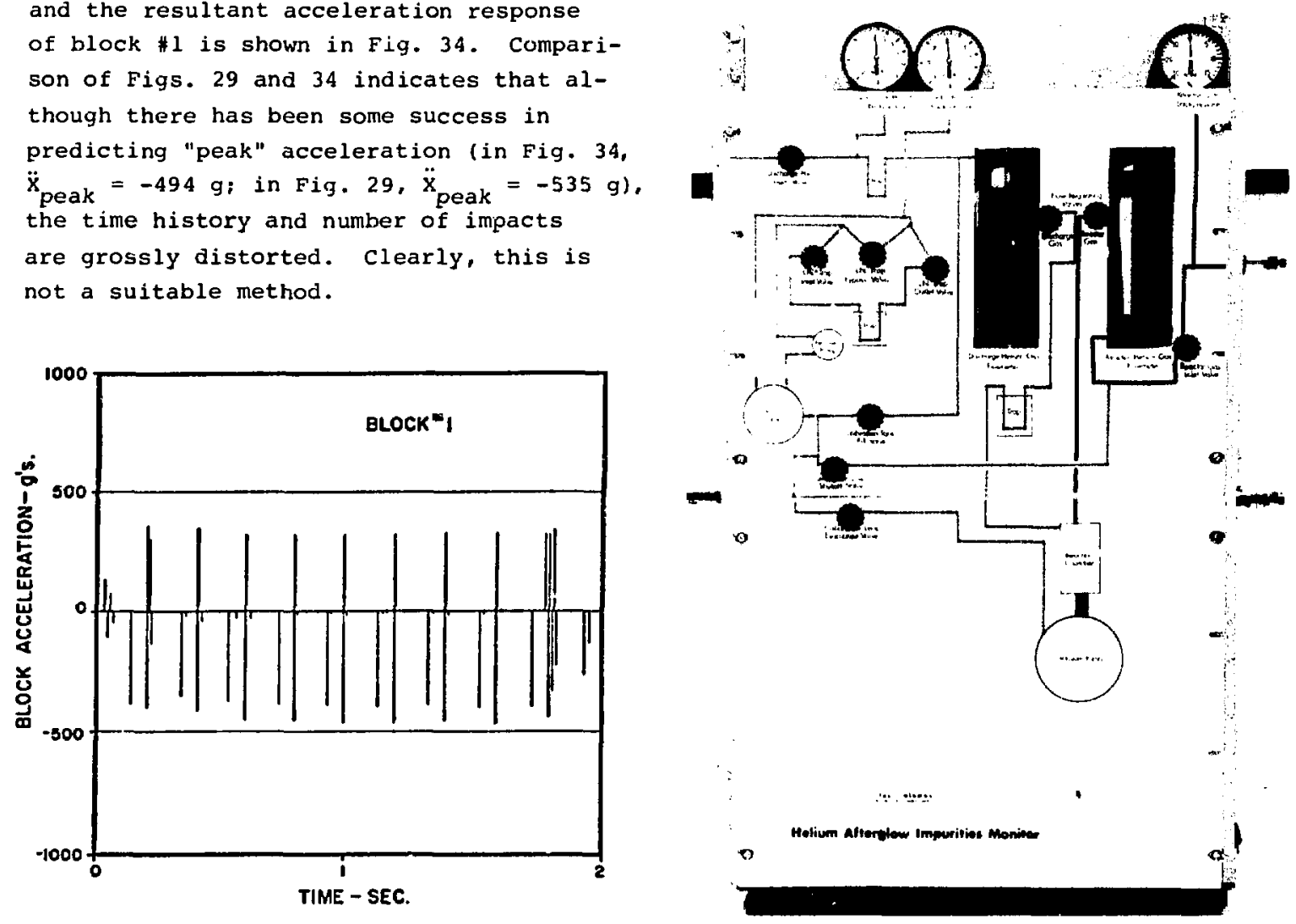

Fig. 34. Acceleration response of distorted model tested with compensating distortion.

\section{TASK 6, SAFETY INSTRUMENTATION AND} CONTROL SYSTEMS

A. Impurities Monitoring (E. J. Dowdy and G. W. Taylor)

The improved version of the LASL Helium Afterglow Impurities Monitor* was completed and is shown (exclusive of the optics and electronics packages) in three views in Figs. 35-38. All piping up to the reaction chamber is stainless steel tubing, $6.35 \mathrm{~mm}$ OD, $0.76 \mathrm{~mm}$ wall thickness, with either swagelok or hard solder

\footnotetext{
For a discussion of the prinsiple of operation and a block diagram of the device, refer to previo:ss quarterly progress reports: LA-5870-PR $(2 / 75)$ and $I A A-5975-P R$ $(6 / 75)$
}

Fig. 35. Front panel of the Helium Afterglow Impurities Monitor.

connections. All valves have brass bodies, stainless stems, teflon o-ring seals and Kel-F seats. Flows are regulatcd through glass tube rotameters with tantalum ball floats.

The monitor was transported to the Ft. St. Vrain plant and operated on line on May 28 and 29, 1975 for the purpose of preliminary analysis of impurities in the primary coolant. During this time, the reactor was at zero power with the helium circulators turning, the primary coolant cleanup system in operation, and 


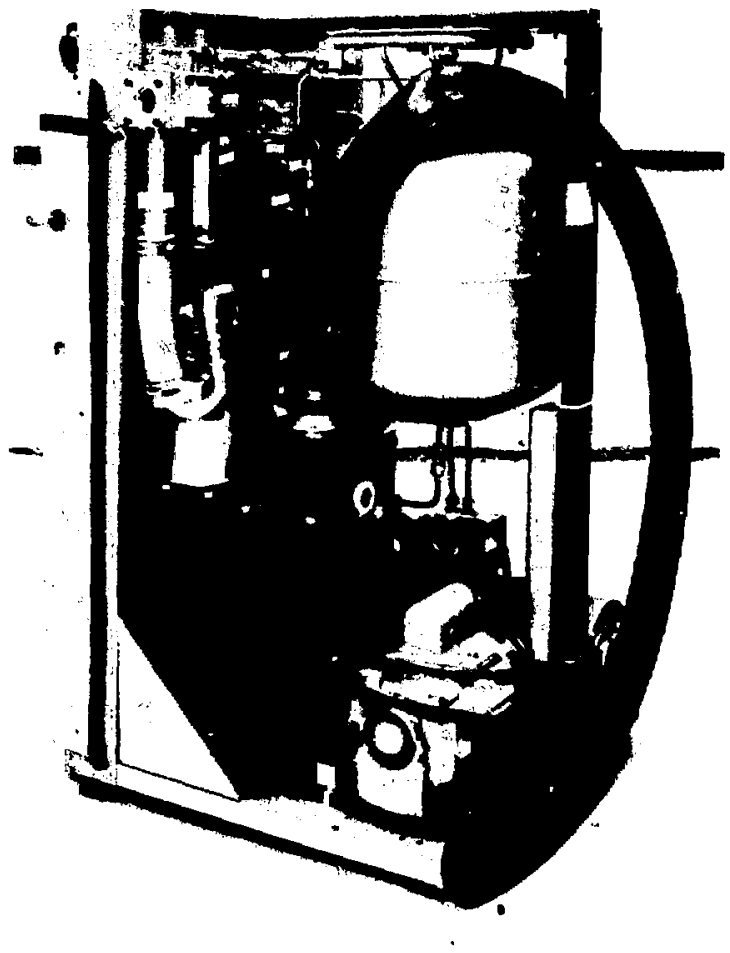

Fig. 36. Side view of the Helium Afterglow Impurities Monitor. The quartz glass helium plasma tube is visible above the brass-faced reaction chamber.

various other components being exercised. The analysis thus provided identification and quantification of the various impurities in the primary loop under cold conditions. These measurements were intended to demonstrate the suitability of the monitor for the entire range of impurities of interest.

The monitor was placed in the analytical instrument room. The primary coolant for analysis was obtained through the main sampling line external to the instrument cabinet. Clean helium for the production of the helium metastables was obtained from the carrier gas line in the instrument cabinet. The discharge helium backpressure was regulated to approximately

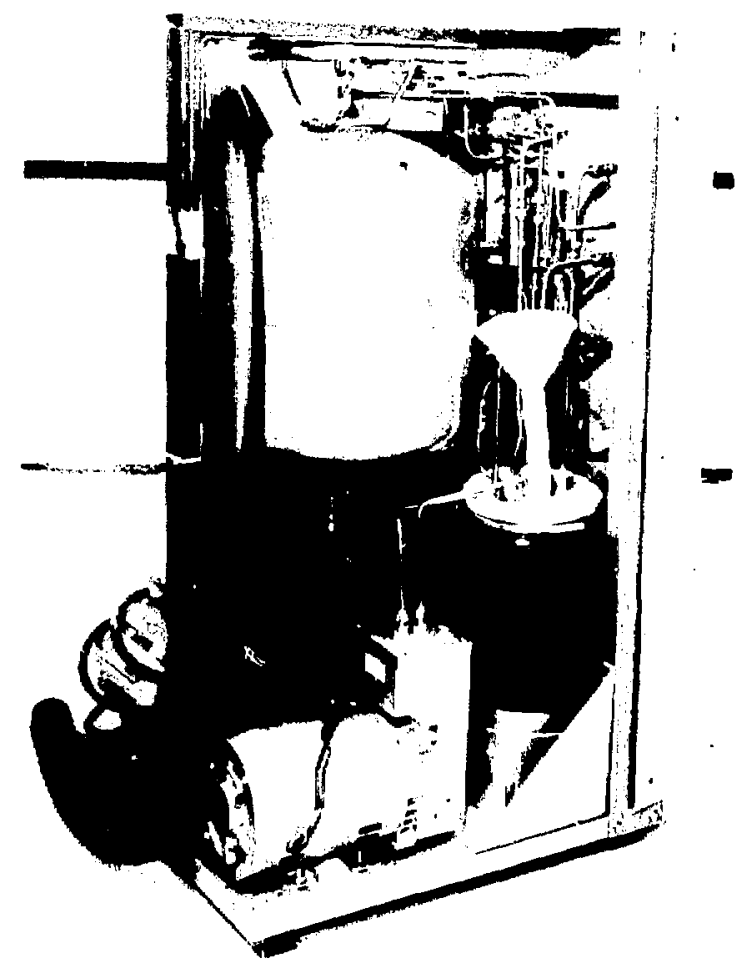

Fig. 37. Side view of the Helium Afterglow Impurities Monitor showing the bellows pump at lower left, the calibration volume and the $\mathrm{LN}_{2}$ traps.

$10 \mathrm{kPa}$. The primary coolant pressure in the sample line was also approximately $10 \mathrm{kPa}$. The flow rates maintained for all measurements in this series were approximately $1000 \mathrm{umoles} / \mathrm{s}$ for the metastable bearing discharge $l$ ine and approximately 100 umoles/s for the primary coolant and calibration gases.

The first scan of the emission spectrum of the primary coolant was obtained about mid-morning on May 28. The scan contained a signal for the $306.4 \mathrm{~nm}$ band structure of $\mathrm{OH}^{\star}$ corresponding to 504 ppmV $\mathrm{H}_{2} \mathrm{O}$ in the primary coolant stream. The sample 1 ine was eyacuated and repressurized for a rescan. The rescan confirmed the presence of 504 ppmV $\mathrm{H}_{2} \mathrm{O}$ in the primary 
loop. An example of these scans appears as the top trace in Fig. 38. In addition to water, we identified $\mathrm{CO}, \mathrm{CO}_{2}$ and $\mathrm{N}_{2}$ as primary coolant impurities from these early scans. Characteristic lines from the helium are apparent in the scan, as well as the hydrogen Balmer series. The source of the Balmer series is at present uncertain; possibilities include free hydrogen, hydrocarbons, or the H-Atom produced by the dissocation of $\mathrm{H}_{2} \mathrm{O}$. This area will receive additional attention. Flom 11:30 a.m. until 1:30 p.m. of May 28, the $306.4 \mathrm{~nm}$ band signal characteristic of water was monitored. The signal strength remained at that corresponding to 504 ppmv water du2ing this period.

At about 10:30 a.m. May 29, another scan of the primary coolant was made, and the result is shown as the middle trace of Fig. 38. The presence of $\mathrm{CO}, \mathrm{CO}_{2}, \mathrm{~N}_{2}$ and $\mathrm{H}_{2} \mathrm{O}$ is again verified. We have also tentatively ascribed the peok at approximately $335 \mathrm{~nm}$ to free hydrogen. In addition, the presence of oxygen was detected by the characteristic emissions at wavelengths > $500 \mathrm{~nm}$. These are not shown in the traces provided in Fig. 38. In this scan, the strength of the $306.4 \mathrm{~nm}$ signal corresponds to a moisture content of 25 ppr.V, down roughly a factor of 20 from the previous day. Calculations show that if no additional moisture entered the primary loop after 1:30 p.m. May 28, the factor of 20 decrease in the level would be consistent with a cleanup rate of 158 per hour, the rated capacity of the Ft. St. vrain primary coolant cleanup system.

To complete the series of measurements, the calibration gas routinely used by the Ft. St. Vrain plant operator for chromatograph calibration was scanned. The result of this scan is shown as the bottom trace of Fig. 38. With the electrometer gains as shown in the figure, we detected the $\mathrm{H}_{2}$, $\mathrm{N}_{2}, \mathrm{CO}_{2}$, He and $\mathrm{O}_{2}$. We have subsequently verified our ability to detect $\mathrm{Ar}$ and $\mathrm{CH}_{4}$ with higher electrometer gains. The peaks characteristic of $C O$ are also apparent in this scan. These are ascribed, in this instance, to secondary reaction processes beginning with the dissociation of $\mathrm{CO}_{2}$. The NO $B$ bands are also sbvious in the scan and result from mixed species recombination of ionized $\mathrm{N}_{2}$ and $\mathrm{O}_{2}$ produced by the helium metastables. Both species are detectable separately as well.

our analysis (using the calibration gas as standards for all but water) thus indicates that at the time of these measurements the impurities in the primary coolant at the Ft. St. Vrain plant include $\mathrm{CO}, \mathrm{CO}_{2}, \mathrm{H}_{2} \mathrm{O}, \mathrm{N}_{2}, \mathrm{O}_{2}$ and $\mathrm{H}_{2}$ in the following quantities:

$\mathrm{CO}$ - unknown due to absence in
standard
$\mathrm{CO}_{2}$ - approximately $1.8 \mathrm{ppmV}$
$\mathrm{H}_{2} \mathrm{O}$ - varied from $25 \mathrm{ppmV}$ to
$\mathrm{N}_{2}-504 \mathrm{ppmV}$
$\mathrm{O}_{2}-$ approximately $5.4 \mathrm{ppmV}$
$\mathrm{H}_{2}-$ approximately $10 \mathrm{ppmv}$

B. Temperature Sensors (V. Starkovich) The feasibility of using the kryptonate method for determining the peak temperature experienced by HTGR fuel has been examined. A proposal to test this method has been written and is under discussion. The test wculd consist of irradiation of small samples of fuel particles in the LASL Omega West Reactor. Post-irradiation reheat of the samples to the temperature for onset of release of noble gas fission products would yield peak exposure temperature. Discussions with personnel responsible for task elements which would benefit from the results of such tests will continue. 

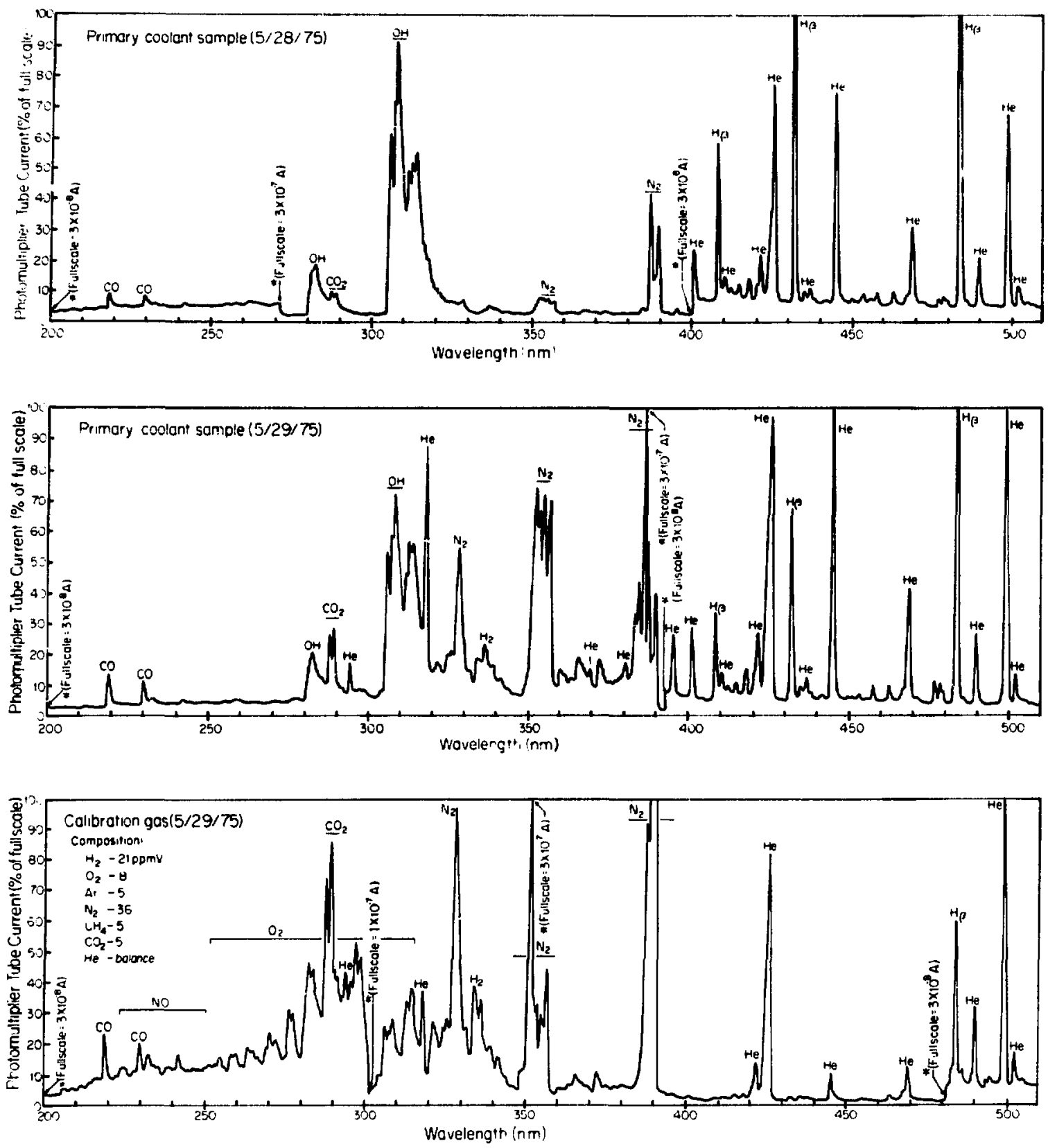

* Scole Change

Fig. 38. Spectra obtained at the Ft. St. Vrain plant. The two upper traces are of the primary coolant, taken on different days. These show the very wide variation of moisture content observed. The bottom trace is the spectrum of the calibration gas used by the operator for gas chromotograph calibration. The composition of the gas is given in the figure. 
VII. TASK 7, ACCIDENT DELINEATION

(M. G. Stevenson)

As part of the HTGR safety research effort, the accident delineation task identifies and provides descriptions of significant accident sequences. We have reviewed the recent GAC report on analyses of anticipated transients with failure of control rod motion. 37 Transients considered in these preliminary analyses for the summit HTGR plant include loss of one feedwater pump. turbine trip, loss of one main cirsulator, and rod withdrawal from both source and full power. The HTGR design allows for control of these transients through the plant control and operating protection system and precludes the necessity for reactor trip. The assumption used in the GAC analyses was that all control and protective systems operated as designed but control rods did not move into the core and lower the reactor power. However, feedwater flow was assumed to be ramped down as the normal response to various reactor trip signals. The characteristic consequence for these anticipated transients is then high inlet helium temperatures to the steam generators. The GAC analyses have not considered consequences of possible steam generator tube failures. We are continuing further delineation of these accident conditions. This work and other initial accident delineation efforts will be presented in a report in preparation.

VIII. TASK 9, PHENOMENA MODELING AND SYSTEMS ANALYSIS

A. HTGR Neutronic Analysis (J.C. Vigil) During the past year, we have performed extensive calculations of the safetyrelated neutronic characteristics of the Fulton Generating Station (FGS) initial core. These have been reported in previous quarterly reports and include the following specific calculations:
1. Isothermal temperature coefficients for one-dimensional cell and finite reactor models, 38

2. Separate fuel and moderator temperature coefficients, ${ }^{44}$

3. Effects of burnable poison, control rods, and $x e$ and $\mathrm{Sm}$ on the isothermal temperatura ccefficients, 34

4. Effect of $233 \mathrm{U}$ on the isothermal cemperature coefficient, and

5. One- and two-dimensional power distributions. 28

In general, these calculations agree quite well with similar GAC analyses for the rGS initisl core. We have concentrated on temperature-dependent reactivity effocts since these are the most important safetyrelated neutronic characteristics of the large HTGR. Our calculations of the effect on the isothermal temperature coefficient of replacing $235 \mathrm{U}$ with ${ }^{233} \mathrm{U}$ in an otherwise initial core loading were made to give a preliminary indication of the relative importance of ${ }^{233} \mathrm{U}$ in equilibriumcycle ccre loadings. The FGS initial core isothermal temperature coefficient is large and negative, but becomes substantially smaller as $233 \mathrm{U}$ is produced in the fertile $\left(\mathrm{ThO}_{2}\right.$ ) particles. Careful analyses, including cross-section set generation, are important in providing an independent assurance that temperature feedbacks remain negative under postulated accident conditions. The neutronics effort during FY-76 will concentrate on analyses of equilibrium cycle core loadings with emphasis on temperature coefficient effects. A detailed report of our FGs initial core neutronic calculations is in preparation. 39

Additional calculations of FGS initial core neutronics characteristics are reported below. We have also calculated the reactivity change due to a postulated dropping of the central refueling region in the FGS initial core. All or the calculations noted here used cross sections generated by the MICROX code 40 and 
provided by GAC. We have also calculated the isothermal temperature coefficient with LASL generated cross sections and the results are reported in the next section.

1. Control-rod Worths in the FGS Initial core

The total reactivity worths of several control-rod configurations including 1,7 , and 73 (a11) rod pairs were calculated using a two-dimensional $(r-2)$ model of the FGS initial core at design temperature. In addition to its total worth, the worth vs axial position of the central control-rod pair was calculated. Where comparison data are available, the results are in good agreement with those in the FGS PSAR ${ }^{41}$ and with those obtained previously at LASL using a one-dimensional radial model.

The calculations were performed with the TWOTRAN-II code 42 in $\mathrm{s}_{4}$ approximation using four energy groups including three fast and one thermal group. The four-group cross sections correspond to the FGS beginning-of-life (BOL) compositions and operating temperature. They were obtained by collapsing nine-group MICROX cross sections using one-dimensional flux spectra. Effective (self-shielded) control-rod cross sections were calculated using shielding factors obtained from auxiliary cell calculations.

Radial dimensions, axial dimensions, and material distributions for the $r-2$ model (which includes five radial core zones or rings, three axial core zones, and reflectors at the top, bottom, and side) are the same as those reported in Ref. 28.

The calculated worths of 1,7, and 73 control-rod pairs are summarized in Table XII below. The single rod-pair results are for the central refueling region which comprises $r$ ing 1 of the model. For this particular rod pair, calculations were also performed with the rod pair at various axial positions. The normalized
TABLE XII

CONTROL-ROD PAIR WORTH

$\begin{array}{cc}\text { Rod-Pairs } & \text { Worth }(\Delta k) \\ 1 & -0.006 \\ 7 & -0.036 \\ 73(\text { al1) } & -0.261\end{array}$

worth versus axial position curve obtainea from these calculations is shown in Fig. 39. Note that insertion into the bottom half of the core accounts for $60 \%$ of the total worth of the rod pair and that there is some residual worth (about 2 of of the total worth) at the top of the core.

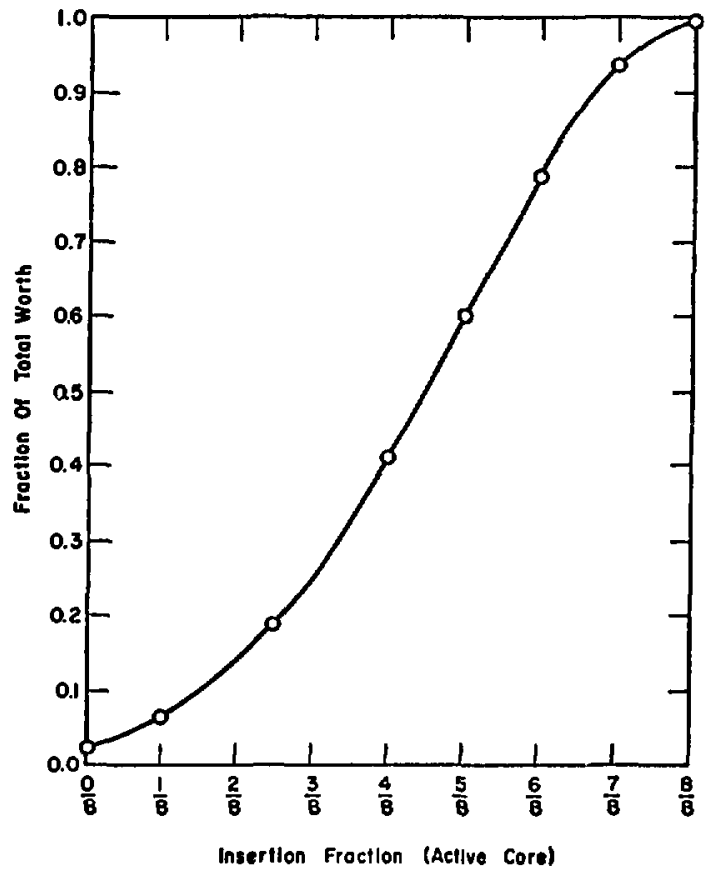

Fig. 39. Reactivity worth versus axial position for the central controlrod pair. 
Previous calculations ${ }^{28}$ with a one-dimensional radial model yielded a worth of $-0.037 \Delta k$ for the seven rod-pair case in good agreement with the above results. The seven rod-pair configuration includes the central rod pair and six of the 12 rod pairs in the third core ring. This configuration presumably corresponds to the hot-critical case at the beginning of the initial cycle with equilibrium xenon and samarium. The multiplication factor from the two-dimensional calculation for this configuration was 1.012 .

For the all-rods-in case, Table 4.3.2-3 of the FGS PSAR gives a worth of $-0.258 \Delta \mathrm{k}$ at operating temperature and the middle of the initial cycle. Our result $(-0.251 \mathrm{Ak})$ is in good agreement with this value.

2. Reactivity Change due to Dropping of the Central Refueling Region

If the three graphite posts that

support the central refueling region ${ }^{\star}$ in the FGS core are postulated to fail, the refueling region would drop a distance of about $2 \mathrm{~m}$ to the bottom of the exit plenum. This distance corresponds to the height of 2.5 fuel blocks. The reactivity change resulting from such a hypothetical geometrical rearrangement has been calculated with TWOTRAN-II. ${ }^{2}$ These calculations indicate that the reactivity change is only a few cents (and negative) regardless of the position of the central control-rod pair. The calculations were performed using the FGS initial core model and four energy group cross sections described above. Except for the central control-rod pair, all control rods were in their withdrawn position.

Calculations were performed with the central control-rod pair at various

* A refueling region consists of a control column and the six surrounding standard columns. axial positions. This rod pair was assumed to remain in its original position after the refueling region was dropped (control-rod support is independent of that for the refueling region). In the dropped (perturbed) configuration, that portion of the central refueling region that extended below the bottom reflector was not included in the perturbed model. This should be a good approximation because the reactivity worth nf materials beyond the bottom reflector is small (twodimensional material worth distributions have been computed for the FGS initial core and will be given in a later report). Reactivity changes obtained from the calculated multiplication factors for the reference and perturbed configurations are summarized in Table XIII. These results show that the reactivity change is small and negative regardless of the position of the control-rod pair.

TABLE XIII

REACTIVITY CHANGE DUE TO CENTRAL REFUELING REGION DROP

\begin{tabular}{lccr}
$\begin{array}{l}\text { Central Rod-Pair } \\
\text { Position }\end{array}$ & $10^{-4} \Delta \mathrm{k}$ & \multicolumn{1}{c}{ Cents } \\
$\begin{array}{l}\text { Completely with- } \\
\text { drawn }\end{array}$ & -3.2 & -4.9 \\
$\begin{array}{l}2.5 \text { blocks into } \\
\text { core }\end{array}$ & -2.9 & -4.5 \\
4 blocks into core & -3.1 & -4.8 \\
6 blocks into core & -1.4 & -2.2 \\
8 blocks into core & -1.9 & -2.9
\end{tabular}

Examination of the material

changes that occur in each axial mesh interval as a result of the drop shows that one should expect negative reactivity efficts above the core midheight and positive effects below the midheight. The results in Table XIII indicate that these effects are essentially compensatory. 
If the thermal flux is not

greatiy perturbed by the region drop, the worth of the control-rod pair should not change greatly (fully inserted, the worth of the central-rod pair is about 906). In this case the net reactivity change due to the refueling-region drop should not be strongly dependent on the axial position of the rod pair. From the results in Table XIII, this would appear to be the casi?. Because the net reactivity changes are small, the accuravy of the $k$-difference results is limited by the problem convergence. At least one of the cases will be checked out by perturbation calculations using direct and adjoint angular fluxes from TWOTRAN-II.

\section{Kinetics Parameters for the FGS Initial core Kinetics parameters including} the effective prompt-neutron generation time $(\bar{\pi})$, delayed-neutron fractions $\left(\bar{B}_{i}\right.$ ' $i=1, \ldots, 6)$, and decay constants $\left(T_{i}, i-1, \ldots, 6\right)$ have been calculated for the FGS (BOL) core. The calculated values of these parameters are in good agreement with those reported in the FGS PSAR. 41

Values for $\bar{\lambda}$ and $\overline{3}_{i}(i=1, \ldots$, 6) were computed using the DAC perturbation theory code, which is an unpublished multidimensional version of the one-dimensional $s_{n}$ perturbation code $\mathrm{DACl} .43$ Two-dimensional $(r, z)$ four-group, $s_{4}$, direct and adjoint angular fluxes computed with the TWOTRAN-II code ${ }^{42}$ were used in the DAC calculations. Compositions used in the model correspond to the BOL fuel and burnable-poison distributions with equilibrium xenon and samarium but no control rods. The geomutrical model, represented by a $33 \times 57 \mathrm{r}, 2$ mesh, includes five radial and three axial core zones surrounded by radial, top, and bottom reflectors as used in the calculations reported above.

Energy boundaries, prompt and delayed neutron spoctra, and neutron velocities for the four-group energy structure are shown in Table XIV. cross sections for this group structure were obtained by collapsing nine-group MICROX cross sections using flux spectra from one-dimensional calculations. Prompt and delayed ission spectra were obtained from information given in Ref. 44. Velocities for the four-group structure were obtained by collapsing nine-group velocities.

These nine-group velocities were in turn obtained by averaging over fine-group fast and thermal neutron spectra generated, respectively, with the $\mathrm{MC}^{2}$ and the GLEN codes. 45,46

Calculation of the effective delayed-neutron fractions and decay constants for a given reactor requires a knowledige of the ${ }_{i}$ and $\lambda_{i}$ for the various fissioning isotopes present in the system. In our computations we have used the sixgroup delayed-neutron data given by Keepin ${ }^{44}$ for thermal fission of ${ }^{235} \mathrm{U}$ and fast fission of ${ }^{232} \mathrm{Th}$. In the BOL core, 99.88 of the fissions occur in ${ }^{235} \mathrm{U}$ and the remainder $(0.28)$ is essentially all in $232 \mathrm{Th}$. Because their concentrations are small compared to that of ${ }^{232} \mathrm{Th}$, fissions in ${ }^{234} \mathrm{U},{ }^{236} \mathrm{U}$, and ${ }^{238} \mathrm{U}$ are negligible.

\section{Kinetics parameters calculated} at LASL, along with those reported in the FGS PSAR, are summarized in Table XV. The LASL value of $\Lambda$ is within 58 of that reported in Table 1.3.1-2 of the FGS PSAR. Because $\Lambda$ is sensitive to the group velocities, particularly that in the thermal group (group four), this agreement provides an indirect verification of the detailed spectra computed with the $\mathrm{MC}^{2}$ and GLEN codes.

As one would expect from the fact that most of the fissions occur in ${ }^{235} \mathrm{U}$ and the fact that the delayed-neutron spectrum in the four-group structure does not differ greatly from the prompt-neutron spectrum, the values of $\bar{B}_{i}$ and $\bar{\lambda}_{i}$ are essentially those for $235^{1}$. The LASL 
TABLE XIV

GROUP PARAMETERS FOR FOUR-GROUP ENERGY STRUCTURE

\begin{tabular}{|c|c|c|c|c|}
\hline \multirow[b]{2}{*}{ Group } & \multirow[b]{2}{*}{$\begin{array}{l}\text { Lower E } \\
\text { Boundary (ev) }\end{array}$} & \multicolumn{2}{|c|}{ Fission spectrum } & \multirow[b]{2}{*}{$\begin{array}{l}\text { Neutron } \\
\text { Velocity }(\mathrm{cm} / \mathrm{s})\end{array}$} \\
\hline & & Prompt & Delayed & \\
\hline 1 & $1.83 \times 10^{5}$ & 1.0 & 0.948 & $1.148 \times 10^{9}$ \\
\hline 2 & 17.6 & 0.0 & 0.052 & $3.054 \times 10^{7}$ \\
\hline 3 & 3.93 & 0.0 & 0.0 & $3.925 \times 10^{6}$ \\
\hline 4 & 0.0 & 0.0 & 0.0 & $5.804 \times 10^{5}$ \\
\hline
\end{tabular}

TABLE XV

KINETIC PARAMETERS FOR FGS BOL CORE

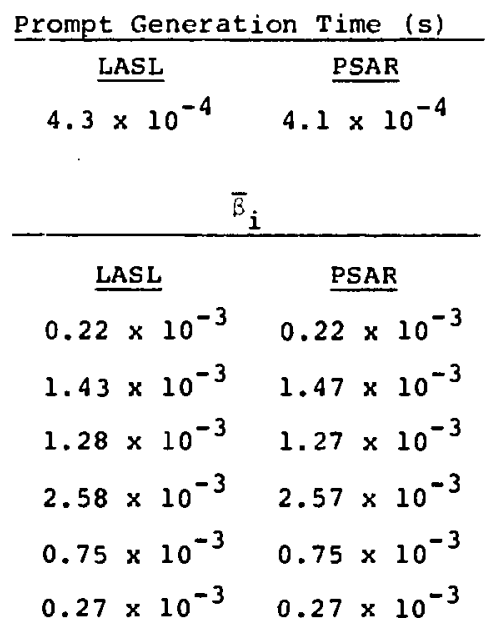

Total Delayed Neutron Fraction LASL PSAR

$6.52 \times 10^{-3} \quad 6.55 \times 10^{-3}$

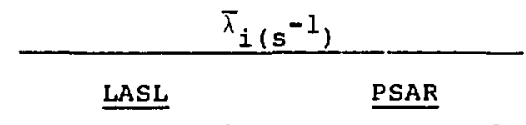

$1.24 \times 10^{-2} \quad 1.24 \times 10^{-2}$

$3.05 \times 10^{-2} \quad 3.05 \times 10^{-2}$

$1.11 \times 10^{-1} \quad 1.11 \times 10^{-1}$

$3.01 \times 10^{-1} \quad 3.01 \times 10^{-1}$

$1.14 \quad 1.14$

$3.01 \quad 3.01$

values for $\bar{B}_{i}$ and $\bar{\lambda}_{i}$ are in almost perfect agreement with those reported in Table Q4.3.2.1-2-1 of the FGS PSAR.

B. Nuclear Data Processing for HTGR Safety Research (M. G. Stamatelatos, R. J. LaEauve, and J.C. Vigil)

Development of the independent LASL cross-section processing code system has reached a state where acceptable broadgroup data can be produced for homogeneous HTGR media. Using a medium characteristic of the FGS initial core, nine-group cross sections were generated for isothermal core temperatures of 300,1200 , and $3000 \mathrm{~K}$. These cross sections were used to compute multiplication factors and isothermal 
temperature coefficients from a cell model which includes the effects of seven control-rod pairs, burnable poison, and equilibrium xenon and samarium. Results of these calculations are compared below with results obtained using cross sections generated from a nine-group MICROX 40 library supplied by GAC. Taking into account the expected effect of core heterogeneity on the broad-group cross sections, the results obtained with the LASL cross sections are in reasonable agreement with those obtained with the GAC cross sections. HTGR cross sections generated previously with the LASL sode system were incorrect because of problems in the $\mathrm{MC}^{2}$ code. 45 Modifications required to produce satisfactory homogeneous-medium cross sections with this code are discussed below.

A single level of heterogeneity can be treated in the fast energy range with the $\mathrm{MC}^{2}$ code by specifying a two-region cylindrical cell model that includes the fuel stick and surrounding moderator. The $\mathrm{MC}^{2}$ calculations will be repeated using such a heterogeneous model in order to determine the effect ion the broadgroup cross sections) of resonance-region self-shielding in the fuel stick.

In the future, however, the $\mathrm{MC}^{2}$ code will be replaced with modified versions of the MINX and IDX codes. 47,48 the modified MINX-1DX package, when completed, will provide treatment of both levels of heterogeneity in the fast energy range. The same procedure used to treat the fertile-particle $\left(\mathrm{ThO}_{2}\right)$ self-shielding in the fast energy range can be applied to the fissile-parificle (UC) self-shielding in the thermal range. These topics are discussed below.

\section{Neutronic Calculations}

The seven region cell model

used to calculate the multiplication factor as a function of core temperature is described in Table XVI. This model represents the control rod explicitly and the
IABI.I: XIJ

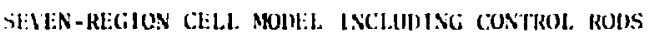

\begin{tabular}{|c|c|c|}
\hline Region & lescription & Outer Radius (cm) \\
\hline 1 & Control Rod Spine & 0.176 \\
\hline 2 & loid & $\therefore .381$ \\
\hline 5 & $\begin{array}{l}\text { Control Rod Inner } \\
\text { Stecve }\end{array}$ & 2.5 .10 \\
\hline 4 & $\begin{array}{l}\text { Control kod Ab- } \\
\text { sorber Compiset }\end{array}$ & 4.280 \\
\hline 5 & $\begin{array}{l}\text { Control Rod Outer } \\
\text { Sleeve }\end{array}$ & 4.445 \\
\hline (1) & Cont rol hod Hole & 5.080 \\
\hline 7 & $\begin{array}{l}\text { Homogenized core } \\
\text { Medjun lexeluding } \\
\text { cont rol rods) }\end{array}$ & 112.78 \\
\hline
\end{tabular}

amount of homogenized core medium (region 7) associated with the control rod corresponds to the case in which seven control-rod pairs are present in the core. This control-rod configuration in turn corresponds to the hot-critical case with equilibrium xenon and samarium. Region 7 aiso contains burnable poison, which was homogerized using shielding factors obtained from auxiliary cell calculations in which the burnable poison pin was represented explicitly.

The k-calculations were performed with the DTF-IV transport theory code 49 in $\mathrm{s}_{4}$ approximation using nine energy groups. The nine-group energy structure, shown in Table XVII, is that in use at GAC and includes five fast (>2.38 ev) and four thermal ( $\% 2.38 \mathrm{eV}$ ) groups. Generation of cross sections with this initial LASL system is time consuming and for this reason iross sections were produced for only three tumperatures $(300,1200$, and $3000 \mathrm{k})$ using this system. On the other hand, the generation of interpolated cross sections from an existing library of MICROX cross sections is a fast procedure. 


\begin{tabular}{cc} 
Group & Lower Energy (ev) \\
1 & $1.83 \times 10^{5}$ \\
2 & 961 \\
3 & 17.6 \\
4 & 3.93 \\
5 & 2.38 \\
6 & 0.414 \\
7 & 0.10 \\
8 & 0.04 \\
9 & 0.0 \\
& \\
\hline
\end{tabular}

Therefore GAC cross sections were generated at four additional temperatures $(500$, 800,1700 , and $2300 \mathrm{k}$ ). Results of the $k$-calculations are summarized in Table XVIII and plotted in Fig. 40. Note that the multiplication factors obtained with the LASL cross sections are slightly smaller than those obtained with the GAC cross sections. The differences range between $1.28 \wedge k$ at $300 \mathrm{~K}$ and $2.68 \mathrm{k}$ at $3000 \mathrm{~K}$. These differences are reasonable considering the fact that heterogeneity effects have not yet been included in the LASL cross sections. Self-shielding in the fertile particle in the resonance energy range is expected to be the most important of these effects. Therefore inclusion of these effects should result principally in a smaller group three adsorption cross section for thorium. A detailed comparison of the LASL and GAC cross sections shows that this is indeed the case.

Note also from Table XVIII that the absolute reactivity change between 300 and $1200 \mathrm{~K}$ is almost the same with both cross-section sets while the change
Infinite Multiplication Factor

GAC

LASL.

Cross Sections Cross Sections

Temp (K)

300

1.0920

1.0797

500

1.0678

800

1,0461

1200

1.0293

1.0160

1700

1.0132

2300

0.9955

3000

0.9765

0.9500

emperature

Interval (K)

$300-1200$

$1200-3000$

$-5.28$

$-6.60$

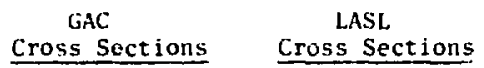

$\longrightarrow$

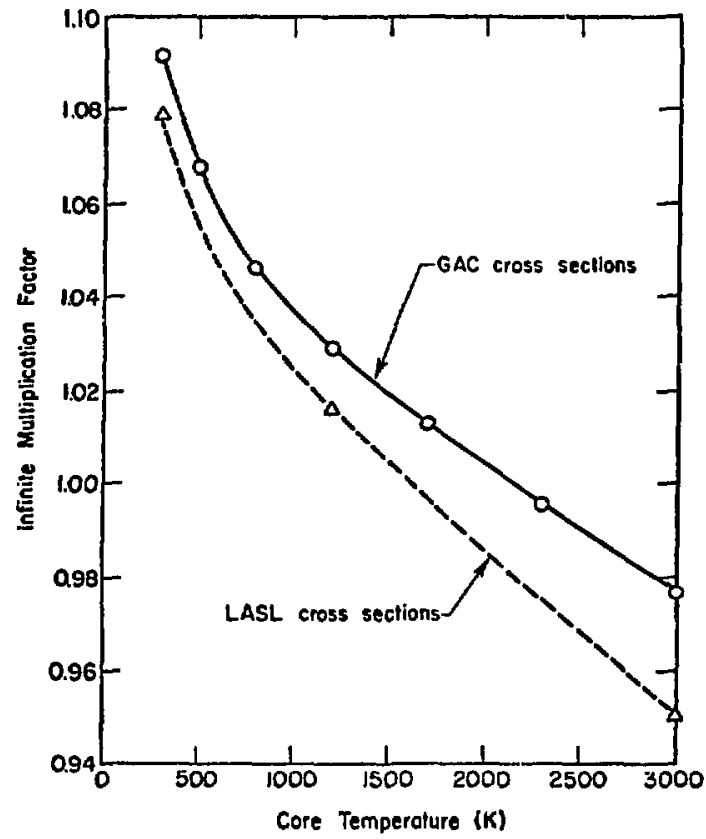

Fig. 40. Infinite multiplication factor for the FGS initial core including the effects of seven control-rod pairs, burnable poison, and equilibrium $\mathrm{Xe}$ and $\mathrm{Sm}$. 
between 1200 and $3000 \mathrm{~K}$ is 25 : laxyer using the LASL cross sections. In other words, there is little difference between the average temperature coefficients in the temperature range $300-1200 \mathrm{~K}$ but in the range $1200-3000 \mathrm{~K}$ the LASL cross sections $y$ ield an average coefficient thai is 258 more negative. This is also illustrated in Fig. 41 where the temperature coefficient is plotted as a function of core temperature. The curves in Fig. 41 were derived from those in Fig. 40.

$$
\text { Because self-shielding effects }
$$

attenuate changes in broad-group cross sect.ons with temperature, and because the Doppler effect in thorium is the principal contributor to the temperature coefficient, the inclusion of self-shielding effects in the broad-group cross sections should result in a smaller (less

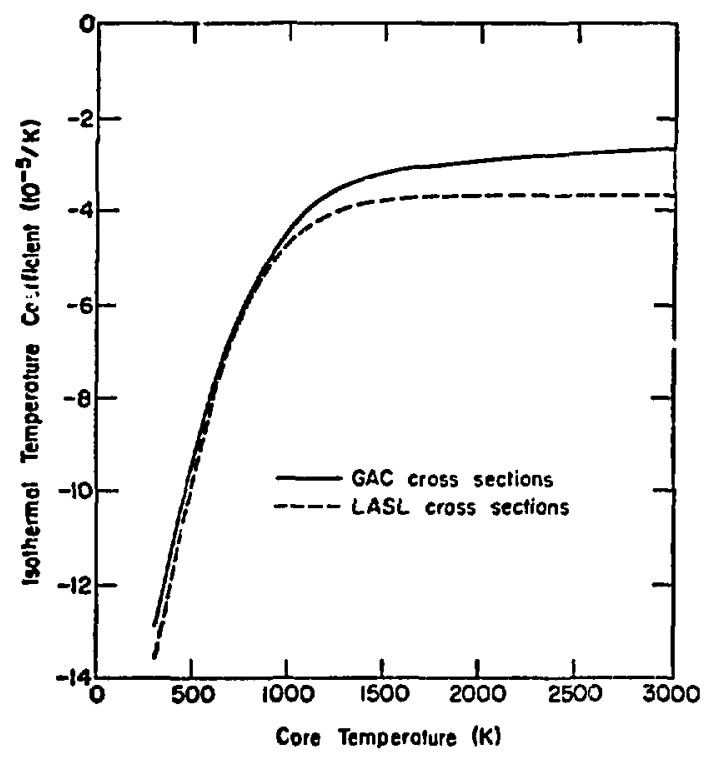

Fig. 41. Isothermal temperature coefficient for the FGS initial core including the effects of seven control-rod pairs, burnable poision, and equilibrium $\mathrm{Xe}$ and Sm. negative) temperature coefficient over the entire temperature range. From $G A C$ resuits shown in Fig. Q4.3.2.3-2-2 of the FGS PSAR, one would expect the ef iect to be $10-208$. Our results shown in Fig. 41 are consistent with the GAC results above $1200 \mathrm{~K}$. Below $1200 \mathrm{~K}$, however, it appears that LASL cross sections could yield a slightly less negative temperature coefficient than the GAC cross sections when self-shielding effects are taken into account in the LASL sets.

2. LASL Cross-Section Generation Methods

The major source of previous disagreement with MICROX cross sections was found in the resolved resonance region where, in the case of the capture cross section of ${ }^{232} \mathrm{Th}$, the $\mathrm{MC}^{2}$ homogenized cross section was found to be lower than the MICROX cross section in which spatial heterogeneities had been accounted for. This discrepancy was initially attributed to a possible coarse energy-mesh representation in $\mathrm{MC}^{2}$ for the resonance region. "Ultra-fine" $\mathrm{MC}^{2}$ runs performed

with 2000 eneryy groups $(1 / 120$ equal lethargy mesh) between $10 \mathrm{MeV}$ and $0.414 \mathrm{eV}$ at 300 and $3000 \mathrm{~K}$ revealed negligible differences from the corresponding "all-fine" $M C^{2}$ result using 68 equal lethargy (0.25) groups for the same energy range.

The 68 fine-group $\mathrm{MC}^{2}$ capture cross sections were then compared with MINX cross sections generated in the same energy structure. The general agreement between these two sets indicated that the $\mathrm{MC}^{2}$ fine-group capture cross sections were not the main cause of discrepancy between the $\mathrm{MC}^{2}$ and the MICROX broadgroup capture cross sections. The broadgroup collapsing method in $\mathrm{MC}^{2}$ became immediately subject to inquiry.

Briefly, the $\mathrm{MC}^{2}$ multigroup averaging method for the resolved-resonance capture cross section is an in-scattering source weighted collapsing process as follows: 


$$
\left(j_{c, J}^{b g}\right)_{\text {resolved }}=\frac{\sum_{\varepsilon J}<\sigma_{c^{\prime}}{ }_{j}^{f g} \text { resolved }_{j}^{Q_{j}}}{\sum_{j \in J} Q_{j}}
$$

where

$$
Q_{j} \equiv \int_{E_{j}}^{E_{j+1}} s_{j}^{f g} \frac{d E}{\Sigma_{T}(E)}
$$

and

$$
\begin{aligned}
& s_{j}^{f g}=\sum_{k \neq j}\left(\Sigma_{\text {inel, } k}^{f g} \phi_{k}^{f g} \frac{\left\langle\Sigma_{\text {ine }}{ }_{k \rightarrow j}\right.}{\left\langle\sum_{\text {ine } l_{k}{ }_{k}}\right.}\right. \\
& +\varepsilon_{n, 2 n, k}^{f g} \underbrace{f g}_{k} \frac{2<\check{\Sigma}_{n, 2 n_{k \rightarrow j}}}{\left\langle\Sigma_{n, 2 n_{k}}\right.}) \\
& +\left\langle\Sigma_{e 1}\right\rangle_{j-1 \rightarrow j}
\end{aligned}
$$

where superscripts bg and $\mathrm{fg}$ indicate "broad-group" and "fine-group" respectively. $J$ and $j$ are subscripts referring to broad-group and fine-group respectively.

This method of multigrouping was developed for fast-spectrum systems and is not appropriate for thermal reactor systems. However, hand calculations using a straight spectrum weighting method $y$ ielded results in general agreement with the MICrox broad-group capture cross section. The larger value of the $\mathrm{MC}^{2}$ resolved-resonance capture cross section was expected since spatial heterogeneity effects were not yet included in the $\mathrm{MC}^{2}$ calculations. The straight spectrum weighting method was then incorporated into $\mathrm{MC}^{2}$ as an alternative and the subsequent results for 300,1200 and $3000 \mathrm{~K}$ were also in reasonable agreement with the MICROX cross sections as noted eariier.
In order to properly account for the double heterogeneity effects on cross sections as well as to take full advantage of the most up-to-date computational techniques employed in the MINX code system, the following course of action will be adopted in future HTGR crosssection generation work at LASL:

1. Use MINX for generating pointwise cross-sectiors in ENDF/B format (PENDF) over the entire energy range desired and for all materials of interest.

2. Apply particle heterogeneity corrections to the point-wise cross-sections in both the above-thermal (resonance) and thermal regions.

3. Use MINX to collapse the particle-heterogeneity corrected PENDF cross sections to the desired fine-group energy structure.

4. Calculate a fine-group neutron spectrum in the above-thermal region with the IDX code and use the same code to collapse the above-thermal fine-group cross sections applying the proper "gross" (fuel-pin/moderator) heterogeneity correction for HTGR fuel pins in a hexagonal lattice. The lDX code has been adapted to accept MINX finegroup cross sections in the Bondarenko formalism.

5. Collapse the thermal fine-group cross sections with the GLEN code. 46

6. Investigate the importance of "gross" heterogeneity effects on thermal cross sections.

7. Format final broad-group sections for input to the DTF-IV discreteordinates transport code. The initial procedure to be used in applying the particle heterogeneity 
corrections to the PENDF capture cross sections will be the sauer formalism used by Wälti in the MICRox code. ${ }^{40}$ Preliminary calculations for the two important capture resonances in ${ }^{232} \mathrm{Th}$, at 21.78 and $23.45 \mathrm{eV}$, have given flux disadvantage factors for 400-um $\mathrm{ThC}_{2}$ particles of 0.7 and 0.58 respectively, in good agreement with Wälti's results. Calculations for $\mathrm{ThO}_{2}$ particles are in progress. Comparisons of wälti's method for treating particle heterogeneity effects on cross sections with other compatille methods and possibly with Monte Carlo calculations will be performed. C. CHAP Code Status (P. A. Secker and J.S. Gilbert)

The Composite HTGR Analysis Program (CHAP) is an independent computer code which will simulate normal operation, anticipated transients, and postulated accidents for High Temperature Gas-cooled Reactors (HTGR). It is generic in its description of the current GAC 2000 and $3000 \mathrm{Mw}(t)$ reactor designs.

CHAP is a whole system code which will describe the thermal, fluid-flow, neutronic (including afterheat) and control response of the HTGR reactor core, primary coolant system, prestressed concrete reactor vessel (PCRV), Core Auxiliary cooling system (CACS), and balance of plant. CHAP is designed to predict critical safety variables such as maximum fuel-rod temperatures and maximum structural-material temperatures. The output from cHAP will provide thermal-hydraulic input to descriptions of fission product release and transport and to descriptions of graphite air and/or steam reactions. Typisal initiating events to be considered are reactor trip, loss of off-site power with turbine trip, loss of main loop cooling. depressurization of the primary system and reactivity insertions.

Dynamic models for reactor core, primary coolant system, steam generator, reheater and main circulator have been developed. These models are being incorporated into CHAP after appropriate evaluation and numerical validation over a broad operating range. A steady-state, frequency response, and time response simulation program, TAF, is being utilized in these studies. 50,28 For selected components detailed codes are being used for evaluation and verification. For example, TPROF, an auxiliary analysis code written to provide fine-mesh, two-dimensional temperature distributions in an HTGR fuel element has been used to benchmark the large-node calculations in the CHAP code. 34 The checkout of each component description is made to determine the simplest version for minimizing computation time, to identify the transient and frequency response limitations of the mathematical model, and to verify the accuracy of all significant variables. TAF has also been used as a framework on which to build the CHAP code itself. TAF is a generalized simulation code providing steady-state, transient, and frequency response of a system defined by a set of first-order ordinary differential equations. The user codes this set of equations in the FORTRAN subroutine DER. In TAF a Newton-Raphson iteration scheme uses the derivatives defined in DER to obtain convergence to a steady-state solution. It then provides the time response for a user-specified transient by using a fourth-order Runge-Kutta numerical integration scheme. TAF can also be used to obtain the frequency response of the linearized system. To execute this option, TAF automatically linearizes the system equations,transforms the linearized system response matrix to the Laplace domain, and then calculates the frequency response (gain and phase angle) of any user-identified output variable with respect to any input variable. We have used this frequency response option in the numerical validation studies. 
A logic schematic of CHAP is given in Fig. 42. CHAP uses much of the basic structure of TAF but does not include the frequency response option. In CHAP, as in TAF, the system variables are identified and initialization calculations are performed in subroutine INPUT. The Runge-Kutta integration in TAF has been replacod with a semi-implicit predictorcorrector numerical integration technique. This was developed for integration of the model equations used in the CHAP code and is inherently stable for any time step size. The method is based on the optimum integrating factor technique for firstorder ordinary differential equatıons. 51 Local error is controlled during a transient solution by varying the solution integration step size.

This technique has been very successful when applied to core transient studies. 38,34 computer running times are short for both fast and slow transients. For example, a calculation of a 28 h real-time core heat-up transient due

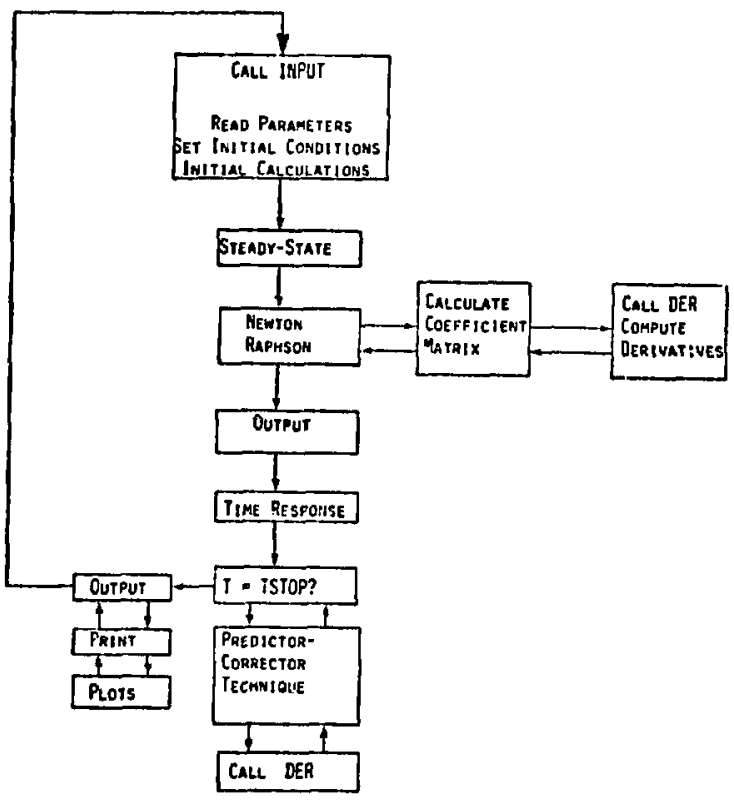

Fig. 42. Block diagram for CHAP. to an assumed loss-of-forced-cooling required $31 \mathrm{~s}$ of CDC 7600 machine time. The method has also been used with good success for calculating transients due to step reactivity insertions up to one dollar.

A detailed status report describing the models developed to this point is in preparation. 52 progress on building CHAP into an integrated consolidated plant model will continue in FY-1976, and an initial version will be produced and released with documentation during FY-1976. This version will be comparable in scope to the GAC systems transient code TAP. 53 It will allow the study of many system transients and accidents, but will not include the complete balance of plant model, a containment model, nor a detailed core cooling model as given in the GAC RECA code. 54 Future versions of CHAP will include these models and other improvements reflecting analyses of accident progressions and consequences performed during FY-1976.

D. Status of HTGR Systems Analysis and Neutronics codes (J. C. Vigil and J. S. Gilbert) The analysis of safety-related characteristics and of postulated accidents in the HTGR requires the use of a number of computer codes. The LASL HTGR safety effort has concentrated on developing new codes or applying existing codes which have been developed independently of the HTGR vendor, the General Atomic Company (GAC). At a lower priority, we have acquired several GAC codes and begun conversion to the LASI computers. Table XIX gives the status of various codes being used or developed in the HTGR safety analysis effort. 
TABLE XIX

HTGR CODE STATUS

Code

CHAP

TAF

BLOOST-7

RECA

CONTEMPT-G

OPUS

TWOTRAN-II

$\mathrm{MC}^{2}$
GAC

GAC

GAC

LASL

LASL

ANL

LASL

LASL

accident analysis

Generalized systems simulation

(steady-state, transient and frequency response

HTGR core transient analysis

(point kinetics and two-

dimensional heat transfer)

HTGR emergency cooling analysis

HTGR containment response

(temperature - pressure)

analysis

HTGR flow network and plant performance (steady-state) analysis

One-dimensional $s_{n}$ transport calculations Two-dimensional $\mathbf{S}_{\mathrm{n}}$ transport
calculations

Multigroup cross section generation
Status

Under development with first version to be released in FY -76

Used in numerical validation of CHAP models

Has compiled and executed successfully on LASL computers

A version has compiled on LASI computers, but additional information is required before execution possible

Has compiled on LASL computers except for input routine

Has compiled on LASL computers but overlay structure must be modified before execution possible

Used extensively in HTGR core neutronics calculations

Used extensively in HTGR core neutronics calculations

Used at LASL to produce initial cross section sets (above-

therma 
TABLE XIX

\section{$\left(\operatorname{con}^{\prime} t\right)$}

Code

originator

LAS L

BNWL

LASI

TOR

LASL

GLEN

GAC

HEXSCAT

GGC-4

GAC

\section{Function}

Multigroup cross section generation

One-dimensional diffusion and multigroup cross section generation

Inelastic thermal-scattering matrices for crystalline materials

Multigroup thermal spectrum and cross-section collapse

Elastic thermal-scattering cross sections for crystalline materials

Combined fast and thermal multigroup cross-section generation for HTGR status

Is operable and will be used at LASL to produce above-

thermal cross sections

Is operable and will be used in combination with MINX to produce above-thermal cross sections

Used at IASL to produce inelastic scattering matrices for graphite

Used at LASL to produce thermal cross-section sets

Used at LASL to produce elastic thermal-scattering cross sections for graphite

Has compiled on LASL computers but has not been executed 


\section{REFERENCES}

1. J. E. Foley, "131 I Release from an HTGR During the LOFC Accident," Los Alamos Scientific Laboratory report LA-5893-MS (March 1975).

2. G. E. Cort, Los Alamos Scientific Laboratory, unpublished report, 1974.

3. R. G. Lawton, "The AYER Heat Conduction Computer Program," Los Alamos Scientific Lakoratory report LA-5613-MS (May 1974).

4. O. C. Zienkiewicz, The Finite Element Method in Engineering Science (McGrawHill, London, 1971).

5. M. H. Schwartz, D. B. Sedgley, and M. M. Mendonca, "SoRS: Computer Programs for Analyzing Fission Product Release from HTGR Cores During Transsient Temperature Excursions," General Atomic Company report GA-Al2462 (April 1974). Fig. 5-1.

6. Summit Power Station PSAR, Delmarva Power and Light Co., Vol. 4, Fig. $6.2-1$.

7. Code of Federal Regulations, Title 10, Part 100 .

8. Fulton Generating Station PSAR, Philadelphia Electric Co., Change 15, p. C.6-3 (September 1974).

9. Regulatory Guide 1.3, Directorate of Regulatory Standards, U.S. Atomic Energy Commission (June 1973).

10. "HTGR Fuels Development Quarterly Progress Report for Period Ending February 28, 1975," General Atomic report GA-A13353, p. 10 .

11. C. F. Kallroth, N. L. Baldwin, C. B. Scott, and L. R. Zumwalt, "Postirradiation Examination of Peach Bottom Fuel Test Element FTE-3," General Atomic Company report GÁ-Al3004,P.28 ff.

12. F. R. Hennig, "Interstitial Compounds of Graphite," Progr. Inorg. Chem. 1, 125 (1959).

13. F. J. Salzano and S. Aronson, "on the Bonding Energy in Cesium-Graphite Compounds," J. Chem. Phys. 44, 4320 (1966)

14. L. Pauling, The Natuze of the Chemical Bond, 3rd Ed. (Cornell, Ithaca, N.Y.. (960), 514.

15. B. L. Holian, Los Alamos Scientific Laboratory, unpublished data,1975.
16. J. O. Hirschfelder, C. F. Curtiss, and R. B. Byrd, Molecular Theory of Gases and Liguids (Wiley, N.Y., 1954), 987.

17. K. S. Pitzer, "Inter- and Intramolecular Forces and Molecular Polarizability," Adv. Chem. Phys. 2 , 59 (1959).

18. C. E. Milstead, "Sorption Characteristic of the cesium-Graphite System at Elevated Temperatures and Low Cesium Pressures," Carbon 7, 199 (1969).

19. L. R. Zumwalt, North Carolina state University, private communication, April, 1975.

20. H. F. Schaefer III, University of California, Berkeley, private communication, March, 1975.

21. B. J. Flder, D. M. Gass, and T. E. Wainwright, "Studies in Molecular Dynamics VIII. The Transport coefficients for a Hard-Sphere Fluid," J. Chem. Phys. 53, 3813 (1970).

22. A. J. Sierk, Cal Tech, private communication, May, 1975.

23. K. Levenberg, "A Method for the Solution of Certain Non-linear Problems in Least Squares," Quarterly Appl. Math. Vol. 2 , 164-168 (1944).

24. D. W. Marquardt, "Algorithm for Leastsquares Estimation on Nonlinear Parameters," J. Soc. Indust. Anal. Ser. B, Vol. 2, No. 2, (1965).

25. E. E. Osborne, "Smallest Least Squares Solutions of Linear Equations," J. SIAM Numer. Anal. Ser. B, Vol. 2, No. 2, (1965).

26. "HTGR Base Program Quarterly Progress Report, Period ending November, 1967," General Atomic Company report GA-8356.

27. J. Board, "The Effect of a Helium Environment on the High Temperature Properties of Structural Materials." Nucl. Energy Soc. J., Vol 9, No. $\underline{2}$ 101 (1970).

28. W. L. Kirk, "Quarterly Report: HTGR Safety Research Program," Los Alamos Scientific Laboratory report LA-59-75-PR (June, 1975).

29. O. Kubachewski and B. E. Hopkins, Oxidation of Metals and Alloys. (Butterworths, 1962) p. 243.

30. S. Adham, A. Bhaumik, and Jo Isenberg, "Reinforced Concrete Constitutive Relations," Air Force Weapons Laboratory, Kirtland AFB, New Mexico, Technical Report, AFWL-TR-74-72. 
31. "NONSAP: A Structural Analysis Program for Static and Dynamic Resporise of Nonlinear Systems," University of California report UC-SESM 74-3 and UC-SESM 74-4 (February 1974).

32. "SAPIV: A Structural Analysis Program for Static and Dynamic Response of Systems," University of Calj.fornia report, EERC 73-11 (June 1973).

33. "SABOR/DRASTIC: A Fortran Program for Linear Elastic Analysis of Thin Shells of Revolution Under Asymmetric Loading Using the Matrix Displacement Method," MIT report, ASTRL-TR-121-6 (June 1965).

34. W. L. Kirk, "Quarterly Report: HTGR Safety Research Program," Los Alamos Scientific Laboratory report LA-5879-PR (February 1975).

35. J. G. Bennett and R. C. Dove, "Proposal for Analysis of HTGR Core Response to Seismic Input," Los Alamos Scientific Laboratory report LA-5821-MS (January 1975).

36. G. Murphy, Similitude in Engineering, (Ronald Press, New York, 1950).

37. D. D. Orvis, "Preliminary Analysis of Anticipated Transients in the HTGR with Failure of Control Rod Motion," General Atomic Company report GA-A13234 (November 1974).

38. K. D. Lathrop, "Quarterly Report: Transport Theory, Reactor Theory, and Reactor Safety," Los Alamos Scientific Laboratory report LA-5778-PR (October 1974).

39. J. C. Vigil, "Neutronics Analysis of the Fulton Generating station Beginning-of-Life Core," Los Alamos Scientific Laboratory report, to be published

40. P. Wälti and P. Koch, "MICROX - A Two-Region Flux Spectrum Code for the Efficient Calculation of Group Cross Sections," Gulf General Atomic report Gulf-GA-A10827 (1972).

41. Fulton Generating Station PSAR, Philadelphia Electric Company, Chapter IV.

42. K. D. Lathrop and F. W. Brinkley, "TWOTRAN-II: An Interfaced, Exportable Version of the TWOTRAN Code for Two-Dimensional Transport," Los Alamos Scientific Laboratory report LA-4B4B-MS (July 1973).
43. B. M. Carmichael, "DACl, A one-Dimensional S Perturbation Code," Los Alamos Scientific Laboratory report $L A=4342$ (April 1970).

44. G. R. Keepin, Physics of Nuclear Kinetics," (Addison-Wesley Publishing Co.. Inc., 1965).

45. B. J. Toppel, D. M. O'Shea, and A. L. Rago, "MC2, A Code to Calculate Multigroup Cross Sections," Argonne Nat. Laboratory report, ANL-7318 (1967).

46. W. W. Clendenin, "Calculation of Thermal Diffusion Length and Group Cross Sections: The GLEN Program," Los Alamos Scientific Laboratory report LA-3893, (1968).

47. C. R. Weisbin, P. D. Soran, D. R. Harris, R. J. LaBauve and J. S. Hendricks, "MINX, A Multigroup Interpolation of Nuclear X-Sections," Trans. Am. Nucl, Soc. 16, 127 (1973).

48. R. W. Hardie and $W . w$. Little, Jr. "IDX, A One-Dimensional Diffusion Code for Generating Effective Nuclear Cross Sections," Battelle-Northwest report, BNL-954 (1968).

49. K. D. Lathrop, "DTF-IV, A Fortran-IV Program for Solving the Multigroup Transport Equation with Anisotropic scattering," Los Alamos Scientific Laboratory report LA-3373 (1965).

50. T. E. Springer and O. A. Farmer, "TAFa Steady State, Frequency Response and Time Response Simulation Program," Proc. Fall Joint Computer Conference, San Francisco, 1968, Vol. 33, p. 359370 .

51. P. A. Secker, "Numerical Integration of Dynamic Nuclear systems Equations by optimum Integrating Factors," Los Alamos Scientific Laboratory report LA -4252 .

52. P. A. Secker and J. S. Gilbert, "status of the CHAP Composite HTGR Analysis Program," Los Alamos Scientific Laboratory report, to be published.

53. C. W. Savery, "TAP-A FORTRAN IV Program for the Transient Analysis of the HTGR Powerplant Performance," General Atomic Company report GAMD-7248 (October 1966).

54. H, W. Chi and G. J. Malek, "Description of the Reactor Emergency Cooling Analysis Code, RECA," General Atomic Company report GA-10273 (August 1970 ). 